\title{
Alkali feldspar dissolution and secondary mineral precipitation in batch systems: 3. Saturation states of product minerals and reaction paths
}

\author{
Chen Zhu*, Peng Lu \\ Department of Geological Sciences, Indiana University, Bloomington, IN 47405, USA
}

Received 30 September 2008; accepted in revised form 16 March 2009; available online 26 March 2009

\begin{abstract}
In order to evaluate the complex interplay between dissolution and precipitation reaction kinetics, we examined the hypothesis of partial equilibria between secondary mineral products and aqueous solutions in feldspar-water systems. Speciation and solubility geochemical modeling was used to compute the saturation indices (SI) for product minerals in batch feldspar dissolution experiments at elevated temperatures and pressures and to trace the reaction paths on activity-activity diagrams. The modeling results demonstrated: (1) the experimental aqueous solutions were supersaturated with respect to product minerals for almost the entire duration of the experiments; (2) the aqueous solution chemistry did not evolve along the phase boundaries but crossed the phase boundaries at oblique angles; and (3) the earlier precipitated product minerals did not dissolve but continued to precipitate even after the solution chemistry had evolved into the stability fields of minerals lower in the paragenesis sequence. These three lines of evidence signify that product mineral precipitation is a slow kinetic process and partial equilibria between aqueous solution and product minerals were not held. In contrast, the experimental evidences are consistent with the hypothesis of strong coupling of mineral dissolution/precipitation kinetics [e.g., Zhu C., Blum A. E. and Veblen D. R. (2004a) Feldspar dissolution rates and clay precipitation in the Navajo aquifer at Black Mesa, Arizona, USA. In Water-Rock Interaction (eds. R. B. Wanty and R. R. I. Seal). A.A. Balkema, Saratoga Springs, New York. pp. 895-899]. In all batch experiments examined, the time of congruent feldspar dissolution was short and supersaturation with respect to the product minerals was reached within a short period of time. The experimental system progressed from a dissolution driven regime to a precipitation limited regime in a short order. The results of this study suggest a complex feedback between dissolution and precipitation reaction kinetics, which needs to be considered in the interpretation of field based dissolution rates.
\end{abstract}

(C) 2009 Elsevier Ltd. All rights reserved.

\section{INTRODUCTION}

As pointed out by Drever (2004) in his foreword to the surficial geochemistry volume of the Treatise on Geochemistry, one fundamental assumption in geochemistry that has received relatively little attention since the initial proposal, is that partial equilibrium may exist among mineral products from the dissolution of the primary mineral (e.g., feld-

\footnotetext{
* Corresponding author.

E-mail address: chenzhu@indiana.edu (C. Zhu).
}

spar) and the aqueous solution (Garrels and Mackenzie, 1967; Helgeson, 1968, 1970, 1971, 1974; Helgeson et al., 1969, 1970; Helgeson and Murphy, 1983). The term "partial equilibrium" was used by Helgeson (1979) to describe the feldspar-water system as an example, in which all aqueous species are at equilibrium with each other and (selected) secondary minerals are at equilibrium with the aqueous solution but the aqueous solution is not at equilibrium with feldspar. As a consequence of partial equilibrium, mass transfer processes in silicate weathering systems is regarded as driven by irreversible dissolution of the primary mineral (Helgeson, 1979). A large body of literature on silicate 
weathering has focused on feldspar dissolution rates in soils and groundwater, with little references to the kinetics of product mineral precipitation (see reviews in Blum and Stillings, 1995; Drever and Clow, 1995; White and Brantley, 2003; Bricker et al., 2004). Over the years, it has been shown through numerical modeling of feldspar hydrolysis - secondary mineral precipitation reactions, that if the partial equilibrium assumption does not hold, aqueous chemistry evolution, mineral paragenesis, and reaction rates could deviate significantly from the Helgeson classic reaction path model (Steefel and Van Cappellen, 1990; Lasaga et al., 1994; Lasaga, 1998; Zhu et al., 2004a; Ganor et al., 2007). However, to date, the partial equilibrium hypothesis has yet to be systematically tested.

What has prompted us to re-examine this hypothesis proposed nearly half a century ago is its current relevance to the interpretation of the well known and extensively discussed apparent discrepancy between the field derived feldspar dissolution rates and those measured in the laboratory (Paces, 1983; Velbel, 1990; Brantley, 1992; Blum and Stillings, 1995; Drever and Clow, 1995; White and Brantley, 2003; Zhu, 2005; and references therein), which currently is under intense and active research. In general, field derived feldspar dissolution rates are two to five orders of magnitude slower than laboratory measured rates (ibid). Note, however, that when comparing field and laboratory derived rates, one must be careful that the former represent bulk and effective rates and the latter are usually measured at conditions far from equilibrium (Zhu, 2005). Nevertheless, such a large discrepancy underscores our poor understanding of some the fundamental chemical and physical processes which control silicate reaction kinetics in nature.

Numerous hypotheses have been proposed in the literature to explain the persistent discrepancy between field and laboratory feldspar dissolution rates. These hypotheses include the possible armoring effects of the secondary minerals that coat the feldspar grain surfaces (Correns and Von Engelhardt, 1938; Correns, 1940; Helgeson, 1971, 1972; Luce et al., 1972; Paces, 1973; Busenberg and Clemency, 1976; Chou and Wollast, 1984; Nugent et al., 1998), the possible effects of the leached layer (Luce et al., 1972; Busenberg and Clemency, 1976; Chou and Wollast, 1984; Hellmann et al., 1990; Brantley and Stillings, 1996; Hellmann, 1997; Nesbitt and Skinner, 2001; Oelkers, 2001), approach to saturation with respect to feldspars (Burch et al., 1993; Gautier et al., 1994; Oelkers et al., 1994; Oelkers, 2001; Beig and Luttge, 2006; Hellmann and Tisserand, 2006), biological effects, inhibition of adsorbed $\mathrm{Al}^{3+}$ on feldspar surfaces (Chou and Wollast, 1985; Gautier et al., 1994; Oelkers et al., 1994; Oelkers, 2001).

One distinction that differentiates the field and laboratory conditions is that weathering product minerals are often intimately associated with the primary minerals in nature (Banfield and Eggleton, 1990; Banfield et al., 1991; Banfield and Barker, 1994; Zhu et al., 2006; Hereford et al., 2007). Conversely, in laboratory experiments, the precipitation of product minerals was often avoided by adjusting the chemistry and rate of recirculation of the fluid phase. Recognizing the close association between the secondary minerals and primary mineral in the field, Zhu et al. (2004a) proposed a new hypothesis for explaining the laboratory-field discrepancy wherein the slow kinetics of secondary clay precipitation is the rate limiting step and thus controls the overall feldspar dissolution rate. Clay precipitation removes solutes from the aqueous solution, maintaining a condition of feldspar undersaturation, makes additional feldspar dissolution possible, but the slow clay precipitation (or smaller effective rate constants with respect to that for the dissolution reaction, see below) results in a steady state in which the aqueous solution is near equilibrium with feldspar. Therefore, slow clay precipitation could effectively reduce feldspar dissolution rates by orders of magnitude, in a fashion consistent with laboratory rates at conditions far from equilibrium, the control of dissolution rates by the Gibbs free energy of the reaction, and many field observations (Zhu et al., 2004a).

The potential control of slow clay precipitation on overall feldspar dissolution rates calls for rigorous testing of the above mentioned partial equilibrium hypothesis. Therefore, we have conducted a series of batch experiments of feldspar dissolution and secondary mineral precipitation at elevated temperatures and pressures ( $\mathrm{Fu}$ et al., 2009). The new experiments are necessary because earlier studies, mostly conducted in the 1960s, typically did not (1) measure the aluminum concentrations that are necessary for saturation index evaluations; (2) analyze (or had the capacity to analyze with the techniques of the time) mineral products of nanometer size in great detail, or (3) take steps to ameliorate the influences of fine particles on the feldspar surfaces that were later found to produce parabolic rate law artifacts (Holdren and Berner, 1979).

This paper presents speciation-solubility modeling evaluating solid-fluid equilibria at discrete time points during physical experiments when fluid samples were analyzed. These calculations were then used to constrain fluid evolution paths in order to determine whether the partial equilibrium assumption provides a reasonable prediction for the reaction paths measured. This approach, while providing only "snapshots" and not a full "movie" of the reaction paths as could be computed using a forward reaction path modeling approach, assumptions involved in applying such a numerical model (e.g., reactive surface areas and the forms of rate laws) which would introduce such potential disadvantages that it is unlikely that we could reliably test the utility of the partial equilibrium model. It is important first to establish the evaluation of the partial equilibrium hypothesis without these assumptions.

\section{BACKGROUND}

To facilitate the discussions that follow, let us start with the classical reaction path model of feldspar hydrolysis (Helgeson, 1968, 1971, 1979; Helgeson et al., 1969), which states that: (1) dissolution of primary feldspar is the ratelimiting irreversible reaction and the driver of all processes in the system; (2) precipitation of all secondary minerals is instantaneous; (3) the aqueous solution is at equilibrium with or undersaturated with respect to all secondary minerals at all times; (4) fluid chemistry obeys the phase rule, 
such that on our two-dimensional activity-activity diagrams (abbreviated as $a-a$ diagrams hereafter) at constant $T$ and $P$, if three phases are present then the fluid must follow a linear phase boundary until one of the solid phases is no longer present; and (5) secondary minerals dissolve and precipitate in a paragenesis sequence as aqueous chemistry evolves. This model has been described in nearly all geochemistry textbooks (see Anderson and Crerar, 1993; Krauskopf and Bird, 1995; Drever, 1997; Faure, 1998).
Consider the classic example of K-feldspar (microcline) hydrolysis at $25^{\circ} \mathrm{C}$ and 1 bar in a closed system (Fig. 1a). Because it is out of equilibrium, feldspar dissolves in pure water (with a little $\mathrm{HCl}$ ) that initially contains essentially no $\mathrm{Si}, \mathrm{K}$, or $\mathrm{Al}$. When the solution reaches point 1 on Fig. 1a, gibbsite forms and the solution is located in the gibbsite stability field. The aqueous solution has a saturation index (SI) of zero for gibbsite and is undersaturated with respect to kaolinite and muscovite. At point 2, kao- (a)

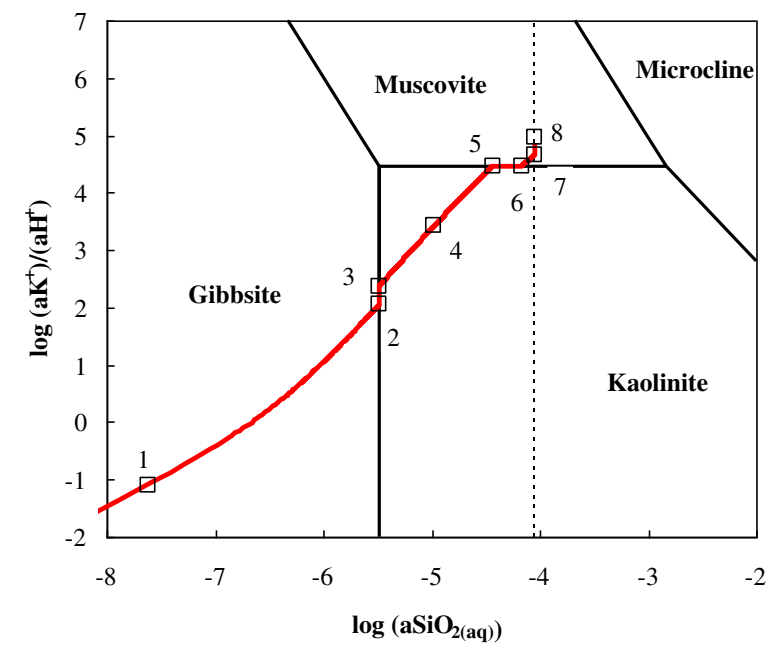

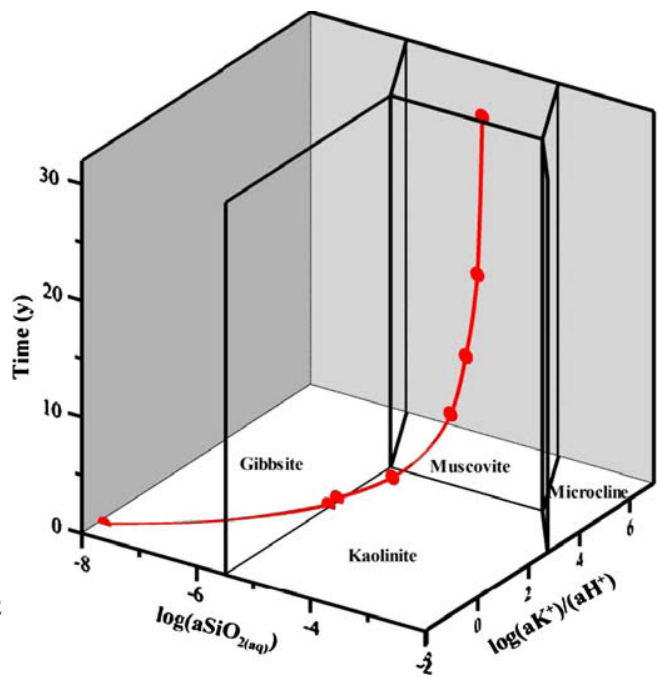

(b)

\begin{tabular}{crrrrrr}
\hline Point number & \multicolumn{1}{c}{ Time $(\mathrm{y})$} & \multicolumn{1}{c}{ Kaolinite } & \multicolumn{1}{c}{ Microcline } & \multicolumn{1}{c}{ Muscovite } & \multicolumn{1}{l}{ Gibbsite } & Quartz \\
\hline 1 & 0.002 & -4.21 & -15.04 & -11.85 & 0 & -3.54 \\
2 & 0.277 & 0 & -5.61 & -2.42 & 0 & -1.43 \\
3 & 0.404 & 0 & -5.29 & -2.10 & 0 & -1.43 \\
4 & 1.426 & 0 & -3.24 & -1.05 & -0.50 & -0.93 \\
5 & 6.133 & 0 & -1.08 & 0 & -1.05 & -0.38 \\
6 & 11.472 & 0 & -0.57 & 0 & -1.31 & -0.12 \\
7 & 18.395 & -0.12 & -0.20 & 0 & -1.49 & 0 \\
8 & 31.710 & -0.25 & -0.08 & 0 & -1.56 & 0 \\
\hline
\end{tabular}

(c)

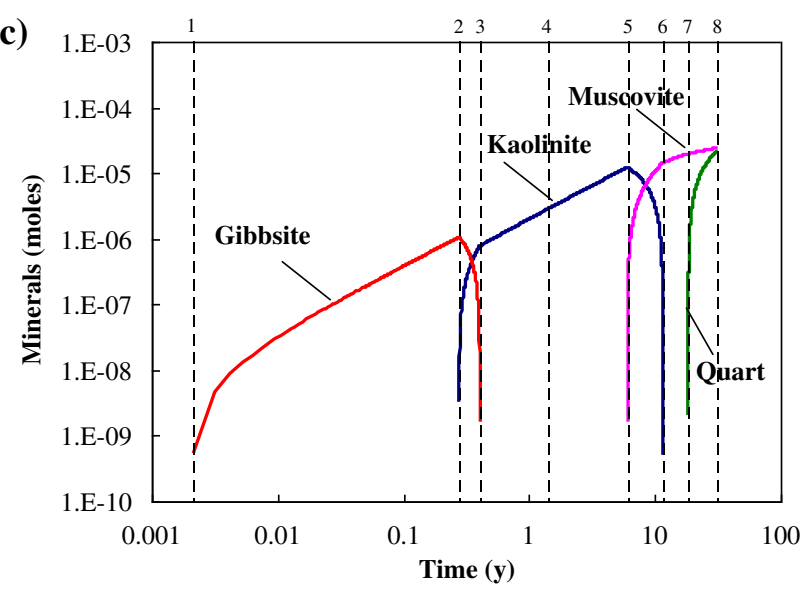

Fig. 1. Reaction path of the dissolution of microcline in pure water at $25^{\circ} \mathrm{C}$. (a) Equilibrium activity-activity diagram; (b) calculated mineral saturation indices; and (c) mineral abundance versus time. Thermodynamic data were from Table 1a, except for gibbsite (Robie and Hemingway, 1995). A linear rate law with a rate constant of $10^{-12} \mathrm{~mol} \mathrm{~m}^{-2} \mathrm{~s}^{-1}$ and a surface area of $0.13 \mathrm{~m}^{2} / \mathrm{g}$ (for total of $0.8 \mathrm{~mol}$ feldspar) for microcline was used. 
linite starts to precipitate. The coexistence of gibbsite and kaolinite buffers the activity of silica, and the fluid composition moves along the gibbsite-kaolinite boundary on the $a-a$ diagram. As feldspar continues to dissolve, gibbsite is converted to kaolinite. Along 2 to 3 , the saturation indices for both gibbsite and kaolinite are zero (at equilibrium) and for muscovite negative (undersaturated) (Fig. 1b). After all of the gibbsite is consumed, the fluid composition departs from the gibbsite-kaolinite boundary and traverses the kaolinite stability field toward microcline. Within the kaolinite stability field (point 4), the solution is undersaturated with respect to gibbsite $(\mathrm{SI}<0)$, saturated with respect to kaolinite $(\mathrm{SI}=0)$, and undersaturated with respect to muscovite (Fig. 1b). Between points 4 and 5, as $\mathrm{K}$ and $\mathrm{Si}$ concentrations increase, the solution reaches saturation with respect to muscovite, and muscovite starts to precipitate. The coexistence of muscovite and kaolinite buffers the activity ratio $\left(a \mathrm{~K}^{+} / a \mathrm{H}^{+}\right)$, and the fluid composition moves horizontally along the muscovite-kaolinite boundary (points 5, 6). After all the kaolinite is consumed, the fluid composition departs from the kaolinite-muscovite boundary and evolves across the muscovite stability field towards K-feldspar. When the reaction path reaches point 7 , quartz saturation is achieved. There are two different paths depending on whether quartz precipitates. If quartz precipitation is inhibited, the solution continues to evolve along the direction of point $6 \rightarrow$ point 7 , towards the K-feldspar field. If quartz precipitates, the solution would evolve along the direction of point $7 \rightarrow$ point 8 , i.e., along the quartz saturation line (dashed line). In the second case, muscovite and quartz both precipitate because the solution is supersaturated with both muscovite and quartz. It is also possible, depending on the starting point, that the reaction path would not encounter the muscovite stability but would reach the microcline field through the kaolinite field or directly from the gibbsite field into muscovite field (Helgeson, 1979; Steinmann et al., 1994). While the $a-a$ diagrams depict the evolution of fluid chemistry (i.e., reaction path) in the feldspar-water system, the mineral abundance versus time diagram (Fig. 1c) depicts the sequential appearance and disappearance of gibbsite, kaolinite, muscovite, and quartz as the fluid moves from one stability field to another following the well known paragenesis sequence determined by thermodynamics.

However, Lasaga (1998) used different ratios of rate constants $k_{i} / k_{\text {feld, }}$, where $i$ stands for clay minerals gibbsite, kaolinite, or muscovite, and showed that reaction paths could deviate from the classic reaction path model if the secondary minerals are not at equilibrium with the aqueous fluid. These calculations used a simplified rate law $R_{i}=k_{i} \frac{\Delta G_{r, i}}{R T}$ where $R_{i}$ stands for the rate of $i$ th chemical reactions, $\Delta G_{r, i}$ the Gibbs free energy of $i$ th reaction, $R$ the gas constant, and $T$ temperature in Kelvin. The rate dependence on the hydrogen ion (Helgeson et al., 1984), adsorbed aluminum (Oelkers et al., 1994), or other complicating factors were not considered in these illustrative calculations.

The deviations from partial equilibrium are manifested in two forms. First, the fluid chemistry no longer evolves along the mineral stability boundaries, but enters into another mineral stability field across the boundary at an oblique angle (hence, the reaction path is different from the classic reaction path model in terms of fluid chemistry). Second, the secondary minerals precipitated earlier no longer dissolve completely as fluid moves into the stability field of another mineral lower in the paragenesis sequence, but persist for a duration determined by the rate constant ratios. For example, some gibbsite persists when the solution chemistry is in the stability field of kaolinite. There may be a region of coexistence of gibbsite and kaolinite, and even a region of coexisting gibbsite, kaolinite, and muscovite. These regions become larger as the ratios of $k_{i} / k_{\text {feld }}$ become smaller. Zhu et al. (2004a,b) showed that when the $k_{i} / k_{\text {feld }}$ ratios (or more precisely, the effective rate constants defined as $k^{*}=k \times$ surface area) are in $10^{-2}$ to $10^{-4}$, clay precipitation becomes the rate limiting step and a steady state persisted at which feldspar continues to dissolve near equilibrium at a much reduced rate due to the free energy effect. The term of "slow clay precipitation" in this communication refers to this scenario (i.e., $\left.k_{i}^{*} / k_{\text {feld }}^{*} \ll 1\right)$. However, these numerical predictions were intuitive and illustrative. The partial equilibrium hypothesis has not been hitherto tested systematically against experimental data.

\section{MODELING RESULTS}

In this paper, saturation indices (SI) for relevant minerals were calculated from the measured temperatures $(T)$, pressures $(P)$, and chemical compositions of experimental aqueous solutions. SI is defined as $\log (Q / K)$, where $Q$ denotes the activity quotient and $K$ the equilibrium constant (Zhu and Anderson, 2002, p. 45). Equilibrium activity-activity diagrams for mineral stability and phase relations were constructed to trace the evolution of the aqueous chemistry during the batch experiments. For all thermodynamic calculations, the standard states for the solids are defined as unit activity for pure end-member solids at the $T$ and $P$ of interest. The standard state for water is the unit activity of pure water. For aqueous species other than $\mathrm{H}_{2} \mathrm{O}$, the standard state is the unit activity of the species in a hypothetical one molal solution referenced to infinite dilution at the $T$ and $P$ of interest. Standard state thermodynamic properties for mineral end-members were taken from Holland and Powell (1998) except for boehmite (see Appendix A), for water from Haar et al. (1984), for Al-bearing aqueous species from Tagi-

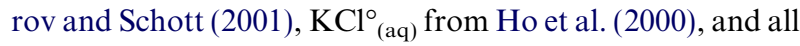
other aqueous species from Shock and Helgeson (1988), Shock et al. (1989, 1997), and Sverjensky et al. (1997) (Table 1a). The $T$ and $P$ dependences of thermodynamic properties for aqueous species, when applicable, were predicted using the parameters of the revised HKF equations of state for aqueous species (Helgeson et al., 1981; Tanger and Helgeson, 1988; Shock et al., 1992).

Calculations of equilibrium constants were facilitated with a modified version of SUPCRT92 (Johnson et al., 1992) with the heat capacity function of Holland and Powell (1998) for minerals. Speciation and solubility calculations were aided with the computer codes PHREEQC (Parkhurst and Appello, 1999) and EQ3/6 (Wolery, 1992) together with our own equilibrium constant databases for 
Table 1a

Equilibrium constants used in this study (for the baseline case).

\begin{tabular}{|c|c|c|c|c|c|c|c|}
\hline & $\begin{array}{l}25^{\circ} \mathrm{C} \\
1 \text { bar }\end{array}$ & $\begin{array}{l}90^{\circ} \mathrm{C} \\
1 \text { bar }\end{array}$ & $\begin{array}{l}150^{\circ} \mathrm{C} \\
\text { Psat }\end{array}$ & $\begin{array}{l}210^{\circ} \mathrm{C} \\
\text { Psat }\end{array}$ & $\begin{array}{l}200{ }^{\circ} \mathrm{C}, 300 \\
\text { bars }\end{array}$ & $\begin{array}{l}300{ }^{\circ} \mathrm{C}, 88 \\
\text { bars }\end{array}$ & Ref \\
\hline \multicolumn{8}{|l|}{ Aqueous reactions } \\
\hline $\mathrm{H}_{2} \mathrm{O}=\mathrm{OH}^{-}+\mathrm{H}^{+}$ & -13.995 & -12.422 & -11.631 & -11.242 & -11.163 & -11.297 & (1) \\
\hline $\mathrm{Al}^{3+}+\mathrm{H}_{2} \mathrm{O}=\mathrm{Al}(\mathrm{OH})^{2+}+\mathrm{H}^{+}$ & -4.964 & -3.248 & -2.129 & -1.265 & -1.446 & -0.22 & (2) \\
\hline $\mathrm{Al}^{3+}+2 \mathrm{H}_{2} \mathrm{O}=\mathrm{Al}(\mathrm{OH})_{2}^{+}+2 \mathrm{H}^{+}$ & -10.921 & -7.360 & -5.045 & -3.264 & -3.63 & -1.119 & (2) \\
\hline $\mathrm{Al}^{3+}+3 \mathrm{H}_{2} \mathrm{O}=\mathrm{Al}(\mathrm{OH})_{3}{ }^{\circ}+3 \mathrm{H}^{+}$ & -17.044 & -12.252 & -9.168 & -6.823 & -7.301 & -4.035 & (2) \\
\hline $\mathrm{Al}^{3+}+4 \mathrm{H}_{2} \mathrm{O}=\mathrm{Al}(\mathrm{OH})_{4}^{-}+4 \mathrm{H}^{+}$ & -22.851 & -17.299 & -13.747 & -11.086 & -11.572 & -8.150 & (2) \\
\hline $\mathrm{Al}^{3+}+\mathrm{Na}^{+}+4 \mathrm{H}_{2} \mathrm{O}=\mathrm{NaAl}(\mathrm{OH})_{4}{ }^{\circ}+4 \mathrm{H}^{+}$ & -22.90 & -16.941 & -13.097 & -10.153 & -10.748 & -6.63 & (2) \\
\hline $\mathrm{Al}^{3+}+\mathrm{SiO}_{2}{ }^{\circ}+2 \mathrm{H}_{2} \mathrm{O}=\mathrm{AlH}_{3} \mathrm{SiO}_{4}{ }^{2+}+\mathrm{H}^{+}$ & -2.357 & -0.276 & 1.026 & 2.001 & 1.86 & 3.188 & (2) \\
\hline $\mathrm{Na}^{+}+\mathrm{H}_{2} \mathrm{O}=\mathrm{NaOH}^{\circ}+\mathrm{H}^{+}$ & -14.205 & -12.561 & -11.642 & -11.047 & -11.087 & -10.480 & (3) \\
\hline $\mathrm{SiO}_{2}{ }^{\circ}+\mathrm{H}_{2} \mathrm{O}=\mathrm{HSiO}_{3}^{-}+\mathrm{H}^{+}$ & -9.585 & -9.016 & -8.802 & -8.860 & -8.707 & -9.430 & (3) \\
\hline $\mathrm{SiO}_{2}{ }^{\circ}+\mathrm{Na}^{+}+\mathrm{H}_{2} \mathrm{O}=\mathrm{NaHSiO}_{3}{ }^{\circ}+\mathrm{H}^{+}$ & -7.754 & -7.748 & -7.753 & -7.829 & -7.767 & -7.986 & (3) \\
\hline $\mathrm{Ca}^{2+}+\mathrm{H}_{2} \mathrm{O}=\mathrm{CaOH}^{+}+\mathrm{H}^{+}$ & -12.833 & -10.433 & -8.903 & -7.757 & -7.961 & -6.435 & (3) \\
\hline Acetate $^{-}+\mathrm{H}^{+}=$HAcetate & 4.757 & 4.904 & 5.195 & 5.599 & & 6.507 & (4) \\
\hline Acetate $^{-}+\mathrm{Na}^{+}=$NaAcetate & -0.103 & 0.089 & 0.428 & 0.863 & & 1.798 & (5) \\
\hline 2 Acetate $^{-}+\mathrm{Na}^{+}=\mathrm{Na}(\text { Acetate })_{2}{ }^{-}$ & -0.485 & -0.361 & 0.246 & 1.078 & & 2.736 & (5) \\
\hline Acetate $^{-}+\mathrm{Ca}^{2+}=\mathrm{CaAcetate}^{+}$ & 0.931 & 1.259 & 1.822 & 2.532 & & 3.947 & (5) \\
\hline 2 Acetate $^{-}+\mathrm{Ca}^{2+}=\mathrm{Ca}(\text { Acetate })_{2}{ }^{\circ}$ & 1.40 & 1.937 & 3.013 & 4.398 & & 7.159 & (5) \\
\hline Acetate $^{-}+\mathrm{Al}^{3+}=\mathrm{Al}(\text { Acetate })^{2+}$ & 2.668 & 2.405 & 2.606 & 3.052 & & 4.171 & (5) \\
\hline 2 Acetate $^{-}+\mathrm{Al}^{3+}=\mathrm{Al}(\text { Acetate })_{2}{ }^{+}$ & 5.27 & 4.322 & 4.429 & 5.083 & & 7.05 & (5) \\
\hline 3 Acetate $^{-}+\mathrm{Al}^{3+}=\mathrm{Al}(\text { Acetate })_{3}^{\circ}$ & 7.169 & 5.296 & 5.138 & 5.878 & & 8.553 & (5) \\
\hline $\mathrm{K}^{+}+\mathrm{H}_{2} \mathrm{O}=\mathrm{KOH}^{\circ}+\mathrm{H}^{+}$ & -14.439 & -12.584 & -11.551 & -10.885 & -10.939 & -10.267 & (3) \\
\hline $\mathrm{Cl}^{-}+\mathrm{Ca}^{2+}=\mathrm{CaCl}^{+}$ & -0.292 & & & & 1.146 & & (3) \\
\hline $2 \mathrm{Cl}^{-}+\mathrm{Ca}^{2+}=\mathrm{CaCl}_{2}^{\circ}$ & -0.644 & & & & 0.672 & & (3) \\
\hline $\mathrm{H}^{+}+\mathrm{Cl}^{-}=\mathrm{HCl}^{\circ}$ & -0.710 & & & & -0.15 & & (6) \\
\hline $\mathrm{K}^{+}+\mathrm{Cl}^{-}=\mathrm{KCl}^{\circ}$ & & & & & 0.456 & & (7) \\
\hline $\mathrm{Na}^{+}+\mathrm{Cl}^{-}=\mathrm{NaCl}^{\circ}$ & -0.777 & & & & 0.019 & & (3) \\
\hline $\mathrm{HCO}_{3}^{-}+\mathrm{H}^{+}=\mathrm{CO}_{2}+\mathrm{H}_{2} \mathrm{O}$ & 6.345 & 6.343 & 6.724 & 7.305 & & 8.525 & (3) \\
\hline $\mathrm{HCO}_{3}^{-}=\mathrm{CO}_{3}^{2-}+\mathrm{H}^{+}$ & -10.329 & -10.082 & -10.2 & -10.534 & & -11.461 & (3) \\
\hline $\mathrm{HCO}_{3}{ }^{-}+\mathrm{Na}^{+}=\mathrm{NaCO}_{3}{ }^{-}+\mathrm{H}^{+}$ & -9.455 & & & & & -8.468 & (10) \\
\hline $\mathrm{HCO}_{3}{ }^{-}+\mathrm{Na}^{+}=\mathrm{NaHCO}_{3}^{\circ}$ & -0.103 & & & & & 2.002 & $(10)$ \\
\hline $\mathrm{HCO}_{3}{ }^{-}+\mathrm{K}^{+}=\mathrm{KCO}_{3}{ }^{-}+\mathrm{H}^{+}$ & -9.455 & & & & & -8.468 & (10) \\
\hline $\mathrm{HCO}_{3}{ }^{-}+\mathrm{K}^{+}=\mathrm{KHCO}_{3}^{\circ}$ & -0.103 & & & & & 2.002 & $(10)$ \\
\hline \multicolumn{8}{|l|}{ Mineral dissolution reactions } \\
\hline $\mathrm{NaAlSi}_{3} \mathrm{O}_{8}$ (Albite) $+4 \mathrm{H}^{+}=\mathrm{Al}^{3+}+\mathrm{Na}^{+}+3 \mathrm{SiO}_{2}{ }^{\circ}+2 \mathrm{H}_{2} \mathrm{O}$ & 2.065 & -0.057 & -1.713 & -3.02 & -2.508 & -4.714 & (8) \\
\hline $\begin{array}{l}\mathrm{NaAlSi}_{2} \mathrm{O}_{7} \mathrm{H}_{2} \text { (Analcime) }+4 \mathrm{H}^{+}=\mathrm{Al}^{3+}+\mathrm{Na}^{+} \\
\quad+2 \mathrm{SiO}_{2}{ }^{\circ}+3 \mathrm{H}_{2} \mathrm{O}\end{array}$ & 6.391 & 3.464 & 1.417 & -0.155 & & -2.118 & (8) \\
\hline $\begin{array}{l}\mathrm{CaAl}_{2} \mathrm{Si}_{2} \mathrm{O}_{8} \text { (Anorthite) }+8 \mathrm{H}^{+}=2 \mathrm{Al}^{3+}+\mathrm{Ca}^{2+} \\
\quad+4 \mathrm{H}_{2} \mathrm{O}+2 \mathrm{SiO}_{2}^{\circ}\end{array}$ & 23.68 & 14.260 & 7.819 & 2.739 & 4.042 & -3.606 & (8) \\
\hline $\mathrm{AlO}_{2} \mathrm{H}($ Boehmite $)+3 \mathrm{H}^{+}=\mathrm{Al}^{3+}+2 \mathrm{H}_{2} \mathrm{O}$ & 7.610 & 4.023 & 1.660 & -.198 & .242 & -2.530 & (9) \\
\hline $\mathrm{AlO}_{2} \mathrm{H}$ (Diaspore) $+3 \mathrm{H}^{+}=\mathrm{Al}^{3+}+2 \mathrm{H}_{2} \mathrm{O}$ & 7.191 & 3.7 & 1.401 & -0.407 & 0.02 & -2.685 & (8) \\
\hline $\mathrm{Al}_{2} \mathrm{Si}_{2} \mathrm{O}_{5}(\mathrm{OH})_{4}($ Kaolinite $)+6 \mathrm{H}^{+}=2 \mathrm{Al}^{3+}+2 \mathrm{SiO}_{2}{ }^{\circ}+5 \mathrm{H}_{2} \mathrm{O}$ & 4.501 & -0.254 & -3.535 & -6.119 & -5.354 & -9.443 & $(8)$ \\
\hline $\mathrm{KAlSi}_{3} \mathrm{O}_{8}$ (Microcline) $+4 \mathrm{H}^{+}=\mathrm{Al}^{3+}+\mathrm{K}^{+}+3 \mathrm{SiO}_{2}{ }^{\circ}+2 \mathrm{H}_{2} \mathrm{O}$ & -1.05 & -2.301 & -3.434 & -4.377 & -3.923 & -5.694 & $(8)$ \\
\hline $\begin{array}{l}\mathrm{KAl}_{3} \mathrm{Si}_{3} \mathrm{O}_{10}(\mathrm{OH})_{2} \\
\text { (Muscovite) }+10 \mathrm{H}^{+}=\mathrm{K}^{+}+3 \mathrm{Al}^{3+}+3 \mathrm{SiO}_{2}^{\circ}+6 \mathrm{H}_{2} \mathrm{O}\end{array}$ & 11.22 & 3.297 & -2.250 & -6.687 & -5.407 & -12.445 & $(8)$ \\
\hline $\begin{array}{l}\mathrm{NaAl}_{3} \mathrm{Si}_{3} \mathrm{O}_{10}(\mathrm{OH})_{2} \\
(\text { Paragonite })+10 \mathrm{H}^{+}=\mathrm{Na}^{+}+3 \mathrm{Al}^{3+}+3 \mathrm{SiO}_{2}{ }^{\circ}+6 \mathrm{H}_{2} \mathrm{O}\end{array}$ & 14.397 & 5.687 & -0.328 & -5.084 & -3.753 & -11.164 & (8) \\
\hline $\begin{array}{l}\mathrm{Al}_{2} \mathrm{Si}_{4} \mathrm{O}_{10}(\mathrm{OH})_{2}(\text { Pyrophyllite })+6 \mathrm{H}^{+}=2 \mathrm{Al}^{3+}+4 \mathrm{H}_{2} \mathrm{O} \\
\quad+4 \mathrm{SiO}_{2}^{\circ}\end{array}$ & -1.724 & -5.394 & -8.234 & -10.549 & -9.733 & -13.647 & (8) \\
\hline $\mathrm{SiO}_{2}($ Quartz $)=\mathrm{SiO}_{2}^{\circ}$ & -4.047 & -3.204 & -2.752 & -2.414 & -2.424 & -2.033 & (8) \\
\hline $\mathrm{KAlSi}_{3} \mathrm{O}_{8}$ (Sanidine) $+4 \mathrm{H}^{+}=\mathrm{Al}^{3+}+\mathrm{K}^{+}+3 \mathrm{SiO}_{2}{ }^{\circ}+2 \mathrm{H}_{2} \mathrm{O}$ & -0.002 & -1.571 & -2.911 & -4.009 & & -5.499 & (8) \\
\hline $\mathrm{KAlSiO}_{4}($ Kalsilite $)+4 \mathrm{H}^{+}=\mathrm{K}^{+}+\mathrm{Al}^{3+}+\mathrm{SiO}_{2}^{\circ}+2 \mathrm{H} 2 \mathrm{O}$ & 12.543 & & & & & 1.187 & $(8)$ \\
\hline $\mathrm{NaAlSiO}_{4}($ Nepheline $)+4 \mathrm{H}^{+}=\mathrm{Na}^{+}+\mathrm{Al}^{3+}+\mathrm{SiO}_{2}{ }^{\circ}+2 \mathrm{H}_{2} \mathrm{O}$ & 13.423 & & & & & 1.185 & $(8)$ \\
\hline
\end{tabular}

(1) Haar et al. (1984); (2) Tagirov and Schott (2001); (3) Sverjensky et al. (1997); (4) Shock (1995); (5) Shock and Koretsky (1993); (6) McCollom and Shock (1997); (7) Ho et al. (2000); (8) Holland and Powell (1998) for minerals and (1), (2), and (3) for aqueous species; (9) Hemingway et al. (1991) for boehmite; (10) Alekseyev et al. (1997).

the programs with thermodynamic properties noted above. Activity coefficients for the charged aqueous species were calculated from the extended Debye-Hückel equation or B-dot equation fitted to mean salt $\mathrm{NaCl}$ activity coefficients
(Helgeson et al., 1978; Oelkers and Helgeson, 1990). Activity coefficients for neutral or uncharged aqueous species were either set to be unity (EQ3NR) or calculated from the Setchénow equation with a coefficient of 0.1 (PHREEQC). 
Activities coefficients for end-members of feldspar solid solutions as a result from compositional impurities were first neglected, but the impacts on calculated SI were later assessed in Appendix A.

In evaluating the aqueous speciation and mineral saturation states at experimental conditions, we used the $\mathrm{pH}$ and total analytical concentrations of the constituents measured at ambient conditions (e.g., $\sim 22{ }^{\circ} \mathrm{C}$ and 1 bar) as input into the modeling codes and then "re-heated" the solution to experimental $T$ and $P$. This method calculates the "in situ" $\mathrm{pH}$ at the experimental conditions by taking account of the effects of $T$ and $P$ on the distribution of aqueous species (Reed and Spycher, 1984). Owing to the relatively low experimental $T$, however, the calculated in situ $\mathrm{pH}$ values were close to those measured at ambient conditions in most cases, with an increase $0.1-0.4$ units for Section 3.1, 0.1-0.4 for Section 3.2, and 0.1-0.8 for Section 3.3, and $0.1-0.2$ for Section 3.4. The large differences between ambient and in situ $\mathrm{pH}$ values in Section 3.3 are due to the use of acetate and sodium acetate buffer, which has a large temperature variance. Note that the experimental design in Sections 3.1 and 3.2 allowed for sampling of aqueous fluids from the on-going reaction at constant $T$ and $P$ without quenching the reactor (Seyfried et al., 1987). Back reactions and precipitation of solids generally were not a concern.

In order to test whether the conclusions still stand when different sets of thermodynamic properties are used, SI values for primary minerals and product minerals were also calculated using three additional sets of thermodynamic properties for mineral end-members and aqueous species. These datasets are referred to $\mathrm{A}, \mathrm{B}$, and $\mathrm{C}$ in the following discussion, and their sources of thermodynamic properties are listed in Table $1 \mathrm{~b}$. The SI values calculated using these three datasets are presented as open symbols in figures of temporal evolution of SI values, together with the baseline case ("BL" represented by solid symbols) described in the preceding paragraphs. The equilibrium constants and calculated values of SI from these three datasets are shown in the Elec- tronic Annex. Table 2 summarizes the batch experiments, for which geochemical modeling was carried out.

\subsection{Alkali feldspar dissolution and clay precipitation}

\subsubsection{Experimental design and results}

Two batch experiments for alkali feldspar dissolution in $\sim 0.20 \mathrm{~m} \mathrm{KCl}$ solution at an initial $\mathrm{pH}$ of 3.1 were conducted at $200{ }^{\circ} \mathrm{C}$ and 300 bars in a flexible $\mathrm{Au} / \mathrm{Ti}$ reaction cell, which was placed in a steel-alloy autoclave ( $\mathrm{Fu}$ et al., 2009). "Orthoclase" crystals having an average size of $\sim 0.5 \mathrm{~cm}$ were obtained from WARD'S Natural Sciences Establishment. X-ray diffraction (XRD) and electron microprobe analysis (EMPA) results show that the feldspar samples were perthitic alkali feldspars and were composed of $35 \%$ low albite $\left(\mathrm{Ca}_{0.04} \mathrm{Na}_{0.95} \mathrm{~K}_{0.01} \mathrm{Al}_{1.04} \mathrm{Si}_{2.96} \mathrm{O}_{8}\right), 60 \%$ orthoclase $\left(\mathrm{K}_{0.85} \mathrm{Na}_{0.15} \mathrm{Al}_{1.04} \mathrm{Si}_{2.97} \mathrm{O}_{8}\right)$, and $5 \%$ quartz. A time series of in situ aqueous samples was analyzed for $\mathrm{Cl}, \mathrm{Si}, \mathrm{Al}, \mathrm{K}, \mathrm{Na}$, and $\mathrm{Ca}$ as well as trace elements. One experiment was terminated at the end of $120 \mathrm{~h}$, and the solids in the experiment were recovered for analysis. XRD and High Resolution Transmission Electron Microscopy (HRTEM) results showed boehmite and trace amount of kaolinite. Scanning Electron Microscopic (SEM) examination showed dissolution channels and the feldspar surfaces were covered with product minerals. The second experiment was terminated after $1872 \mathrm{~h}$. XRD of the solids detected boehmite and kaolinite, but no detectable muscovite. SEM images of the reaction products after the batch experiments showed that hexagonally shaped secondary minerals were present on the grains of alkali feldspars, but with no clear orientation or preferential sites on the feldspar surfaces. Laminar channels and etch pits on the surface of alkali feldspars indicated dissolution heterogeneity. The surface coverage of the secondary minerals was approximately $20 \%$.

\subsubsection{Reaction paths and mineral saturation indices}

The time evolution of aqueous chemistry in the system $\mathrm{Na}_{2} \mathrm{O}-\mathrm{K}_{2} \mathrm{O}-\left(\mathrm{Al}_{2} \mathrm{O}_{3}\right)-\mathrm{SiO}_{2}-\mathrm{H}_{2} \mathrm{O}-\mathrm{HCl}$ system is traced on

Table $1 \mathrm{~b}$

Different sets of thermodynamic properties for aqueous and mineral species used for calculations of saturation indices. ${ }^{a}$

\begin{tabular}{|c|c|c|c|c|}
\hline Notation & A & $\mathrm{B}$ & $\mathrm{C}$ & $\mathrm{BL}=$ baseline case \\
\hline \multirow[t]{3}{*}{$\begin{array}{l}\text { Aqueous } \\
\text { species }\end{array}$} & $\begin{array}{l}\text { Al-bearing species and } \\
\mathrm{NaOH}^{\circ} \text { from Pokrovskii and } \\
\text { Helgeson }(1995)\end{array}$ & $\begin{array}{l}\text { Al-bearing species, from } \\
\text { Shock et al. (1997) }\end{array}$ & $\begin{array}{l}\text { Al-bearing species, from } \\
\text { Shock et al. (1997) }\end{array}$ & $\begin{array}{l}\text { Al-bearing species from } \\
\text { Tagirov and Schott }(2001) \text {; } \\
\mathrm{KCl}^{\circ} \text { from Ho et al. (2000) }\end{array}$ \\
\hline & All other species from & All other species from & All other species from & All other species from \\
\hline & $\begin{array}{l}\text { Sverjensky et al. (1997) and } \\
\text { those internally consistent to } \\
\text { Sverjensky et al. (1997) in } \\
\text { earlier Helgeson and co- } \\
\text { workers' publications }\end{array}$ & $\begin{array}{l}\text { Sverjensky et al. (1997) and } \\
\text { those internally consistent to } \\
\text { Sverjensky et al. (1997) in } \\
\text { earlier Helgeson and co- } \\
\text { workers' publications }\end{array}$ & $\begin{array}{l}\text { Sverjensky et al. (1997) and } \\
\text { those internally consistent to } \\
\text { Sverjensky et al. (1997) in } \\
\text { earlier Helgeson and co- } \\
\text { workers' publications }\end{array}$ & $\begin{array}{l}\text { Sverjensky et al. (1997) and } \\
\text { those internally consistent to } \\
\text { Sverjensky et al. (1997) in } \\
\text { earlier Helgeson and co- } \\
\text { workers' publications }\end{array}$ \\
\hline Minerals & $\begin{array}{l}\text { Al oxyhydroxides from } \\
\text { Pokrovskii and Helgeson } \\
\text { (1995); all others from } \\
\text { Helgeson et al. (1978) }\end{array}$ & Helgeson et al. (1978) & Holland and Powell (1998) & $\begin{array}{l}\text { Holland and Powell (1998); } \\
\text { Boehmite from Hemingway } \\
\text { et al. (1991) }\end{array}$ \\
\hline
\end{tabular}

\footnotetext{
${ }^{\mathrm{a}}$ Equilibrium constants for other datasets, corresponding to those listed in Table 1a for the baseline case, are listed in the Electronic Annex.
} 
Table 2

Summary of feldspar dissolution experiments used in this study.

\begin{tabular}{|c|c|c|c|c|c|c|c|}
\hline Mineral Reactant & $\begin{array}{l}\mathrm{SA}^{(1)} \\
\left(\mathrm{m}^{2} / \mathrm{g}\right)\end{array}$ & $\begin{array}{l}\text { Initial } \mathrm{pH} \\
\text { at } 25^{\circ} \mathrm{C}\end{array}$ & $\begin{array}{l}\text { Solution } \\
\text { chemistry }\end{array}$ & $\begin{array}{l}T^{\circ} \mathrm{C} \\
\mathrm{P} \text { bar }^{(2)}\end{array}$ & $\begin{array}{l}\text { Reaction } \\
\text { time }(\mathrm{h})\end{array}$ & $\begin{array}{l}\text { Secondary } \\
\text { minerals }\end{array}$ & Sources \\
\hline $\begin{array}{l}\text { Alkali-feldspar ( } 35 \% \\
\text { low albite; } 60 \% \\
\text { orthoclase; } 5 \% \text { quartz) }\end{array}$ & 0.132 & 3.0 & $0.20 \mathrm{~m} \mathrm{KCl}$ & 200,300 & 1872 & Boehmite + Kaolinite & Fu et al. (2009) \\
\hline $\begin{array}{l}\text { Alkali-feldspar ( } 35 \% \\
\text { low albite; } 60 \% \\
\text { orthoclase; } 5 \% \text { quartz) }\end{array}$ & 0.132 & 4.0 & $\begin{array}{l}0.20 \mathrm{~m} \mathrm{KCl}^{+} \\
0.05 \mathrm{~m} \mathrm{CO}_{2}\end{array}$ & 200,300 & 648 & Boehmite + Kaolinite & Appendix B \\
\hline \multirow[t]{3}{*}{ Anorthite } & $0.00333\left(\mathrm{~m}^{2} / \mathrm{L}\right)$ & 4.56 & $\begin{array}{l}0.03 \mathrm{~m} \mathrm{NaAc}+ \\
\mathrm{HAc}\end{array}$ & 90 & 8520 & $\mathrm{Bhm}+\mathrm{Mod} . \mathrm{Bhm}^{(3)}$ & $\begin{array}{l}\text { Murakami et al. } \\
\text { (1998) }\end{array}$ \\
\hline & & 4.56 & & 150 & 2160 & $\mathrm{Bhm}+$ Mod. Bhm ${ }^{(3)}$ & \\
\hline & & 4.56 & & 210 & 3960 & $\begin{array}{l}\text { Bhm + Mod. } \mathrm{Bhm}^{(3)} \\
+ \text { Kaolinite }\end{array}$ & \\
\hline Low albite & 0.12 & $8.8-8.9$ & $0.1 \mathrm{~m} \mathrm{KHCO}_{3}$ & 300,88 & 1848 & Sanidine & Alekseyev et al. \\
\hline Sanidine & 0.14 & $8.8-8.9$ & $0.1 \mathrm{~m} \mathrm{NaHCO}_{3}$ & & & Analcime & (1997) \\
\hline
\end{tabular}

(1) SA stand for specific BET surface area except for anorthite, which is geometric SA measured by microscopic observations; (2) $T^{\circ} \mathrm{C}, P$ bar refer temperature and pressure; (3) Bhm and Mod. Bhm refer to boehmite and modified boehmite, respectively, as reported in Murakami et al. (1998).

$a-a$ diagrams (Fig. 2). The parentheses on $\mathrm{Al}_{2} \mathrm{O}_{3}$ indicate that $\mathrm{Al}_{2} \mathrm{O}_{3}$ is used as the balancing component in writing reversible reactions for this system. Although three-dimensional (3D) phase diagrams with axes of $\log a \mathrm{SiO}_{2(\mathrm{aq})}-$ $\log \left(a \mathrm{~K}^{+} / a \mathrm{H}^{+}\right)-\log \left(a \mathrm{Na}^{+} / a \mathrm{H}^{+}\right)$represent the reaction paths more realistically, the $3 \mathrm{D}$ diagrams in publications are difficult to view without the ability to rotate the axes. Therefore, although we constructed the 3D $a-a$ diagrams and used them for data analysis, we present the $a-a$ diagrams in two-dimensions (2D), which can be viewed as the 2D projection of the three-dimensional diagrams on the plane that intersects zero on the third axis. Because this experiment is a $\mathrm{K}^{+}$-dominated system with respect to $\mathrm{Na}^{+}$, we present the $2 \mathrm{D} \log a \mathrm{SiO}_{2(\mathrm{aq})}-\log \left(a \mathrm{~K}^{+} / a \mathrm{H}^{+}\right) a-a$ diagrams, which approximately portray the phase relations pertaining to the experimental system. Microcline was used in place of orthoclase because thermodynamic properties for orthoclase are not available in the database of Holland and Powell (1998) or any other databases known to us. To illustrate the temporal evolution of the system, we added time as the vertical axis in Fig. 2b.

The solution chemistry fell within the boehmite stability field after $24 \mathrm{~h}$. The $120 \mathrm{~h}$ sample showed that the aqueous fluid crossed the boehmite-kaolinite boundary and entered into the kaolinite stability field. Fluid chemistry fell in the muscovite stability field from 216 to $1872 \mathrm{~h}$, but muscovite was not detected in the products (Fu et al., 2009). Dissolution of the microcline should have stopped at $456 \mathrm{~h}$ because the microcline was supersaturated at this point (see below), but the fluid chemistry did not reach the microcline stability field even at the end of the experiment. It should be noted that the conventional "stability fields" represent equilibrium phase relationships, but the saturation indices were determined by speciation-solubility calculations with a numerical code.

Although albite continued to dissolve in the experiment (Fu et al., 2009), the $2 \mathrm{D} \log a \mathrm{SiO}_{2(\mathrm{aq})}-\log \left(a \mathrm{Na}^{+} / a \mathrm{H}^{+}\right)$diagram is omitted here because it gives misleading projection that samples 3-7 fell within the kaolinite stability. In the 3D $a-a$ diagram (not shown), it is clear that these samples fell within the muscovite stability field in this $\mathrm{K}^{+}$-dominated system.

SI values of the minerals of interest were calculated at each sampling time (Table 3). All sampled solutions were undersaturated with respect to albite (i.e., the major reactant), but the experimental solution changed from undersaturation with respect to microcline from 24 to $216 \mathrm{~h}$ to supersaturation at $456 \mathrm{~h}$. The solutions reached supersaturation with respect to boehmite, kaolinite, and muscovite at the earliest sampling time of $24 \mathrm{~h}$, and these phases continued to be supersaturated during the entire experiment (Fig. 3 and Table 3). Boehmite SI decreased slightly from 24 to $216 \mathrm{~h}$ coinciding with the fluid chemistry entries into the kaolinite field, increased to a maximum of 2.4 at $456 \mathrm{~h}$, and then decreased toward the end of the experiment. Kaolinite SI showed a maximum at $456 \mathrm{~h}$, and then decreased toward the end of the experiment.

The supersaturation of kaolinite and muscovite while the fluid chemistry is located in the boehmite stability field, and the supersaturation of boehmite while the fluid chemistry is located in the kaolinite and muscovite fields, indicate a departure from partial equilibria between the aqueous solution and the secondary phases. Lasaga (1998) found muscovite supersaturation while the fluid is in the kaolinite field in the reaction path simulations that incorporated kinetics of secondary mineral dissolution and precipitation.

The solution was undersaturated with respect to paragonite from $24 \mathrm{~h}$ to $216 \mathrm{~h}$, but supersaturated from $456 \mathrm{~h}$ to $1872 \mathrm{~h}$ (Table 3) while the solution was located in the muscovite stability field. The sampled solutions were undersaturated with respect to quartz up to $816 \mathrm{~h}$, but close to equilibrium with quartz after $1368 \mathrm{~h}$ (Table 3).

The conclusion of supersaturation of product minerals for the baseline case (with solid symbols and connecting 

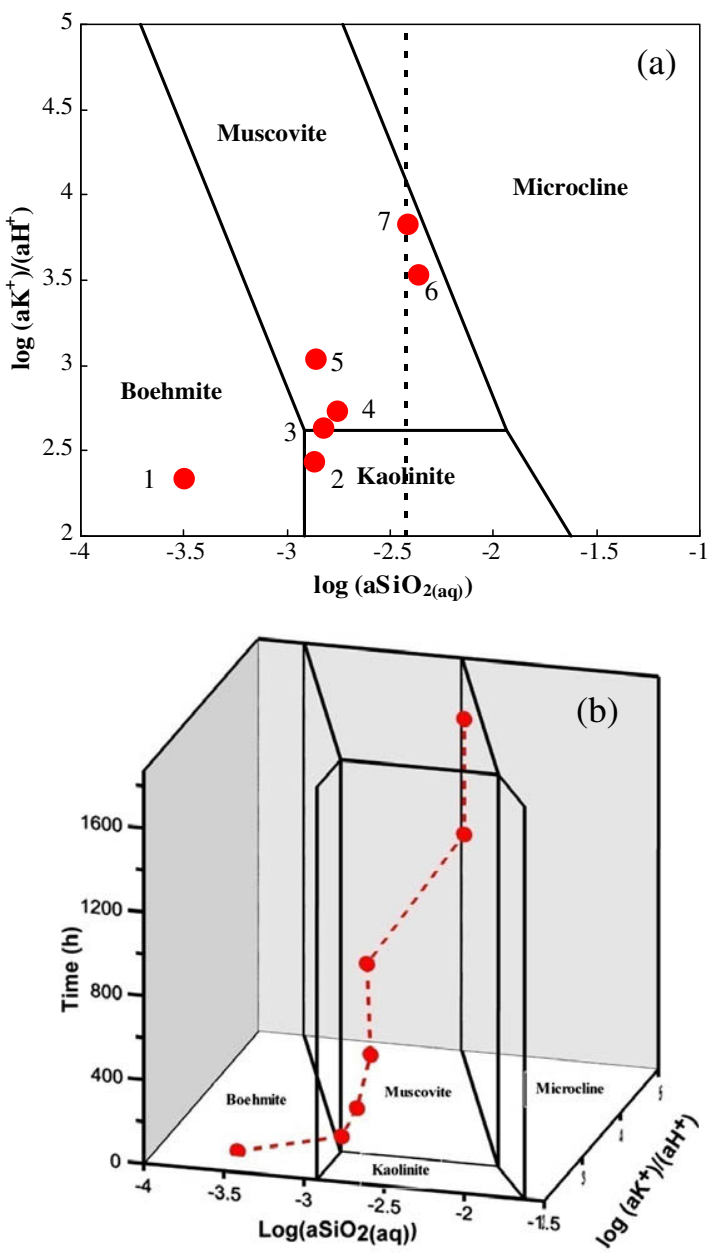

Fig. 2. Activity-activity diagrams showing the phase relations in the system $\mathrm{K}_{2} \mathrm{O}-\left(\mathrm{Al}_{2} \mathrm{O}_{3}\right)-\mathrm{SiO}_{2}-\mathrm{H}_{2} \mathrm{O}-\mathrm{HCl}$ at $200{ }^{\circ} \mathrm{C}$ and 300 bars. The dashed line in (a) denotes quartz saturation. Symbols represent experimental results of alkali feldspar dissolution in $0.2 \mathrm{~m} \mathrm{KCl}$ solution at $200{ }^{\circ} \mathrm{C}$ and 300 bars (Fu et al., 2009, see Section 3.1). The activity and activity ratios were obtained from speciation modeling of the experimental system $\mathrm{Na}_{2} \mathrm{O}-\mathrm{K}_{2} \mathrm{O}-\mathrm{Al}_{2} \mathrm{O}_{3}-\mathrm{SiO}_{2}-$ $\mathrm{H}_{2} \mathrm{O}-\mathrm{HCl}$, based on the experimental solution chemistry data of $\mathrm{Fu}$ et al. (2009) and equilibrium constants listed in Table 1a. Points 1-7 represent experiment solutions at reaction time of 24, 120, 216, $456,816,1368$, and $1872 \mathrm{~h}$, respectively. The red dashed line in (b) connecting experimental data is for visualization of fluid chemical evolution. lines in Fig. 3) seems to sustain when different sets of thermodynamic properties are used (Fig. 3, open symbols and labeled as "A", "B", "C", see Table 1b). In other words, the uncertainties of the thermodynamic properties for mineral end-members and aqueous species are not large enough to result in indications of opposite reaction directions for the experiments examined. To evaluate the baseline case further, the propagated errors in SI values were calculated for $95 \%$ confidence interval from the reported standard deviation of enthalpy of formation at $25^{\circ} \mathrm{C}$ alone (Hemingway et al., 1991; Holland and Powell, 1998).

The reaction path from sample at $816 \mathrm{~h}$ to samples at $1368 \mathrm{~h}$ and $1872 \mathrm{~h}$ requires the total consumption of boehmite in the partial equilibrium case. However, as noted earlier, the prolonged experiment did not show the disappearance of boehmite even though the solution chemistry had drastically departed from the boehmite field (Fig. 2b). In other words, the experimental data did not show sequential mineral dissolution and precipitation or paragenesis from boehmite to kaolinite to muscovite, as predicted by theoretical calculations assuming partial equilibrium between the product minerals and the aqueous solution with evolving chemistry. It should also be noted that the solution reached boehmite supersaturation very quickly after the experiment commenced (the earliest sampling time was $24 \mathrm{~h}$ after the experiment started).

\subsection{Alkali feldspar dissolution and clay precipitation in $\mathrm{CO}_{2}$ Charged systems}

\subsubsection{Experimental design and results}

These two batch experiments for alkali feldspar dissolution were similar in design to those presented in the preceding section. However, the experiments differed by adding $50 \mathrm{mM} \mathrm{CO}$ into the experimental charge. One experiment was terminated at the end of $120 \mathrm{~h}$, and a second experiment was terminated after $648 \mathrm{~h}$. SEM images of the reaction products showed extensive dissolution features and secondary mineral coverage on feldspar grain surfaces. TEM study detected boehmite in samples after $120 \mathrm{~h}$ reaction, and XRD patterns indicated boehmite and possibly muscovite in the $648 \mathrm{~h}$ sample. The fluid chemistry data are presented in Appendix B.

Table 3

Mineral saturation indices at each sampling time in experiments for the alkali feldspar dissolution in $0.2 \mathrm{~m} \mathrm{KCl}$ solution at $200{ }^{\circ} \mathrm{C}$ and 300 bars. $^{\text {a }}$

\begin{tabular}{lllllllllll}
\hline Time $(\mathrm{h})$ & In situ pH & Albite & Boehmite & Diaspore & Kaolinite & Microcline & Muscovite & Paragonite & Pyrophyllite & Quartz \\
\hline 24 & 3.3 & -6.80 & 1.23 & 1.45 & 1.30 & -2.75 & 1.67 & -2.62 & -1.30 & -1.07 \\
$(120)$ & 3.4 & -4.80 & 0.93 & 1.15 & 1.96 & -1.08 & 2.75 & -1.22 & 0.61 & -0.44 \\
216 & 3.6 & -4.37 & 0.90 & 1.13 & 2.01 & -0.75 & 3.02 & -0.83 & 0.75 & -0.39 \\
456 & 3.7 & -2.33 & 2.40 & 2.62 & 5.13 & 1.02 & 7.79 & 4.20 & 3.99 & -0.33 \\
816 & 4.0 & -2.66 & 2.11 & 2.33 & 4.34 & 0.75 & 6.93 & 3.28 & 3.02 & -0.43 \\
1368 & 4.5 & -1.02 & 1.47 & 1.69 & 4.05 & 2.07 & 6.98 & 3.65 & 3.71 & 0.06 \\
$(1872)$ & 4.8 & -2.36 & 0.26 & 0.48 & 1.53 & 1.02 & 3.50 & -0.12 & 1.09 & 0.01 \\
\hline
\end{tabular}

${ }^{\text {a }}$ Solution chemistry data are from Fu et al. (2009). The parentheses on time in the first column on left denote to the time that the experiment was terminated and solids were recovered for characterization. In situ $\mathrm{pH}$ was calculated from the speciation modeling. Italic values highlight supersaturation. 

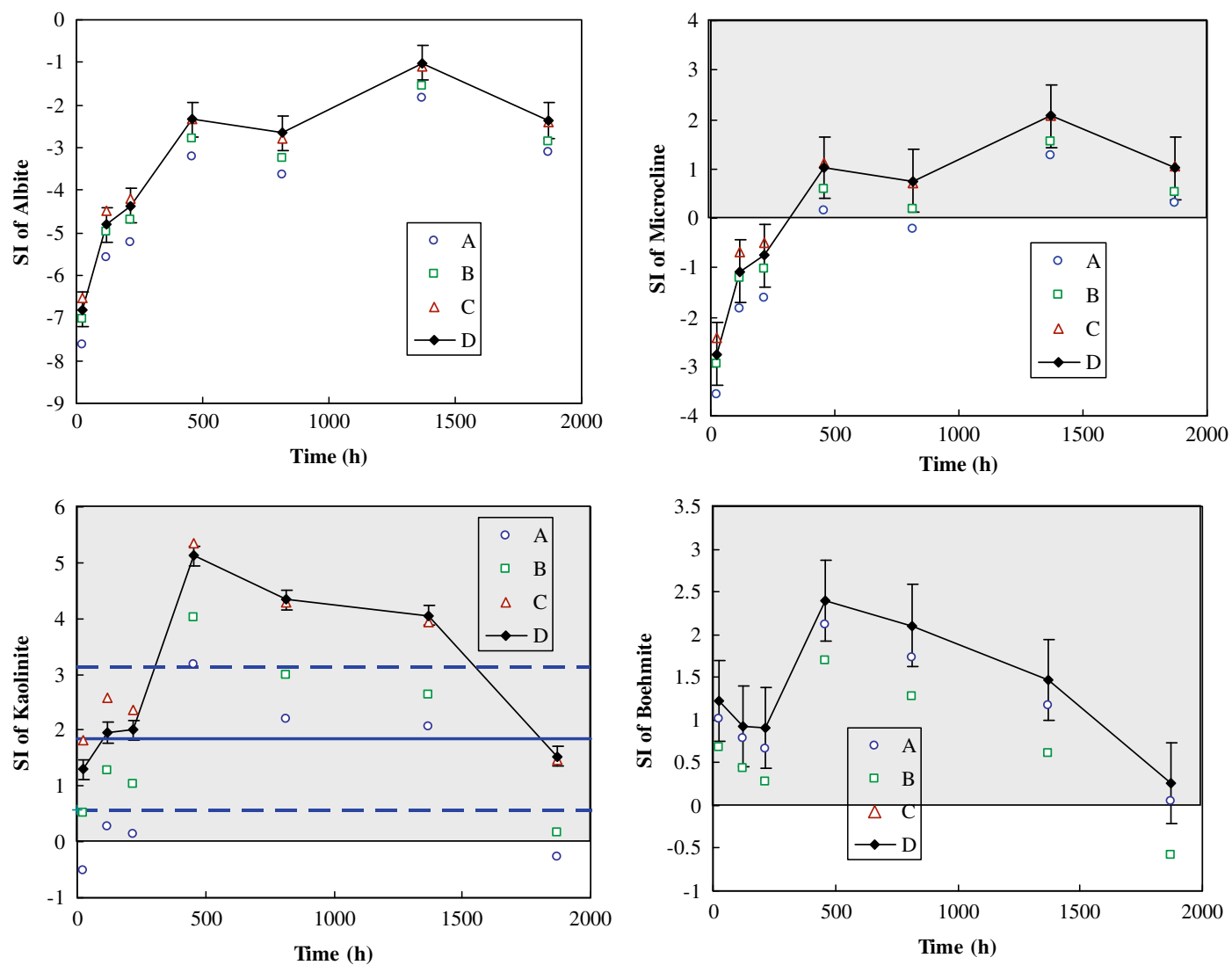

Fig. 3. Mineral saturation indices during the course of alkali feldspar dissolution in $0.2 \mathrm{~m} \mathrm{KCl}$ solution at $200{ }^{\circ} \mathrm{C}$ and 300 bars ( $\mathrm{Fu}$ et al., 2009, see Section 3.1). "BL" (baseline case, Table 1a), and "A", "B", and "C" stand for calculated SI using thermodynamic datasets as described in Table $1 \mathrm{~b}$. Vertical errors bars represent the uncertainty from the $\Delta H_{\mathrm{f}}^{\circ}$ at $25^{\circ} \mathrm{C}$ alone. The gray shaded areas highlight mineral supersaturation. For the kaolinite graph, the solid line stands for zero SI of halloysite and dashed lines variations of SI values resulting from the $2 \sigma$ of $\Delta G_{\mathrm{f}}^{\circ}$ of halloysite.

\subsubsection{Reaction paths and mineral saturation indices}

The reaction paths from these two batch experiments (Fig. 4) are different from those in the counterpart experiments without $\mathrm{CO}_{2}$ (cf. Fig. 2) because they started with a higher initial $\mathrm{pH}$ so that the kaolinite field was skipped. SI values of the minerals of interest are listed in Table 4. All sampled solutions were undersaturated with respect to albite, but the experimental solution changed from undersaturation with respect to microcline to supersaturation after $24 \mathrm{~h}$. As in the experiments without $\mathrm{CO}_{2}$, the solutions attained supersaturation with respect to boehmite, pyrophyllite, kaolinite, and muscovite at the earliest sampling time of $24 \mathrm{~h}$, and these phases were supersaturated during the entire experiment (Fig. 5 and Table 4). The supersaturation of muscovite while the fluid chemistry has located in the boehmite stability field, and the supersaturation of boehmite while the fluid chemistry was located in the muscovite stability field are, again, indicative of a departure from partial equilibria between the aqueous solution and secondary phases (Lasaga, 1998).

Similar to what Steinmann et al. (1994) illustrated in classroom exercises at room temperature, the fluid chemistry would be fixed at a point on the boehmite-muscovite boundary for the partial equilibrium case because the reaction

$$
\begin{aligned}
& \mathrm{AlOOH} \text { (Boehmite) }+\mathrm{KAlSi}_{3} \mathrm{O}_{8} \text { (K-feldspar) } \\
& \quad \rightarrow \mathrm{KAl}_{3} \mathrm{Si}_{3} \mathrm{O}_{10}(\mathrm{OH})_{2} \text { (Muscovite) }
\end{aligned}
$$

does not change aqueous compositions of the system. However, the experimental data show that the aqueous fluid departed from the boehmite-muscovite boundary while boehmite was still observed at the end of the experiment. Apparently, partial equilibria were not observed.

\subsection{Anorthite dissolution batch experiments}

\subsubsection{Experimental design and results}

Murakami et al. (1998) performed three series of batch experiments for anorthite $\left(\mathrm{An}_{95} \mathrm{Ab}_{5}\right)$ dissolution in $0.03 \mathrm{M}$ sodium acetate at 90,150 , and $210^{\circ} \mathrm{C}$ with a room temperature initial $\mathrm{pH}$ of 4.56 . Single crystals of anorthite were prepared by crushing and pieces with fresh surfaces approximately $1 \times 1 \times 1 \mathrm{~mm}$ in size were selected. The geometric surface areas of the single crystals were estimated under a light microscope (Table 2). The crystals were washed ultrasonically in acetone in an attempt to remove fine particles 

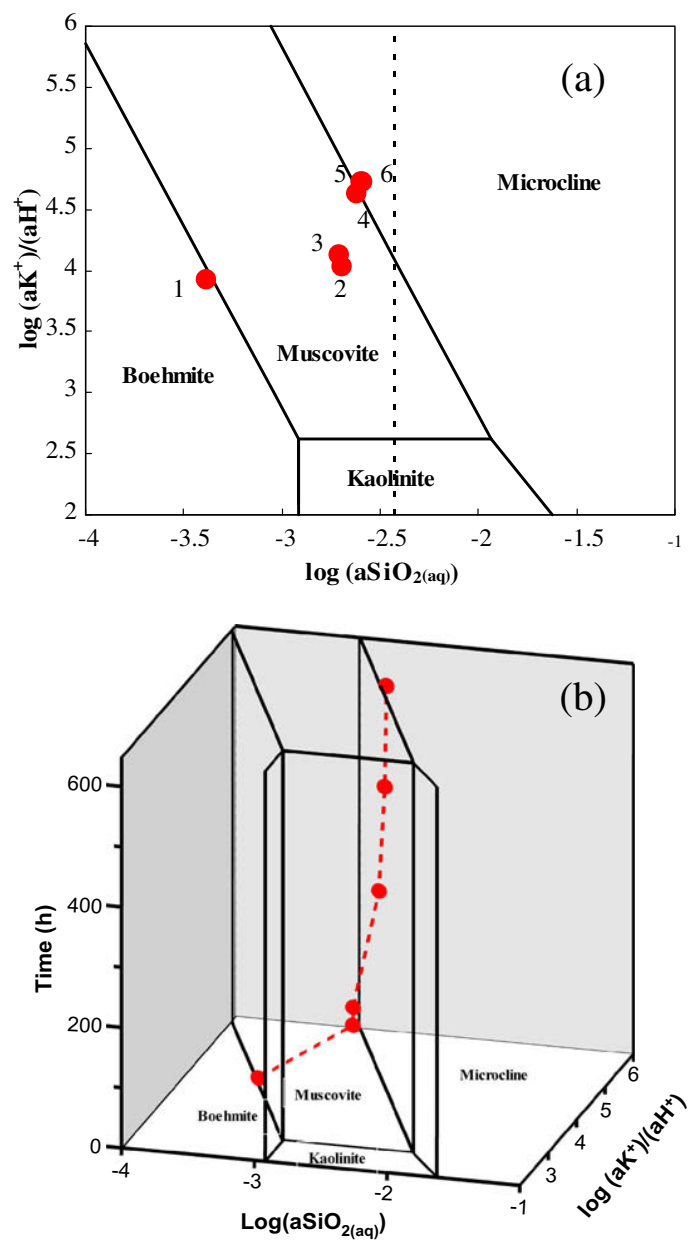

Fig. 4. Activity-activity diagrams showing the phase relations in the system $\mathrm{K}_{2} \mathrm{O}-\left(\mathrm{Al}_{2} \mathrm{O}_{3}\right)-\mathrm{SiO}_{2}-\mathrm{H}_{2} \mathrm{O}-\mathrm{HCl}$ at $200{ }^{\circ} \mathrm{C}$ and 300 bars. The dashed line in (a) denotes quartz saturation. Solid dots represent experimental results of alkali feldspar dissolution in $0.2 \mathrm{~m}$ $\mathrm{KCl}$ and $0.05 \mathrm{~m} \mathrm{CO}_{2}$ solution at $200{ }^{\circ} \mathrm{C}$ and 300 bars (cf. Section 3.2 and Appendix B). The activity and activity ratios were obtained from speciation modeling of the experimental system $\mathrm{Na}_{2} \mathrm{O}-\mathrm{K}_{2} \mathrm{O}-$ $\mathrm{Al}_{2} \mathrm{O}_{3}-\mathrm{SiO}_{2}-\mathrm{H}_{2} \mathrm{O}-\mathrm{HCl}-\mathrm{CO}_{2}$, based on the experimental solution chemistry data in Appendix B and equilibrium constants listed in Table 1a. The red dashed line in (b) connecting experimental data is for visualization of fluid chemical evolution. (For interpretation of color mentioned in this figure legend the reader is referred to the Web version of the article.) from the surface. Experimental runs were from $72 \mathrm{~h}$ to $8520 \mathrm{~h}$. After the run, the reaction vessel was cooled to room temperature within $30 \mathrm{~min}$, and the aqueous solution was filtered with $0.22 \mu \mathrm{m}$ filters. Secondary minerals formed during the experiments were identified with XRD, SEM, and HRTEM. A sequence of secondary minerals, including boehmite, "modified boehmite" with silica, and kaolinite, was formed with increasing reaction time. Table 5 summarizes their reported experimental times when the different product minerals were observed.

\subsubsection{Reaction path and mineral saturation indices}

The time evolution of Murakami et al.'s (1998) aqueous solution chemistry in the system $\mathrm{CaO}-\mathrm{Na}_{2} \mathrm{O}-\left(\mathrm{Al}_{2} \mathrm{O}_{3}\right)$ $\mathrm{SiO}_{2}-\mathrm{H}_{2} \mathrm{O}-\mathrm{HCl}-$ acetate was traced on the $a-a$ diagrams (Fig. 6). In all experiments, the solution chemistry quickly evolved from the boehmite stability field to the kaolinite stability field after 240, 72, and $72 \mathrm{~h}$, at 90, 150 and $210^{\circ} \mathrm{C}$, respectively. The solution chemistry stayed within the kaolinite field with little change for thousands more hours. This results in an almost vertical trend on the 3D $a-a-t$ diagrams (Fig. 6b). Murakami et al. (1998) found that boehmite and "modified boehmite" are the main product minerals from anorthite dissolution at 90, 150, and $210^{\circ} \mathrm{C}$. Kaolinite was found after $2328 \mathrm{~h}$ of experiment at $210^{\circ} \mathrm{C}$, long after the solution chemistry had entered into the kaolinite stability field.

The solutions were supersaturated with respect to boehmite and kaolinite during the entire experiments at 90, 150, and $210^{\circ} \mathrm{C}$ (Fig. 7 and Table 5). Kaolinite supersaturation occurred when the fluid chemistry was still located in the boehmite field. The solutions were undersaturated with respect to anorthite during the $90{ }^{\circ} \mathrm{C}$ experiment, but changed from undersaturation to supersaturation at $150{ }^{\circ} \mathrm{C}$ after $240 \mathrm{~h}$, and $210^{\circ} \mathrm{C}$ after $816 \mathrm{~h}$ (Fig. 7 and Table 5). At 90 and $150^{\circ} \mathrm{C}$, anorthite SI did not vary monotonically. There was an increase, and then a decrease with time, probably coincident with precipitation of product mineral(s). Murakami et al. (1998) believed that anorthite dissolution continued during the entire experiment as evidenced by the continued increase of $\mathrm{Ca}^{2+}$ concentrations. Therefore, the calculated SI $(>0)$ of anorthite in the experiments could result from uncertainties of thermodynamic properties for anorthite,

Table 4

Mineral saturation indices at each sampling time in experiments for the alkali feldspar dissolution in $0.2 \mathrm{~m} \mathrm{KCl}$ and $0.05 \mathrm{~m} \mathrm{CO}_{2}$ solution at $200{ }^{\circ} \mathrm{C}$ and 300 bars. $^{\mathrm{a}}$

\begin{tabular}{lllllllllll}
\hline Time $(\mathrm{h})$ & In situ $\mathrm{pH}$ & Albite & Boehmite & Diaspore & Kaolinite & Microcline & Muscovite & Paragonite & Pyrophyllite & Quartz \\
\hline 24 & 4.9 & -5.13 & 1.18 & 1.40 & 1.43 & -0.88 & 3.44 & -1.04 & -0.96 & -0.96 \\
$(120)$ & 5.0 & -2.41 & 0.87 & 1.09 & 2.18 & 0.99 & 4.69 & 1.06 & 1.19 & -0.27 \\
144 & 5.1 & -2.85 & 1.00 & 1.22 & 2.42 & 1.16 & 5.13 & 0.88 & 1.38 & -0.29 \\
312 & 5.6 & -1.94 & 0.83 & 1.05 & 2.25 & 1.75 & 5.37 & 1.44 & 1.39 & -0.20 \\
480 & 5.7 & -1.22 & 1.21 & 1.43 & 3.05 & 2.30 & 6.68 & 2.93 & 2.23 & -0.18 \\
$(648)$ & 5.7 & -1.17 & 1.38 & 1.61 & 3.43 & 2.51 & 7.25 & 3.33 & 2.63 & -0.16 \\
\hline
\end{tabular}

${ }^{a}$ See solution analytical data in Appendix B. The parentheses on time in the first column on left denote to the time that the experiment was terminated and solids were recovered for characterization. In situ $\mathrm{pH}$ was calculated from the speciation modeling. Italic values highlight supersaturation. 

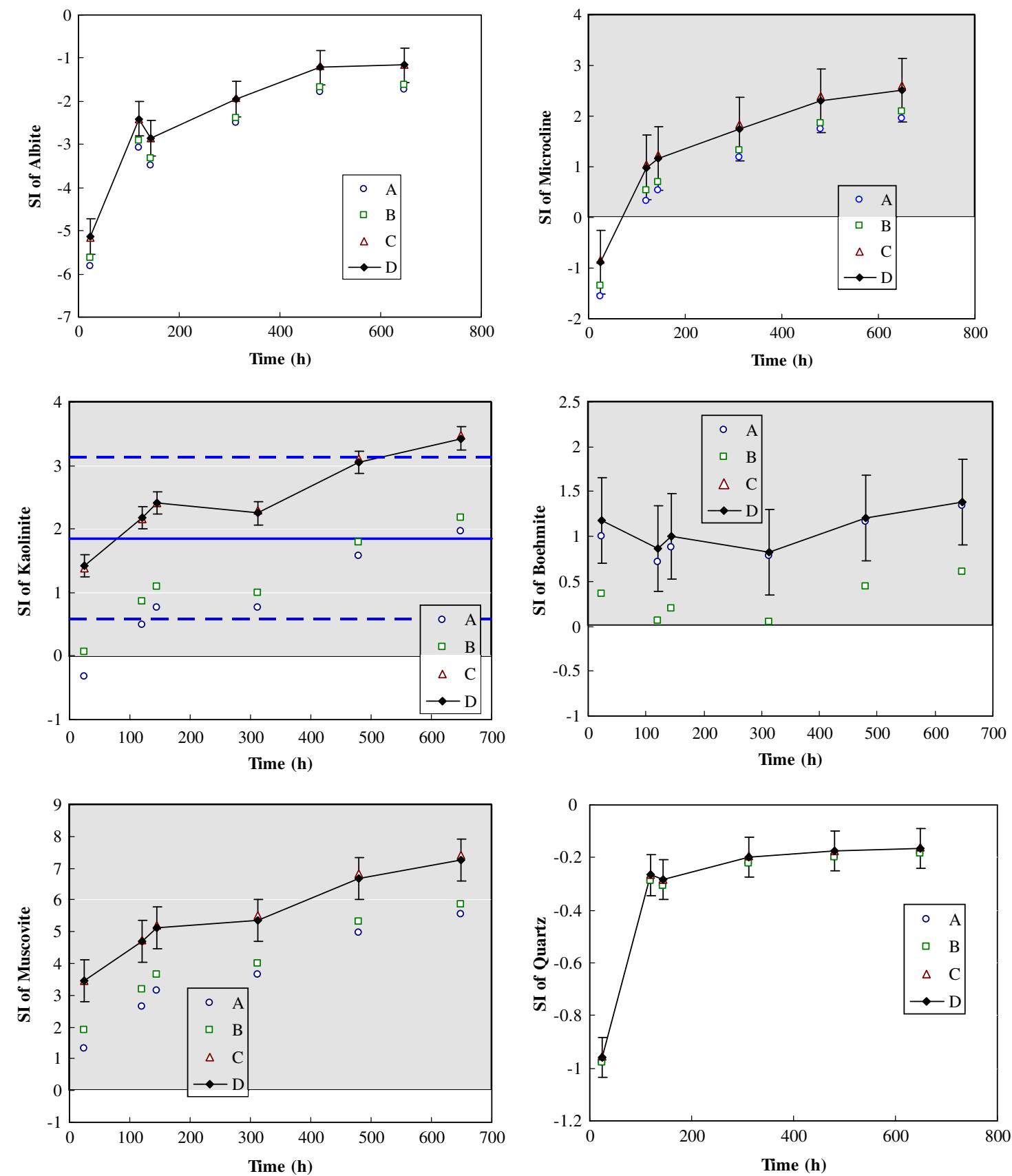

Fig. 5. Mineral saturation indices during the course of alkali feldspar dissolution in $0.2 \mathrm{~m} \mathrm{KCl}$ and $0.05 \mathrm{~m} \mathrm{CO}_{2}$ solution at $200{ }^{\circ} \mathrm{C}$ and 300 bars (cf. Section 3.2 and Appendix B). See the caption for Fig. 3 for notations.

which show an unusually large range in the literature (Arnórsson and Stefánsson, 1999). The experimental solutions were also supersaturated with respect to paragonite. The experimental solutions were close to quartz saturation at the end of the experiments.

\subsection{Sanidine and albite dissolution experiments}

Alekseyev et al. (1997) conducted two series of batch experiments. The first one was for sanidine $\left(\mathrm{KNa}_{0.03} \mathrm{Al}_{0.99}\right.$
$\left.\mathrm{Si}_{3} \mathrm{O}_{8}\right)$ dissolution in $0.1 \mathrm{~m} \mathrm{NaHCO}$ solution and the second series for low albite $\left(\mathrm{Na}_{0.97} \mathrm{~K}_{0.02} \mathrm{AlSi}_{3.01} \mathrm{O}_{8}\right)$ dis-solution in $0.1 \mathrm{~m} \mathrm{KHCO}_{3}$ solution, both at $300^{\circ} \mathrm{C}$ and 88 bars and with duration as long as $1848 \mathrm{~h}$ (Alekseyev et al., 1997). The $\mathrm{pH}$ was buffered by the dissolved carbonate and bicarbonate to near 9. XRD and SEM results indicate that the secondary minerals formed for sanidine and albite dissolution were analcime $\left(\mathrm{NaAlSi}_{2} \mathrm{O}_{6} \cdot \mathrm{H}_{2} \mathrm{O}\right)$ (after $\sim 7 \mathrm{~h}$ ) and sanidine (after $\sim 16 \mathrm{~h}$ ), respectively. Alekseyev et al. (1997) carried out speciation-solubility modeling to 


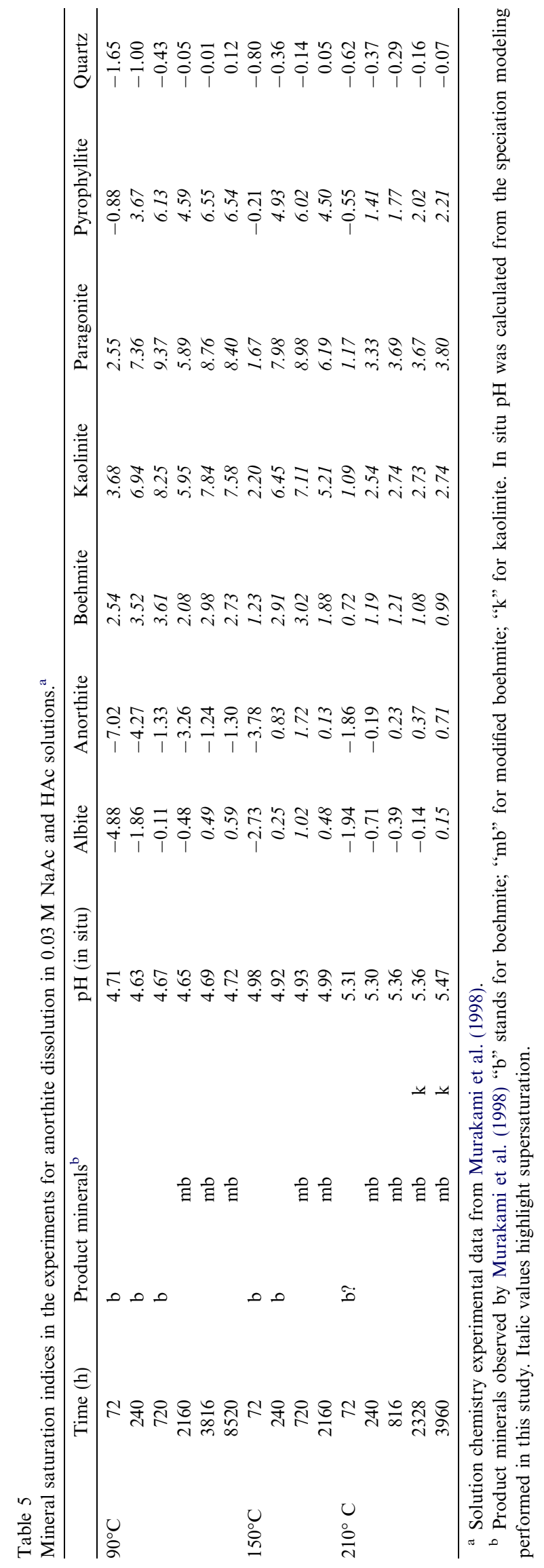

evaluate the saturation states for the primary and secondary minerals in their experimental solutions. They also performed mathematical calculations to show that the partial equilibrium assumption would not be consistent with their temporal solute concentration data. Here, we conducted speciation-solubility modeling using their experimental data, but with four different sets of thermodynamic properties for minerals and aqueous species (see Table 1b), which is different from the thermodynamic data set that they used. We also traced the solution chemistry evolution on phase $a-a$ diagrams.

\subsubsection{Sanidine dissolution in $\mathrm{NaHCO}_{3}$ solution}

The evolution of the aqueous solution chemistry during Alekseyev et al.'s (1997) experiments is depicted in the $a-a$ diagrams for the $\mathrm{Na}_{2} \mathrm{O}-\mathrm{K}_{2} \mathrm{O}-\left(\mathrm{Al}_{2} \mathrm{O}_{3}\right)-\mathrm{SiO}_{2}-\mathrm{H}_{2} \mathrm{O}-\mathrm{CO}_{2}$ system, projected for the zero $\log \left(a \mathrm{~K}^{+} / a \mathrm{H}^{+}\right)$for the Nadominated experimental system (Fig. 8). The solution chemistry evolved from the paragonite stability field to the analcime stability field after $0.25 \mathrm{~h}$. The solution stayed in the analcime stability field from 0.25 to $7 \mathrm{~h}$, and entered into the albite stability field and stayed there until the end of the experiment (16-1848 h) (Fig. 8b). Even though the solution chemistry fell in the albite stability field, albite was not detected with either XRD or SEM and was undersaturated (see below). Alekseyev et al. (1997) observed analcime precipitation from 16 to $1848 \mathrm{~h}$. Because both the $\mathrm{pH}$ of the solution was buffered around 9 and $\mathrm{Na}^{+}$was predominant, the $a \mathrm{Na}^{+} / a \mathrm{H}^{+}$ratios stayed nearly constant.

Saturation indices for minerals of interest were calculated for each experiment (Fig. 9 and Table 6). The solutions were undersaturated with respect to sanidine during the entire experiment (Fig. 9 and Table 6). The solutions were supersaturated with respect to analcime and albite during 7 to $72 \mathrm{~h}$ and 16 to $72 \mathrm{~h}$ reaction time, respectively. During the other time intervals, the solutions were undersaturated with respect to analcime and albite. The apparent conflict between calculated $\mathrm{SI}<0$ values and the observation of continued analcime precipitation (Alekseyev et al., 1997) is puzzling, but could be related to uncertainties in the thermodynamic properties for analcime. As a member of the zeolite group, analcime may have a range of chemical compositions and structural details. Our calculated analcime SI values are within $\sim 0.2$ units of those calculated by Alekseyev et al. (1997) who used different thermodynamic properties but also showed negative SI while reporting analcime precipitation. However, it is clear from the experimental data that, although the experiments had progressed into the albite stability field, analcime is the mineral that was detected.

\subsubsection{Albite dissolution in $\mathrm{KHCO}_{3}$ solution}

Activity-activity diagrams projected for the zero log $\left(a \mathrm{Na}^{+} / a \mathrm{H}^{+}\right)$for this $\mathrm{K}$-dominated experimental system in the $\mathrm{K}_{2} \mathrm{O}-\mathrm{Na}_{2} \mathrm{O}-\left(\mathrm{Al}_{2} \mathrm{O}_{3}\right)-\mathrm{SiO}_{2}-\mathrm{H}_{2} \mathrm{O}-\mathrm{CO}_{2}$ system are shown in Fig. 10. The solution chemistry evolved from the muscovite stability field to the sanidine stability field after only $0.5 \mathrm{~h}$. For the next $16 \mathrm{~h}$, fluid chemistry moved horizontally in the sanidine field as the $a \mathrm{~K}^{+} / a \mathrm{H}^{+}$ratios 

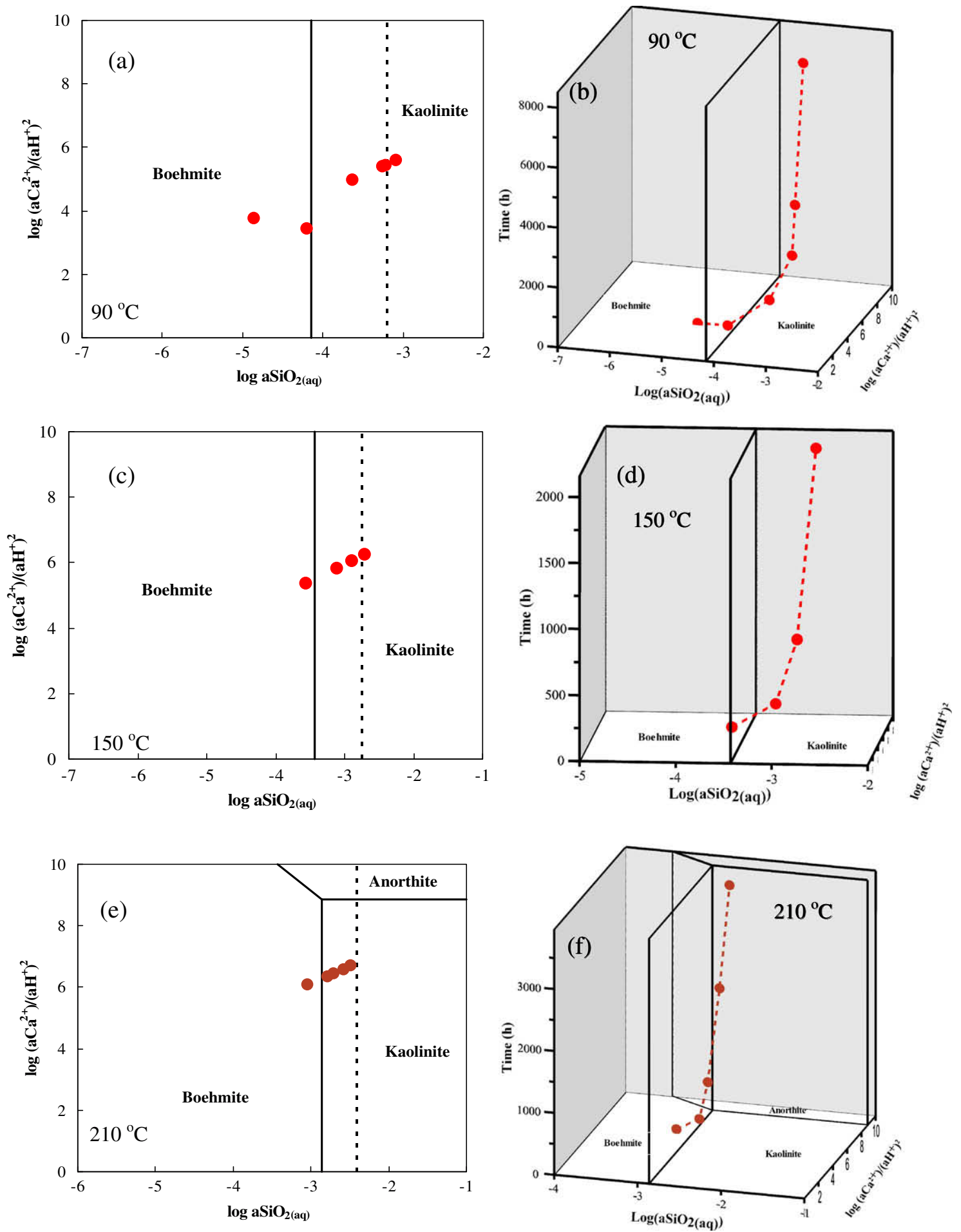

Fig. 6. Activity-activity diagrams showing the phase relations in the system $\mathrm{Ca}_{2} \mathrm{O}-\left(\mathrm{Al}_{2} \mathrm{O}_{3}\right)-\mathrm{SiO}_{2}-\mathrm{H}_{2} \mathrm{O}$ at $90{ }^{\circ} \mathrm{C}(\mathrm{a}$ and $\mathrm{b}), 150{ }^{\circ} \mathrm{C}(\mathrm{c}$ and $\mathrm{d})$, and $210^{\circ} \mathrm{C}$ (e and $\mathrm{f}$ ) and pressures of vapor saturation. The dashed lines in (a, c and e) denote quartz saturation. Solid dots represent experimental results of anorthite dissolution in $0.03 \mathrm{~m} \mathrm{NaAc}$ solutions, which were published in Murakami et al. (1998). The activity and activity ratios were obtained from speciation modeling of the experimental system $\mathrm{Ca}_{2} \mathrm{O}-\mathrm{Al}_{2} \mathrm{O}_{3}-\mathrm{SiO}_{2}-\mathrm{H}_{2} \mathrm{O}-\mathrm{HAc}-\mathrm{NaAc}$, based on the experimental solution chemistry data from Murakami et al. (1998) and equilibrium constants listed in Table 1a. The red dashed lines in (b, d and f) connecting experimental data are for visualization of fluid chemical evolution. (For interpretation of color mentioned in this figure legend the reader is referred to the Web version of the article.)

were buffered and silica activity increased with time. Thereafter, the fluid chemistry changed little from 16 to
$1848 \mathrm{~h}$ within the sanidine field, which is manifested on overlapping data points on the 2D diagram (Fig. 10a) 

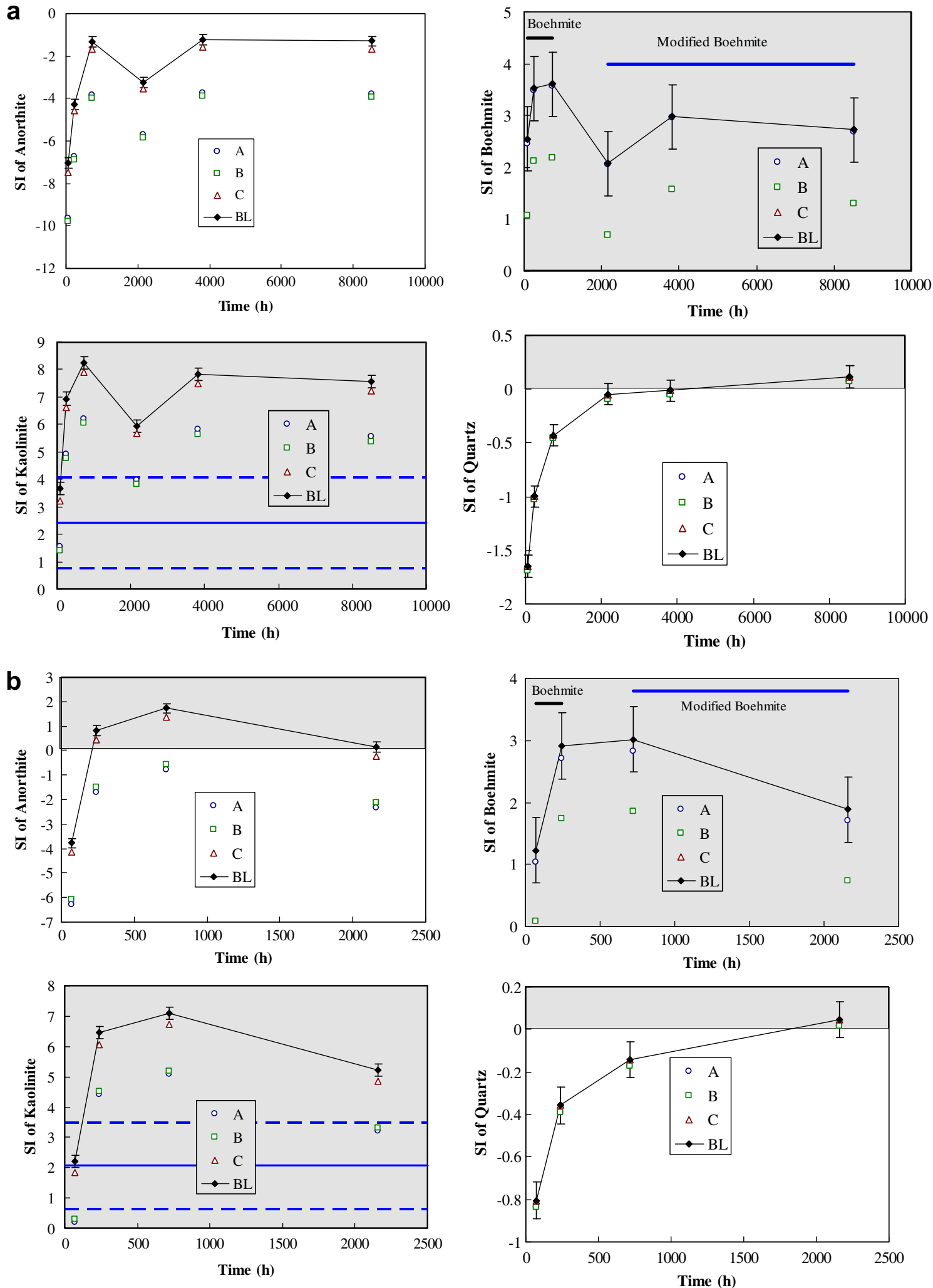

Fig. 7. (a) Calculated saturation indices for anorthite dissolution experiments (Murakami et al., 1998) at $90^{\circ} \mathrm{C}$. See the caption for Fig. 3 for notations. The bars in the boehmite graph indicate the time scale when the respective phases were observed in the mineralogical analysis. (b) Calculated saturation indices for anorthite dissolution experiments (Murakami et al., 1998) at $150{ }^{\circ} \mathrm{C}$. See the caption for Fig. 3 for notations. The bars in the boehmite graph indicate the time scale when the respective phases were observed in the mineralogical analysis. (c) Calculated saturation indices for anorthite dissolution experiments (Murakami et al., 1998) at $210{ }^{\circ} \mathrm{C}$. See the caption for Fig. 3 for notations. The bars in the boehmite and kaolinite graphs indicate the time scale when the respective phases were observed in the mineralogical analysis. 

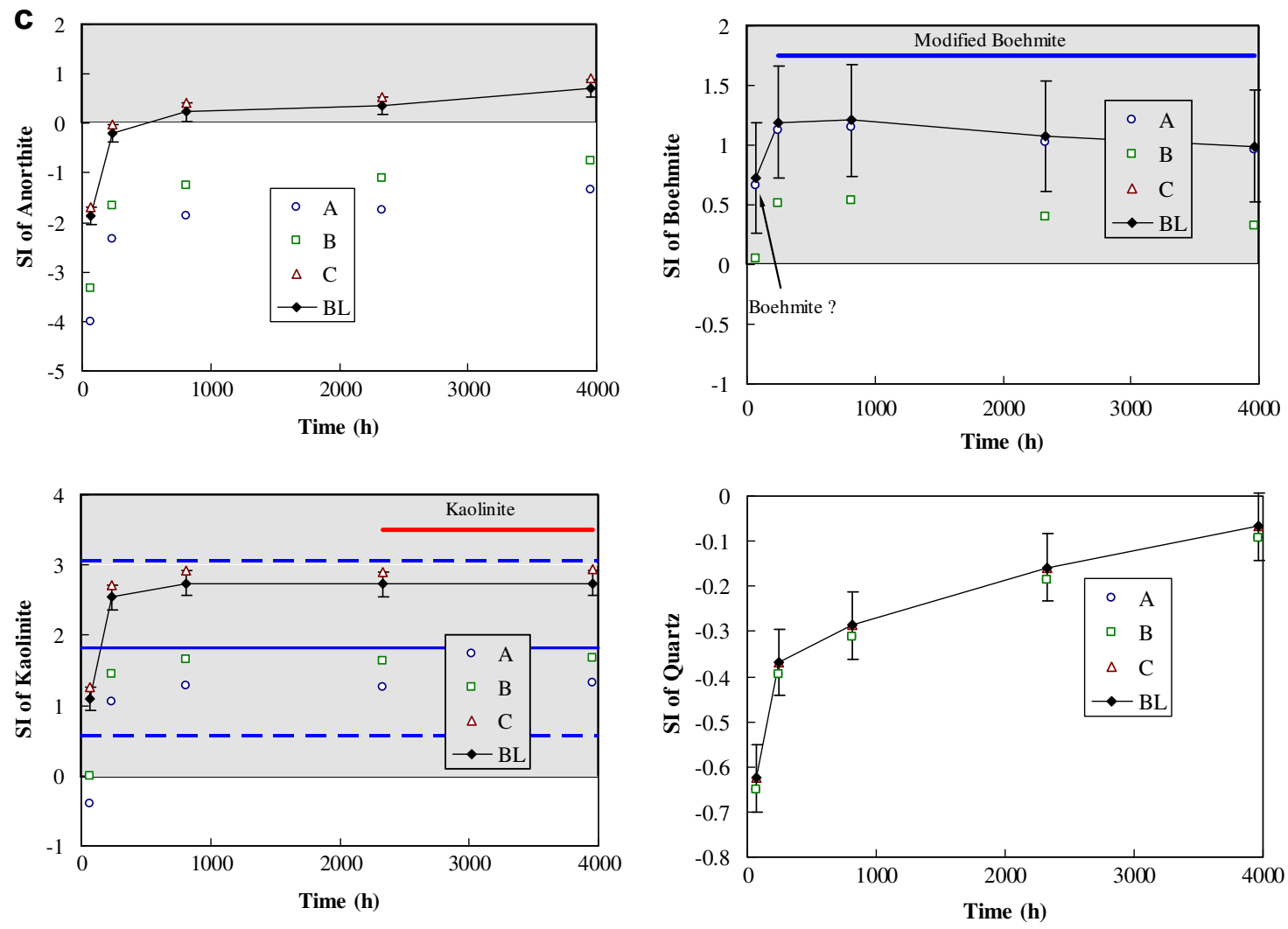

Fig. 7 (continued)

and a straight vertical line on the 3D diagram (Fig. 10b). Alekseyev et al. (1997) observed that sanidine precipitated during this period of time.

The solutions were undersaturated with respect to albite during the entire experiment and supersaturated with respect to sanidine after $1.25 \mathrm{~h}$ (Table 7 and Fig. 11), shortly after the solution chemistry entered into the sanidine field at $0.5 \mathrm{~h}$. Alekseyev et al. (1997) observed no sanidine precipitation during this time period, and their analysis of solution chemistry stoichiometry showed that albite dissolution was congruent. The solution was undersaturated with respect to muscovite during the time $(0-0.5 \mathrm{~h})$ while the fluid composition was located in the muscovite stability field. After that, for the duration of the experiment, muscovite was either supersaturated $(7-48 \mathrm{~h})$ or undersaturated (all other times).

Alekseyev et al. (1997) concluded that slow precipitation of secondary minerals dominated the overall reactions in these two experimental series. The relatively higher temperature $\left(300{ }^{\circ} \mathrm{C}\right)$ in the experiments resulted in fast chemical evolution into the field of more stable phases, but a steady state was reached for the coupled dissolution-precipitation reactions (Figs. $8 \mathrm{~b}$ and $10 \mathrm{~b}$ ), which prevailed during the majority of the experiments. Zhu et al. (2004a,b) used reaction path modeling to show that such a steady state could be reached when the effective precipitation rate constants are lower than the dissolution effective rate constants.

\section{DISCUSSION}

\subsection{Uncertainties of thermodynamic properties on calculated saturation indices}

The calculated saturation states depend on the values of the standard state thermodynamic properties of both the minerals and aqueous species. Various internally consistent databases for thermodynamic properties for mineral species have been compiled (Helgeson et al., 1978; Berman, 1988, 1990; Robie and Hemingway, 1995; Holland and Powell, 1998). However, controversies and discrepancies still exist, particularly for the alumino-silicate minerals that are the primary focus of this study (see Pokrovskii and Helgeson, 1995; Arnórsson and Stefánsson, 1999). We chose to use the thermodynamic properties for mineral species from Holland and Powell (1998) as the base case because this database is internally consistent and it has incorporated recent experimental data as compared to other databases. Thermodynamic properties for boehmite are not available from the Holland and Powell (1998) database, and are discussed in Appendix A.

It is known that thermodynamic properties of minerals derived from calorimetric and phase equilibrium experiments rarely can predict experimental solubility results accurately (Sverjensky et al., 1991). The Holland and Powell thermodynamic properties for feldspars, kaolinite, and muscovite were derived from calorimetric and phase equi- 

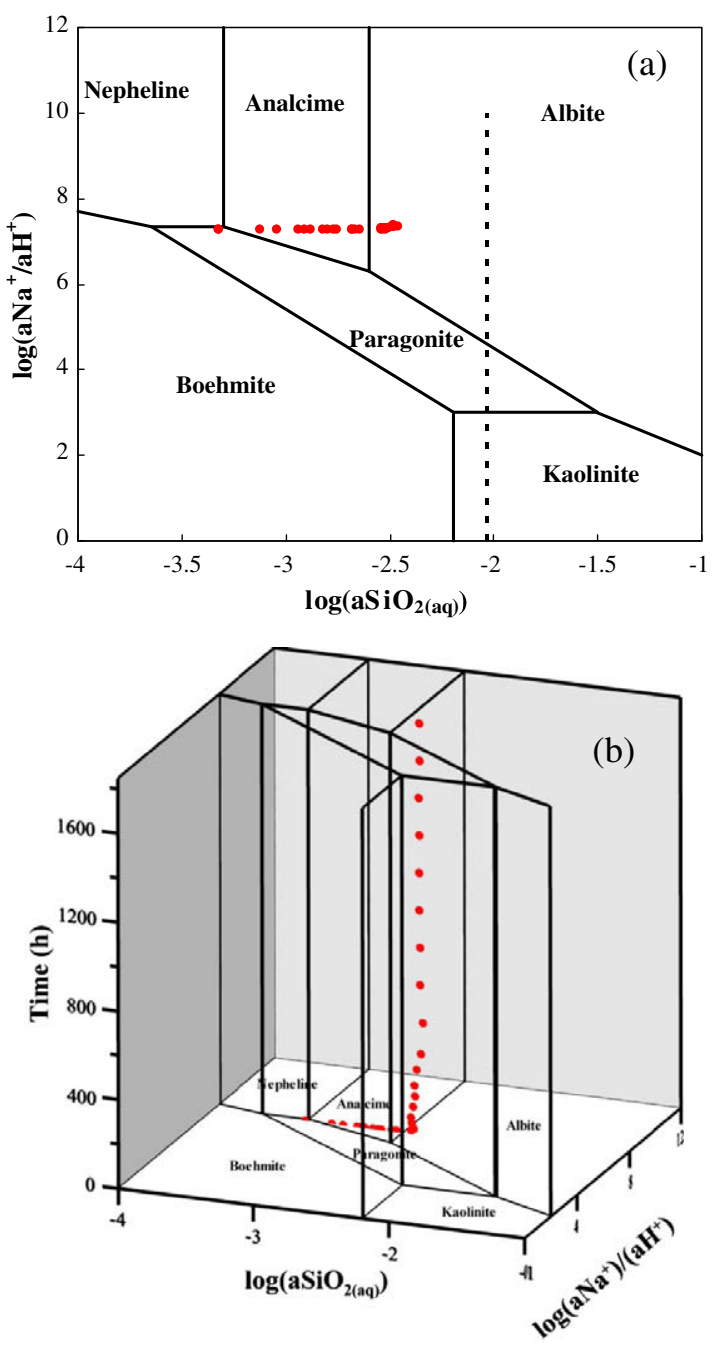

Fig. 8. Activity-activity diagrams showing phase relations in the system $\mathrm{Na}_{2} \mathrm{O}-\left(\mathrm{Al}_{2} \mathrm{O}_{3}\right)-\mathrm{SiO}_{2}-\mathrm{H}_{2} \mathrm{O}$ at $300^{\circ} \mathrm{C}$ and 88 bars. Symbols represent results from experiments conducted by Alekseyev et al. (1997) for sanidine dissolution in $0.1 \mathrm{~m} \mathrm{NaHCO}_{3}$ solutions. The dashed line in (a) denotes quartz saturation. Activity and activity ratios were obtained from speciation modeling in the system $\mathrm{K}_{2} \mathrm{O}$ $\mathrm{Na}_{2} \mathrm{O}-\left(\mathrm{Al}_{2} \mathrm{O}_{3}\right)-\mathrm{SiO}_{2}-\mathrm{H}_{2} \mathrm{O}-\mathrm{CO}_{2}$ based on solution chemistry data from Alekseyev et al. (1997) and values of $\log K$ listed in Table 1a.

librium measurements. However, Holland and Powell (1998) showed (their Fig. 2) that although the solubility data in the $\mathrm{K}_{2} \mathrm{O}-\mathrm{Al}_{2} \mathrm{O}_{3}-\mathrm{SiO}_{2}-\mathrm{H}_{2} \mathrm{O}-\mathrm{HCl}$ system reported by Sverjensky et al. (1991) were not used simultaneously together with phase equilibrium and calorimetric data in regressing thermodynamic properties for alumino-silicates, the off-sets of calculated phase stability fields from experimental data are small. This adds confidence to our calculated saturation indices for the $\mathrm{K}_{2} \mathrm{O}-\mathrm{Al}_{2} \mathrm{O}_{3}-\mathrm{SiO}_{2}-\mathrm{H}_{2} \mathrm{O}-$ $\mathrm{HCl}$ system.

The boundaries of mineral stability fields are sensitive to the free energies used in the construction of $a-a$ diagrams (Zhu and Anderson, 2002). For example, an increase of $1.2 \mathrm{~kJ} / \mathrm{mol}$ of the $\Delta G_{\mathrm{f}}^{\circ}$ for boehmite would move the boehmite-kaolinite phase boundary to the right about
0.13 unit of $\log a \mathrm{SiO}_{2(\mathrm{aq})}$ in Fig 2a. The adjusted $\Delta G_{\mathrm{f}}^{\circ}$ value of $-919.6 \mathrm{~kJ} / \mathrm{mol}$ is still within the uncertainties of the $\Delta G_{\mathrm{f}}^{\circ}$ values given by Hemingway et al. (1991) and McHale et al. (1997), and would fit to the kaolinite-boehmite phase equilibrium experiments by Hemley et al. (1980) better but fit the boehmite-andalusite phase equilibrium less well (see Appendix A). Likewise, the adjustment of $1.2 \mathrm{~kJ} / \mathrm{mol}$ to $\Delta G_{\mathrm{f}}^{\circ}$ for boehmite would lead to an adjustment of $0.13 \mathrm{SI}$ units for boehmite, which, however, is insufficient to change the nature of boehmite supersaturation, as boehmite was one to two SI unit supersaturated in these sampled solutions (cf. Table 3). In other words, it would require an adjustment of $21.7 \mathrm{~kJ} / \mathrm{mol}$ to $\Delta G_{\mathrm{f}}^{\circ}$ for boehmite to be at equilibrium with the aqueous solution at $456 \mathrm{~h}$ in $\mathrm{Fu}$ et al.'s (2009) experiments. This conclusion also applies to the alkali feldspar experiments with $\mathrm{CO}_{2}$ (Table 4) and experiments by Murakami et al. (1998), which show boehmite supersaturation from one to two SI units (cf. Table 5).

As discussed briefly earlier, to further test the validity of the conclusion that experimental solutions were supersaturated with respect to product minerals in the batch experiments that we have examined, we calculated saturation indices using different sets of thermodynamic properties for aqueous species and minerals, and different combinations of the two. The Electronic Annex Electronic Annex of this paper shows the detailed results of these calculations. The conclusion of supersaturation of product minerals still holds for the batch experiments examined in this study. In other words, the calculated saturation states are valid with the known uncertainties of thermodynamic properties.

Another layer of uncertainties may arise that amorphous or poorly crystalline metastable phases may be present in addition to the crystalline phases during the feldspar hydrolysis experiments (Helgeson, 1971, 1972; Petrovic, 1976). Further, metastable or poorly crystalline phases may transform during the experiments (e.g., Murakami et al., 1998). Appendix $C$ shows that partial equilibrium between possible amorphous phases and aqueous solutions may explain the initial stage of the experiments, but not the entire experiments.

\subsection{The coupling of dissolution and precipitation reaction kinetics}

Lasaga (1998) showed, analytically, how the precipitation kinetics of secondary minerals could be coupled to the rate of feldspar dissolution reaction. The kinetics of secondary mineral formation comes into play in the mass balance equations. Starting with the mass balance on $\mathrm{Al}$ and assuming the metastable coexistence of kaolinite and boehmite, we have,

$R_{\mathrm{feld}}=\frac{-R_{\mathrm{bhm}}-2 R_{\mathrm{kln}}}{\left[\sum_{j} \frac{d n_{A l j}, \mathrm{aq}}{d \xi}-1\right]}$

where $R_{i}$ is the net rate $(d \xi / d t)$ of dissolution of feldspar, boehmite, and kaolinite $\left(R_{i}<0\right.$ means precipitation). $n$ denotes the moles of $j$ th $\mathrm{Al}$ aqueous species and $\xi$ the overall 

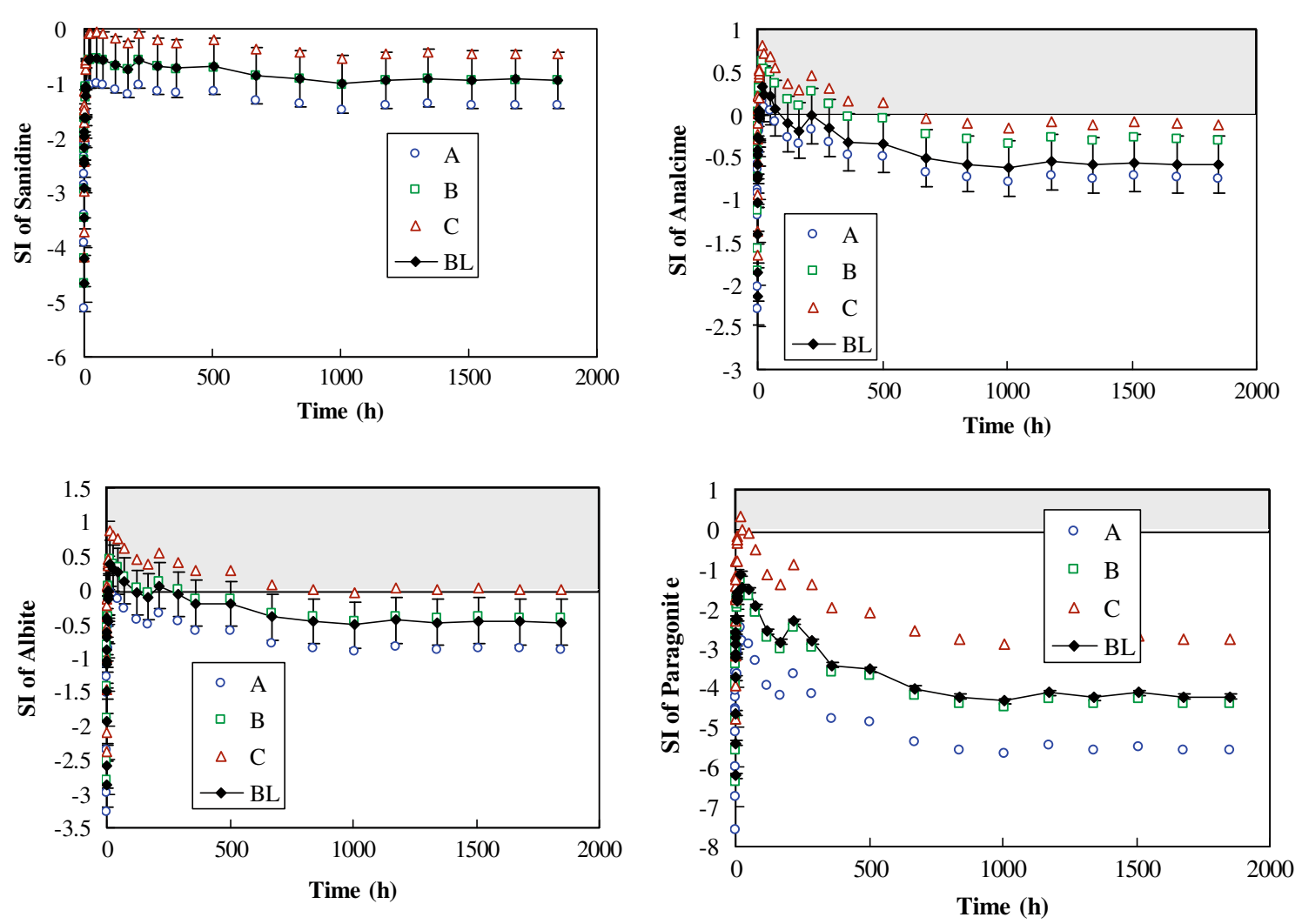

Fig. 9. Calculated saturation indices (SI) from experimental data for sanidine dissolution in $0.1 \mathrm{~m} \mathrm{NaHCO}_{3}$ solutions at $300{ }^{\circ} \mathrm{C}$ and 88 bars. Experimental data from Alekseyev et al. (1997). See the caption for Fig. 3 for notations.

progress variable (Helgeson, 1968). Eq. (1) is equivalent to Lasaga's (1998) Eq. (1.235).

If we expand the net rate expression and divide the right hand side by $k_{\text {feld }}$, we have,

$R_{\text {feld }}=\frac{-k_{\mathrm{bhm}} / k_{\text {feld }} S_{\mathrm{bhm}} f\left(\Delta G_{\mathrm{bhm}}\right)-2 k_{\mathrm{kln}} / k_{\mathrm{feld}} S_{\mathrm{kln}} f\left(\Delta G_{\mathrm{kln}}\right)}{\left[\sum_{j} \frac{d n_{A l_{j, \mathrm{aq}}}}{d \xi}-1\right] / k_{\text {feld }}}$

where $k_{i}$ denotes the rate constant, $S_{i}$ the surface area, and $\Delta G_{i}$ the Gibbs free energy of the $i$ th reactions. $f\left(\Delta G_{i}\right)$ stands for the relationship between rate and Gibbs free energy of reaction.

Eq. (2) shows the inter-dependence between the rate constants of feldspar dissolution and those of boehmite and kaolinite precipitation. The net feldspar dissolution rate is a function of $k_{i} / k_{\text {feld }}$ ratios. The smaller the $k_{i} / k_{\text {feld }}$ ratio, the slower feldspar dissolves, provided that all other quantities are kept the same. In fact, the experiments discussed in Section 3 showed that secondary minerals were several SI units supersaturated. Zhu et al. (2004a, 2004b) explored the inter-connections numerically via reaction path modeling. When the effective rate constant ratios $k^{*}{ }_{i} / k^{*}$ feld (defined as $k \times S$ ) are between $10^{-2}$ to $10^{-4}$, slow clay precipitation became the limiting step, and the net feldspar dissolution rates are orders of magnitude slower than that at conditions at far from equilibrium.
Note that the above discussion following Lasaga (1998) is a necessary oversimplification as a starting point and the rate law expression in Eq. (2) only means to facilitate further discussions. Obviously, the expression neglects other terms such as those accounting for the well known effects of hydrogen and $\mathrm{Al}$ on the rates (Aagaard and Helgeson, 1982; Helgeson et al., 1984; Oelkers et al., 1994; Oelkers, 2001). In a sense, the rate constant $k_{i}$ is only a nominal; the relationship between dissolution and precipitation kinetics still stands when other factors also play a role in the rate laws (e.g., $\mathrm{H}, \mathrm{Al})$. One could just replace $k_{i}^{*}$ with $k_{i}$, with $k_{i}^{*}$ lumping all other factors except the $f\left(\Delta G_{r}\right)$ term. This statement is necessary because while $k_{i}$ is meant to represent the intrinsic kinetics properties, in reality it is a value derived after subtraction of all "known" environmental factors from experimental data. In other words, the coupled relationship between dissolution and precipitation reactions originates from the principle of mass balance and the sharing of same aqueous components in the $f\left(\Delta G_{r}\right)$ term (Lasaga, 1998). It is broader than what Eq. (2) represents.

It follows then it is difficult to extrapolate experimental results from elevated temperatures and pressures, as examined here, to ambient conditions where silicate weathering occurs. The precipitation rates of clay minerals as a function of temperatures have not been completely understood. If the temperature dependence of $k_{i}$ for feldspar dissolution, 
Table 6

Mineral saturation indices in each batch experiment for sanidine dissolution in $0.1 \mathrm{~m} \mathrm{NaHCO}{ }_{3}$ solution at $300{ }^{\circ} \mathrm{C}$ and 88 bars. ${ }^{\mathrm{a}}$

\begin{tabular}{|c|c|c|c|c|c|c|c|c|c|c|c|}
\hline$t, h$ & Sanidine & Analcime & Albite & Quartz & Boehmite & Kaolinite & Muscovite & Paragonite & Pyrophyllite & Kalsilite & Nepheline \\
\hline 0 & -4.66 & -2.14 & -2.86 & -1.29 & -2.37 & -7.01 & -7.52 & -6.22 & -9.44 & -4.71 & -2.12 \\
\hline 0.25 & -4.19 & -1.86 & -2.59 & -1.29 & -2.10 & -6.46 & -6.51 & -5.40 & -8.89 & -4.24 & -1.85 \\
\hline 0.5 & -3.45 & -1.42 & -1.95 & -1.09 & -2.04 & -5.95 & -5.66 & -4.64 & -8.00 & -3.89 & -1.60 \\
\hline 0.75 & -2.92 & -1.04 & -1.48 & -1.01 & -1.82 & -5.34 & -4.68 & -3.73 & -7.22 & -3.53 & -1.30 \\
\hline 1 & -2.41 & -0.72 & -1.04 & -0.88 & -1.76 & -4.96 & -4.04 & -3.16 & -6.58 & -3.27 & -1.11 \\
\hline 1.25 & -2.46 & -0.76 & -1.11 & -0.90 & -1.75 & -5.00 & -4.08 & -3.22 & -6.67 & -3.27 & -1.13 \\
\hline 1.5 & -2.18 & -0.59 & -0.88 & -0.85 & -1.70 & -4.77 & -3.69 & -2.88 & -6.32 & -3.11 & -1.02 \\
\hline 2 & -1.88 & -0.42 & -0.62 & -0.76 & -1.69 & -4.59 & -3.38 & -2.62 & -5.98 & -2.98 & -0.93 \\
\hline 2.5 & -1.97 & -0.48 & -0.7 & -0.79 & -1.70 & -4.66 & -3.48 & -2.71 & -6.09 & -3.01 & -0.96 \\
\hline 3 & -1.63 & -0.27 & -0.43 & -0.72 & -1.61 & -4.35 & -2.97 & -2.26 & -5.66 & -2.80 & -0.81 \\
\hline 3.5 & -1.64 & -0.28 & -0.45 & -0.74 & -1.60 & -4.36 & -2.96 & -2.26 & -5.69 & -2.79 & -0.81 \\
\hline 4 & -1.24 & -0.04 & -0.13 & -0.65 & -1.54 & -4.05 & -2.42 & -1.81 & -5.21 & -2.56 & -0.66 \\
\hline 5 & -1.09 & 0.04 & -0.02 & -0.63 & -1.49 & -3.92 & -2.18 & -1.61 & -5.04 & -2.45 & -0.60 \\
\hline 6 & -1.12 & 0.00 & -0.09 & -0.65 & -1.49 & -3.97 & -2.22 & -1.69 & -5.13 & -2.44 & -0.62 \\
\hline 7 & -1.05 & 0.02 & -0.03 & -0.61 & -1.54 & -3.99 & -2.25 & -1.72 & -5.08 & -2.45 & -0.63 \\
\hline \multicolumn{12}{|c|}{ Analcime started to precipitate } \\
\hline 16 & -0.57 & 0.33 & 0.38 & -0.51 & -1.44 & -3.58 & -1.58 & -1.11 & -4.46 & -2.18 & -0.44 \\
\hline 24 & -0.56 & 0.24 & 0.32 & -0.49 & -1.58 & -3.82 & -1.83 & -1.46 & -4.66 & -2.20 & -0.54 \\
\hline 48 & -0.53 & 0.21 & 0.27 & -0.50 & -1.59 & -3.87 & -1.83 & -1.52 & -4.73 & -2.15 & -0.56 \\
\hline 72 & -0.57 & 0.07 & 0.13 & -0.51 & -1.73 & -4.17 & -2.14 & -1.94 & -5.05 & -2.17 & -0.69 \\
\hline 120 & -0.66 & -0.11 & -0.04 & -0.50 & -1.96 & -4.59 & -2.69 & -2.57 & -5.45 & -2.29 & -0.88 \\
\hline 168 & -0.75 & -0.19 & -0.11 & -0.48 & -2.06 & -4.78 & -2.99 & -2.85 & -5.60 & -2.4 & -0.98 \\
\hline 216 & -0.57 & -0.02 & 0.06 & -0.49 & -1.88 & -4.42 & -2.45 & -2.31 & -5.25 & -2.22 & -0.80 \\
\hline 288 & -0.68 & -0.16 & -0.07 & -0.47 & -2.07 & -4.76 & -2.93 & -2.81 & -5.55 & -2.36 & -0.96 \\
\hline 360 & -0.73 & -0.33 & -0.20 & -0.44 & -2.31 & -5.18 & -3.45 & -3.42 & -5.91 & -2.47 & -1.16 \\
\hline 504 & -0.69 & -0.34 & -0.20 & -0.42 & -2.36 & -5.25 & -3.52 & -3.53 & -5.96 & -2.46 & -1.19 \\
\hline 672 & -0.86 & -0.52 & -0.40 & -0.45 & -2.50 & -5.58 & -3.97 & -4.01 & -6.33 & -2.59 & -1.34 \\
\hline 840 & -0.91 & -0.58 & -0.47 & -0.45 & -2.57 & -5.72 & -4.17 & -4.22 & -6.47 & -2.64 & -1.41 \\
\hline 1008 & -1.01 & -0.63 & -0.52 & -0.45 & -2.60 & -5.78 & -4.32 & -4.32 & -6.54 & -2.73 & -1.45 \\
\hline 1176 & -0.94 & -0.56 & -0.45 & -0.45 & -2.53 & -5.64 & -4.10 & -4.11 & -6.40 & -2.65 & -1.38 \\
\hline 1344 & -0.91 & -0.59 & -0.48 & -0.45 & -2.58 & -5.74 & -4.17 & -4.25 & -6.50 & -2.62 & -1.41 \\
\hline 1512 & -0.93 & -0.57 & -0.46 & -0.45 & -2.53 & -5.65 & -4.11 & -4.13 & -6.42 & -2.64 & -1.38 \\
\hline 1680 & -0.93 & -0.59 & -0.47 & -0.45 & -2.57 & -5.72 & -4.18 & -4.22 & -6.47 & -2.65 & -1.41 \\
\hline 1848 & -0.94 & -0.59 & -0.48 & -0.45 & -2.57 & -5.72 & -4.19 & -4.22 & -6.48 & -2.66 & -1.41 \\
\hline
\end{tabular}

${ }^{a}$ Experiments conducted by Alekseyev et al. (1997). SI values were calculated in this study using their solution chemistry data. Italic values highlight supersaturation. 

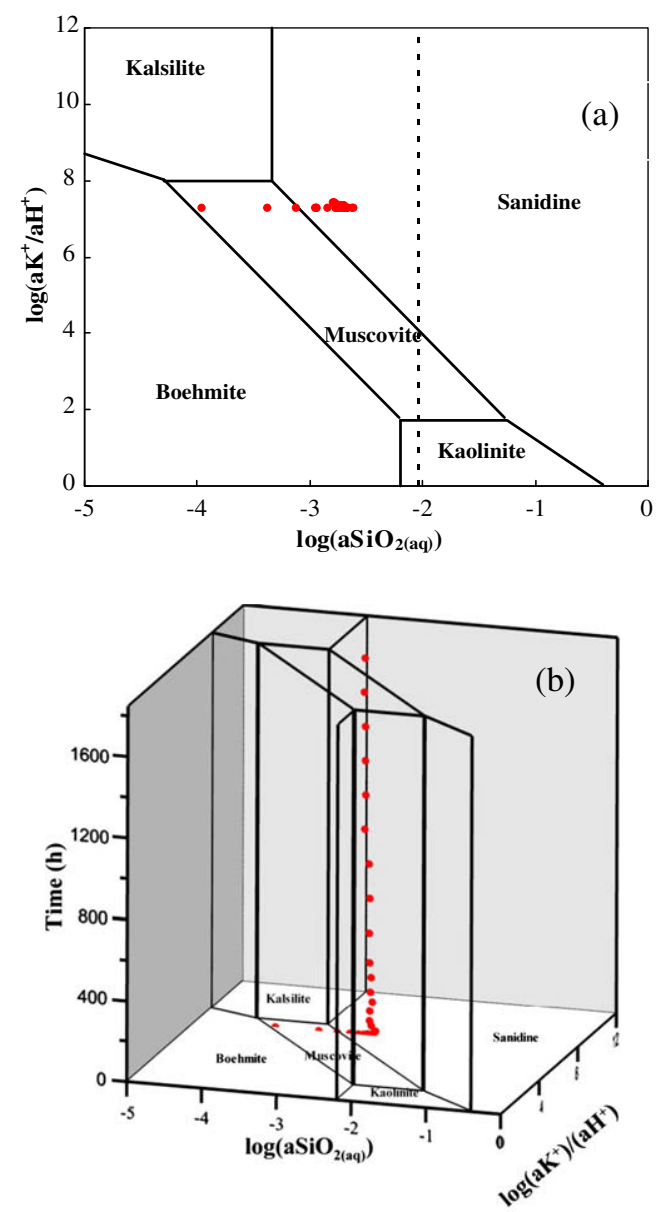

Fig. 10. Activity-activity diagrams showing phase relations in the system $\mathrm{K}_{2} \mathrm{O}-\left(\mathrm{Al}_{2} \mathrm{O}_{3}\right)-\mathrm{SiO}_{2}-\mathrm{H}_{2} \mathrm{O}$ at $300{ }^{\circ} \mathrm{C}$ and 88 bars. Symbols represent results from experiments conducted by Alekseyev et al. (1997) for albite dissolution in $0.1 \mathrm{~m} \mathrm{KHCO}_{3}$ solutions. The dashed line in (a) denotes quartz saturation. Activity and activity ratios were obtained from speciation modeling in the system $\mathrm{K}_{2} \mathrm{O}-\mathrm{Na}_{2} \mathrm{O}-$ $\mathrm{Al}_{2} \mathrm{O}_{3}-\mathrm{SiO}_{2}-\mathrm{H}_{2} \mathrm{O}-\mathrm{CO}_{2}$ based on solution chemistry data from Alekseyev et al. (1997) and $\log K$ listed in Table 1a.

or more broadly, all the terms in the rate law, is significantly higher than those for secondary mineral formation, the $k_{i} / k_{\text {feld }}$ ratio or the inter-dependence of dissolution-precipitation reaction kinetics may possibly change at ambient temperature and pressure. However, coupled reactions under ambient conditions are too slow to be measured in laboratory experiments. The temperature dependence remains to be an unknown factor at the present time.

In summary, through systematic analysis of a broad range of experimental data, we confirm early conjecture that secondary minerals might not be at equilibrium with the fluid (Steefel and Van Cappellen, 1990; Lasaga, 1998). This conjecture was previously supported by specific experiments and limited modeling analysis (Alekseyev et al., 1997). Here, we have conducted a comprehensive modeling study and have shown that the slow kinetics nature of secondary mineral precipitation was evident from both the fluid chemistry, which crossed the phase boundaries on the $a-a$ diagrams, and from mineral product analysis, which show persistent boehmite presence even after the fluid chemistry had evolved into the kaolinite and muscovite stability fields.

\subsection{Extrapolation to natural systems}

Natural systems differ from the laboratory experiments examined here mainly in two aspects. First, experimental results from batch systems cannot be applied directly to systems where advective and dispersive fluxes are significant. However, even in the case of fluid flow in a hydrological system flushed with fresh dilute water, the downstream water receives the solute fluxes from upstream, and the effects of supersaturation with respect to secondary minerals must be similar if the flow system has persisted for a while. These scenarios can be tested in a coupled reactive mass transport model in the future.

Second, laboratory experiments are brief on the scale of geological time. It is therefore necessary to examine samples from geological systems. Assessments of SI in the field are difficult, however, because of the absence or difficulty of aluminum analyses, the complex chemistry and structures of clay minerals, and the lack of internally consistent thermodynamic properties for clay minerals with such complex chemistry and structures. Nevertheless, Kwicklis (2004) calculated SI values of alumino-silicate minerals in the volcanic tuff aquifer in southern Nevada in the vicinity of Yucca Mountain. While the groundwaters there are undersaturated with respect to albite, they are supersaturated with respect to smectite and Ca-clinoptilolite. The more meaningful aspect of his findings is probably the areal distribution of the SI values - the SI values increase four to five fold southward along the groundwater flow from the Yucca Mountain and Fortymile Wash area to the Amargosa desert. These solubility-speciation modeling exercises are marred by the general problems with $\mathrm{Al}$ analysis and clay mineral properties discussed above, and specifically by the assumption of equilibrium between kaolinite and groundwaters. Nevertheless, the southward increase of SI for smectite and Ca-clinoptilolite along the flow path appears to support Kwicklis's (2004) assertion that "silicate weathering reactions are providing ions to the groundwater faster than they can be removed by smectite precipitation."

\section{CONCLUDING REMARKS}

Feldspars comprise over $50 \%$ of the volume of the earth's crust. Establishing reliable rates for low-temperature feldspar dissolution is essential to quantify many basic geological and environmental processes. Among these are the functional relationship between silicate weathering and the global climate over geologic time (Berner and Berner, 1997), controls on surface and groundwater quality, global elemental cycling (Lasaga et al., 1994), the availability of inorganic nutrients in soils (Federer et al., 1989; Likens et al., 1998), impacts of acid mine drainage, neutralization of acid precipitation in watersheds (Drever and Clow, 1995), safety of nuclear waste repositories (Spy- 
Table 7

Mineral saturation indices in each batch experiment for albite dissolution in $0.1 \mathrm{~m} \mathrm{KHCO}_{3}$ solution at $300{ }^{\circ} \mathrm{C}$ and 88 bars. ${ }^{\mathrm{a}}$

\begin{tabular}{|c|c|c|c|c|c|c|c|c|c|c|c|}
\hline$t, h$ & Albite & Sanidine & Microcline & Boehmite & Kaolinite & Muscovite & Paragonite & Pyrophyllite & Quartz & Kalsilite & Nepheline \\
\hline 0 & -7.50 & -4.08 & -3.89 & -2.49 & -8.49 & -7.17 & -11.1 & -12.2 & -1.92 & -2.87 & -5.50 \\
\hline 0.25 & -5.18 & -1.99 & -1.79 & -2.13 & -6.62 & -4.37 & -8.05 & -9.15 & -1.34 & -1.93 & -4.34 \\
\hline 0.5 & -4.09 & -0.99 & -0.79 & -1.86 & -5.59 & -2.83 & -6.43 & -7.64 & -1.09 & -1.43 & -3.74 \\
\hline 0.75 & -3.20 & -0.24 & -0.05 & -1.63 & -4.78 & -1.62 & -5.07 & -6.48 & -0.92 & -1.02 & -3.19 \\
\hline 1 & -3.15 & -0.21 & -0.02 & -1.64 & -4.78 & -1.60 & -5.03 & -6.45 & -0.91 & -1.02 & -3.17 \\
\hline 1.25 & -3.14 & -0.22 & -0.03 & -1.64 & -4.78 & -1.61 & -5.03 & -6.46 & -0.91 & -1.02 & -3.15 \\
\hline 1.5 & -2.61 & 0.23 & 0.43 & -1.51 & -4.30 & -0.9 & -4.24 & -5.76 & -0.8 & -0.79 & -2.85 \\
\hline 2 & -2.33 & 0.47 & 0.67 & -1.46 & -4.08 & -0.56 & -3.86 & -5.41 & -0.74 & -0.68 & -2.69 \\
\hline 2.5 & -2.37 & 0.45 & 0.64 & -1.48 & -4.12 & -0.63 & -3.95 & -5.45 & -0.74 & -0.7 & -2.73 \\
\hline 3 & -2.23 & 0.56 & 0.75 & -1.41 & -3.96 & -0.38 & -3.67 & -5.26 & -0.72 & -0.62 & -2.62 \\
\hline 3.5 & -2.19 & 0.55 & 0.75 & -1.45 & -4.00 & -0.45 & -3.69 & -5.29 & -0.71 & -0.64 & -2.60 \\
\hline 4 & -2.20 & 0.56 & 0.76 & -1.46 & -4.01 & -0.46 & -3.72 & -5.28 & -0.71 & -0.64 & -2.62 \\
\hline 5 & -1.88 & 0.84 & 1.03 & -1.36 & -3.70 & 0.00 & -3.21 & -4.85 & -0.65 & -0.49 & -2.42 \\
\hline 6 & -2.02 & 0.69 & 0.89 & -1.40 & -3.85 & -0.22 & -3.43 & -5.07 & -0.68 & -0.56 & -2.49 \\
\hline 7 & -1.81 & 0.88 & 1.08 & -1.36 & -3.67 & 0.04 & -3.14 & -4.8 & -0.63 & -0.48 & -2.38 \\
\hline 16 & -1.70 & 0.99 & 1.19 & -1.37 & -3.60 & 0.148 & -3.04 & -4.65 & -0.59 & -0.44 & -2.35 \\
\hline \multicolumn{12}{|c|}{ Sanidine started to precipitate } \\
\hline 24 & -1.63 & 1.06 & 1.25 & -1.35 & -3.54 & 0.24 & -2.94 & -4.55 & -0.58 & -0.41 & -2.31 \\
\hline 48 & -1.83 & 0.87 & 1.06 & -1.37 & -3.69 & 0.019 & -3.17 & -4.82 & -0.63 & -0.48 & -2.39 \\
\hline 72 & -1.93 & 0.77 & 0.96 & -1.40 & -3.80 & -0.15 & -3.34 & -4.98 & -0.66 & -0.54 & -2.44 \\
\hline 120 & -1.87 & 0.76 & 0.96 & -1.42 & -3.83 & -0.18 & -3.31 & -5 & -0.66 & -0.55 & -2.39 \\
\hline 168 & -1.79 & 0.86 & 1.05 & -1.42 & -3.76 & -0.09 & -3.23 & -4.87 & -0.62 & -0.52 & -2.37 \\
\hline 216 & -1.78 & 0.83 & 1.02 & -1.37 & -3.72 & -0.02 & -3.13 & -4.88 & -0.65 & -0.49 & -2.32 \\
\hline 288 & -1.69 & 0.84 & 1.03 & -1.39 & -3.75 & -0.06 & -3.09 & -4.89 & -0.64 & -0.5 & -2.25 \\
\hline 360 & -1.72 & 0.76 & 0.95 & -1.42 & -3.85 & -0.2 & -3.17 & -5.03 & -0.66 & -0.54 & -2.23 \\
\hline 504 & -1.55 & 0.72 & 0.92 & -1.45 & -3.93 & -0.3 & -3.07 & -5.13 & -0.67 & -0.56 & -2.05 \\
\hline 672 & -1.44 & 0.74 & 0.94 & -1.46 & -3.93 & -0.29 & -2.96 & -5.13 & -0.67 & -0.55 & -1.94 \\
\hline 840 & -1.40 & 0.67 & 0.86 & -1.51 & -4.07 & -0.48 & -3.04 & -5.29 & -0.68 & -0.59 & -1.88 \\
\hline 1008 & -1.51 & 0.50 & 0.69 & -1.52 & -4.20 & -0.65 & -3.15 & -5.55 & -0.74 & -0.64 & -1.86 \\
\hline 1176 & -1.44 & 0.55 & 0.74 & -1.50 & -4.15 & -0.57 & -3.06 & -5.47 & -0.73 & -0.61 & -1.81 \\
\hline 1344 & -1.44 & 0.49 & 0.68 & -1.56 & -4.28 & -0.74 & -3.17 & -5.62 & -0.74 & -0.65 & -1.79 \\
\hline 1512 & -1.43 & 0.50 & 0.70 & -1.54 & -4.24 & -0.69 & -3.13 & -5.58 & -0.74 & -0.64 & -1.79 \\
\hline 1680 & -1.46 & 0.43 & 0.62 & -1.57 & -4.35 & -0.83 & -3.22 & -5.72 & -0.76 & -0.68 & -1.78 \\
\hline 1848 & -1.43 & 0.47 & 0.67 & -1.56 & -4.30 & -0.76 & -3.16 & -5.65 & -0.75 & -0.65 & -1.77 \\
\hline
\end{tabular}

${ }^{a}$ Experimental data are from Alekseyev et al. (1997). SI values were calculated in this study using their solution chemistry data. Italic values highlight supersaturation. 

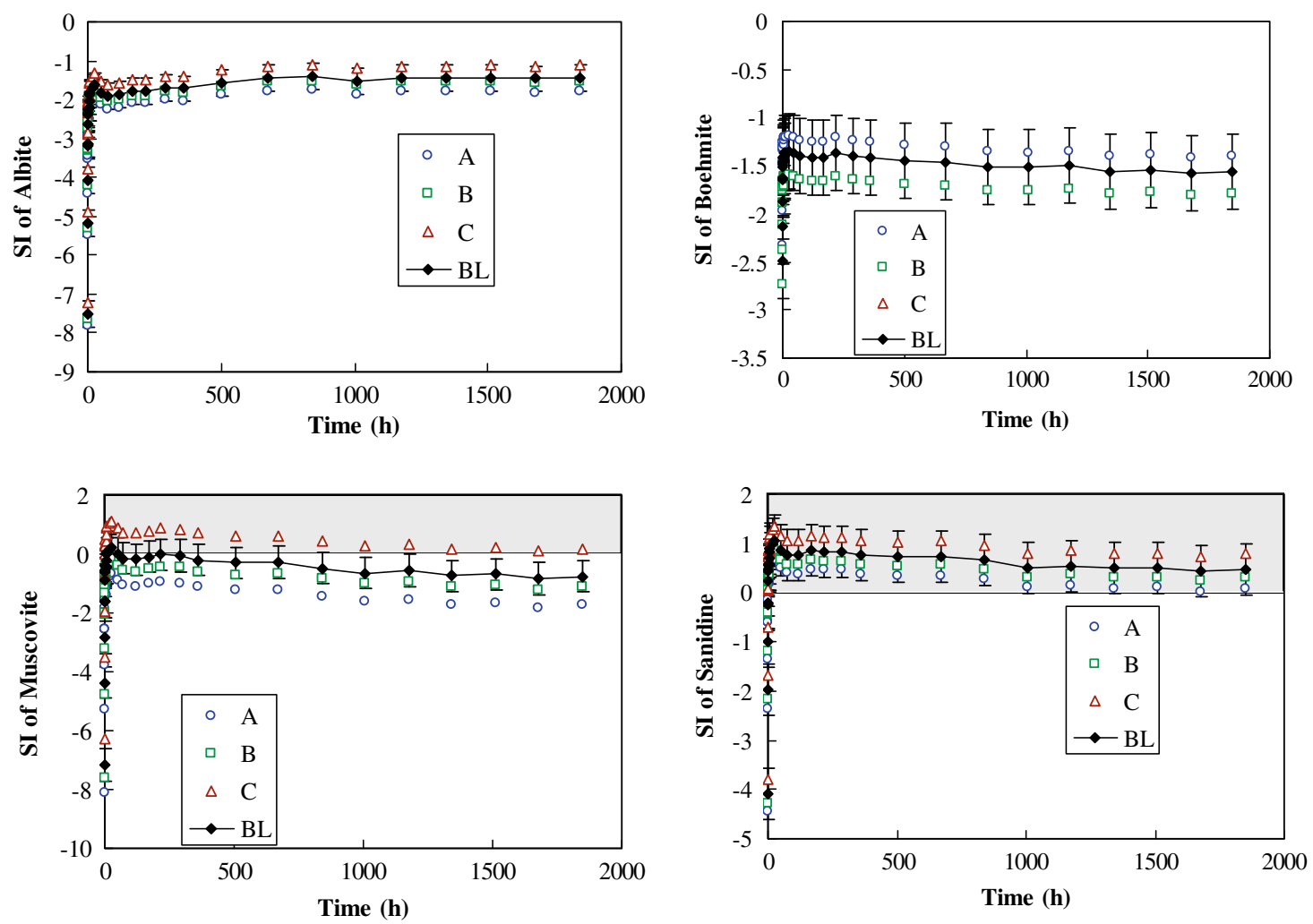

Fig. 11. Calculated saturation indices (SI) from experimental data for albite dissolution in $0.1 \mathrm{~m} \mathrm{KHCO}$ solutions at $300{ }^{\circ} \mathrm{C}$ and 88 bars. Experimental data from Alekseyev et al. (1997). See the caption for Fig. 3 for notations.

cher et al., 2003), and geological carbon sequestration (White et al., 2003).

The pioneering work by Helgeson and co-workers (Garrels and Mackenzie, 1967; Helgeson, 1968; Helgeson et al., 1969, 1984; Aagaard and Helgeson, 1982; Helgeson and Murphy, 1983) to model feldspar hydrolysis as a process of coupled dissolution and precipitation reactions transformed the study of water-rock interactions into a quantitative science and opened up vast new fields of geochemistry in the following decades. The early model, however, assumed partial equilibria between the aqueous solution and the secondary phases. Although the assumption of partial equilibrium has been questioned in the intervening years (Steefel and Van Cappellen, 1990; Nagy and Lasaga, 1993; Small, 1993; Lasaga et al., 1994; Alekseyev et al., 1997; Lasaga, 1998; Zhu et al., 2004a; Price et al., 2005; Zhu, 2006; Ganor et al., 2007), until now there has never been a rigorous examination of this hypothesis. Here, we systematically analyzed our own feldspar hydrolysis batch experiments (Fu et al., 2009) and those in the literature. We find three lines of experimental evidence that contradicts the partial equilibrium hypothesis in the experimental feldspar-water system: saturation indices, reaction paths, and secondary mineral paragenesis. However, we must emphasize that the partial equilibrium assumption between secondary minerals and aqueous solutions often produces a useful approximation of geochemical processes. Partial equilibrium may well exists for systems that involve rapidly precipitating secondary minerals (e.g., pyrite oxidation and precipitation of amorphous iron oxyhydroxides and in the case of evaporation and the resultant deposition of salt minerals as modeled by Garrels and Mackenzie (1967)) or even for the feldspar-water system at higher temperatures and pressures.

In the feldspar-water system, the slow kinetics of secondary mineral precipitation results in close inter-dependence of the dissolution and precipitation reaction rates (Steefel and Van Cappellen, 1990; Lasaga et al., 1994; Alekseyev et al., 1997; Lasaga, 1998), which, if clay precipitation $k^{*}$ are sufficiently slower than feldspar dissolution $k^{*}$, could rationalize the well-known discrepancy between field feldspar dissolution (bulk, effective) rates and rates measured in laboratory dissolution experiments at conditions far from equilibrium (Zhu et al., 2004a). Field studies often focused on the dissolution rates only. However, as seen in the batch experiments examined by this study, the congruent dissolution stage in the closed systems is short, probably a matter of hours at $90-300{ }^{\circ} \mathrm{C}$. A steady state or near steady state of aqueous chemistry for some constituents persisted as a consequence of the coupled dissolution and precipitation reactions. Zhu et al. (2004a) used a numerical reaction path model to show that such a steady state can result if the effective rate constants of clay precipitation are orders of magnitude smaller than those of feld- 
spar. Note that although the reaction Gibbs free energy effect on dissolution rates is a widely cited reason to explain the field-laboratory rate discrepancy, there is a need of a control that such a state of proximity to equilibrium can be maintained in natural systems for prolonged time and over long distance. Slow clay precipitation may serve this role.

Clearly, interpretation of field based reaction rates needs to consider dissolution reactions within a network of dissolution-precipitation reactions. Future work should employ numerical modeling of reaction paths to match the experimental data and hence to quantitatively evaluate the inter-dependence of dissolution-precipitation reactions. However, the challenge is to measure precipitation rates and derive proper rate laws to describe precipitation processes. While the details may evolve over time (e.g., Al adsorption on feldspar surface as a retardation mechanism (Oelkers et al., 1994) and slow clay precipitation kinetics discussed here), the framework of modeling mass transfer in geological systems developed by Helgeson and co-workers will continue to serve as the foundation for rigorous and quantitative geochemical predictions.

\section{ACKNOWLEDGMENTS}

This work is supported by the U.S. Department of Energy under Award No. DE-FG26-04NT42125 and partially by the National Science Foundation under Award No. EAR0423971 and EAR0509775 to C.Z. Any opinions, findings, and conclusions or recommendations expressed in this material, however, are those of the authors and do not necessarily reflect the views of the United States Government or any agency thereof. We thank Jim Brophy, Kurt Swingle, and Jeff Dick for review of the manuscript before submission. We are especially grateful to Tom Wolery and two anonymous reviewers for constructive comments. C.Z. also wishes to thank Bill Seyfried for his permission to include experiments in Section 3.2 and Appendix B ahead of the publication of their joint research. We want to dedicate this work to Harold C. Helgeson, who passed away in May 2007. It is on his pioneering work that our efforts are based.

\section{APPENDIX A. DISCUSSION OF THERMODYNAMIC PROPERTIES}

\section{A.1. Thermodynamic properties for Boehmite}

The only aluminum oxyhydroxide mineral listed in the Holland and Powell (1998) database is diaspore. However, boehmite was detected in the experiments that we examined in this study (Murakami et al., 1998; Fu et al., 2009). Here, we adopted the heat capacity, entropy, and enthalpy of formation for boehmite from Hemingway et al. (1991). The experimental heat capacity values were fitted to the Holland and Powell heat capacity function. Hemingway et al. (1991) derived their $\Delta H^{\circ}$ of $-996.4 \pm 2.2 \mathrm{~kJ} / \mathrm{mol}$ from their third-law entropy measurements and solubility data in alkaline solutions taken from the literature. Hemingway et al.'s (1991) $\Delta H^{\circ}{ }_{\mathrm{f}}$ was used by Tagirov and Schott (2001) in their derivation of Al hydrolysis constants (see below). Later, McHale et al. (1997) measured calorimetrically a $\Delta H_{\mathrm{f}}^{\circ}$ of $-995.4 \pm 1.6 \mathrm{~kJ} / \mathrm{mol}$. These two values are within each other's experimental errors. Note that the solubilitybased $\Delta G^{\circ}$ f proposed by Hemingway et al. (1991) is only half to $1 \mathrm{~kJ} / \mathrm{mol}$ different from those of Boucier et al. (1993) and Pokrovskii and Helgeson (1995), who also derived $\Delta G_{\mathrm{f}}^{\circ}$ for boehmite from solubility data.

To examine the consistency of these adopted thermodynamic properties for boehmite with the rest of the Holland and Powell (1998) database, we compared the calculated phase boundary against the kaolinite-boehmite experimental data of Hemley et al. (1980) and Hemley's andalusite-boehmite experiment reported by Helgeson et al. (1978, p. 114) (Fig. A1). Hemley et al. (1980) warned that the scattering of the kaolinite-boehmite at low temperatures might have resulted from boehmite being metastable and being re-crystallized to diaspore. For this reason, we also calculated the diaspore-kaolinite boundary (the dashed line). The comparison shows that most experimental data match more closely to the diaspore-kaolinite equi-
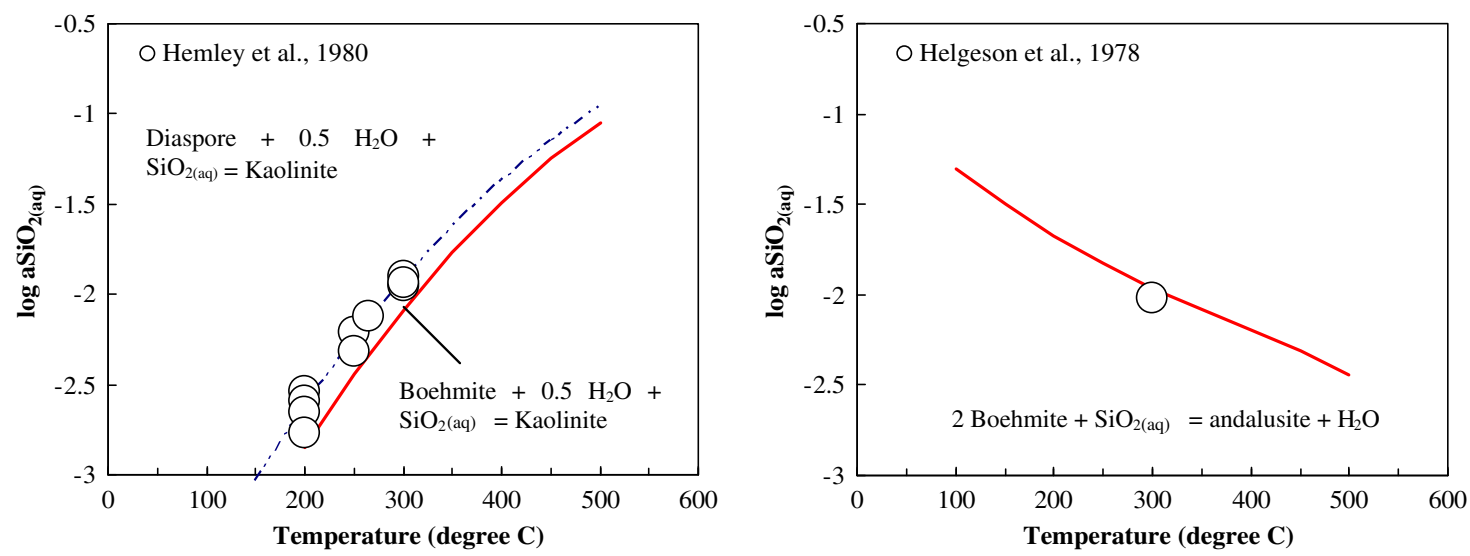

Fig. A1. Comparison of experimental (symbols) and calculated (lines) phase equilibrium involving boehmite. Thermodynamic properties for kaolinite and andalusite are from Holland and Powell (1998), for $\mathrm{SiO}_{2}{ }^{\circ}$ (aq) from Shock et al. (1989), and for boehmite from Hemingway et al. (1991). As in Hemley et al. (1980), the only aqueous silica species is assumed to be $\mathrm{SiO}_{2}{ }^{\circ}$ (aq) and the activity coefficient for this neutral species is assumed to be unity. The andalusite-boehmite experiment was conducted by Hemley, but as cited in Helgeson et al. (1978). 
librium curve than to the boehmite-kaolinite equilibrium curve although experiments with lower $\mathrm{SiO}_{2}$ concentrations match with the boehmite-kaolinite equilibrium curve. The maximum discrepancies between the experimental and calculated boehmite-kaolinite boundary are about $0.25-0.3 \log$ unit of $a_{\mathrm{SiO} 2}{ }^{\circ}$ (aq).

No detailed description of the boehmite-andalusite experiment was given, but the one experimental datum matches the calculation. These comparisons demonstrate that the adopted boehmite thermodynamic properties are approximately consistent with other Al-bearing minerals in Holland and Powell (1998) in the temperature and pressure range of our interest. Note that Holland and Powell (1998) have included other phase equilibrium experiment data of Hemley et al. (1980) in their derivation of $\Delta H^{\circ}$ values for diaspore, kaolinite, andalusite, and pyrophyllite.

\section{A.2. Thermodynamic properties for aqueous Al species}

Various competing Al hydrolysis constants and Al-metal complexes were proposed at the temperatures and pressures of our interest (among them: Apps and Neil, 1990; Bourcier et al., 1993; Pokrovskii and Helgeson, 1995; Shock et al., 1997; Tagirov and Schott, 2001). We adopted the species and equilibrium constants from Tagirov and Schott (2001) because their constants are consistent with the latest boehmite solubility measurements (Bénézeth et al., 1997, 2001; Palmer et al., 2001) and at the same time, they adopted the Hemingway et al. (1991) thermodynamic properties for boehmite, which we also adopted. Thus, the calculated saturation indices for boehmite should be consistent with the knowledge of boehmite solubilities in the temperature and pressure range of our interest.

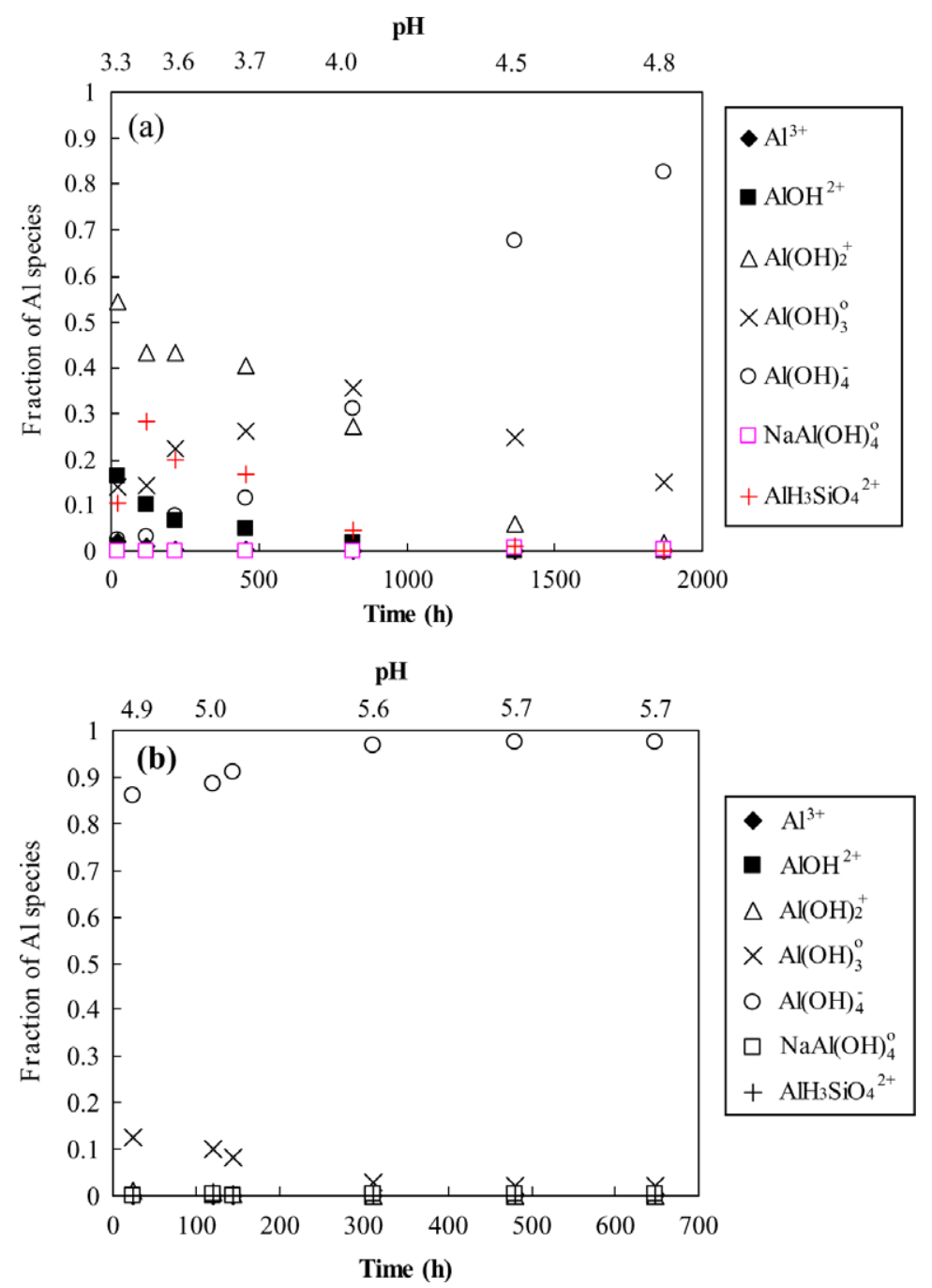

Fig. A2. Fraction of $\mathrm{Al}$ aqueous species as a function of time for alkali feldspar dissolution and clay precipitation experiment at $200{ }^{\circ} \mathrm{C}$ and 300 bar. (a) Alkali feldspar $+0.2 \mathrm{~m} \mathrm{KCl}$ (described in Section 3.1) and (b) alkali feldspar $+0.2 \mathrm{~m} \mathrm{KCl}+0.05 \mathrm{~m} \mathrm{CO}_{2}$ (described in Section 3.2). Al aqueous speciation was calculated with the thermodynamic properties from Table 1a. Solution $\mathrm{pH}$ increased from the start of the experiment to end from 3.3 to 4.8 for (a) and from 4.9 to 5.7 for (b). 
As suspected, our calculations show that $\mathrm{Al}$ speciation is dependent on $\mathrm{pH}$, solution chemistry, and temperature (Figs. A2-A4). For the experiments of alkali feldspar dissolution in $\mathrm{KCl}$ solution at $200{ }^{\circ} \mathrm{C}$ and 300 bars (Section 3.1), the dominant $\mathrm{Al}$ species are $\mathrm{Al}(\mathrm{OH})_{2}{ }^{+}, \mathrm{Al}(\mathrm{OH})^{2+}, \mathrm{Al}(\mathrm{O}-$ $\mathrm{H})_{3}{ }_{(\mathrm{aq})}$, and $\mathrm{AlH}_{3} \mathrm{SiO}_{4}{ }^{2+}$ at $\mathrm{pH} 3.3-4.0$, and $\mathrm{Al}(\mathrm{OH})_{4}{ }^{-}$ and $\mathrm{Al}(\mathrm{OH})_{3}^{\circ}{ }_{(\mathrm{aq})}$ at $\mathrm{pH} 4.5-4.8$ (Fig. A2a). Thus, the $\mathrm{Al}$ aqueous complex $\mathrm{AlH}_{3} \mathrm{SiO}_{4}{ }^{2+}$ proposed by Tagirov and Schott (2001) is an important Al species at the early stage of the experiment when $\mathrm{pH}$ was below 4.0. The omission of this species would result in higher calculated SI values for boehmite, kaolinite, muscovite, and feldspars. For the experiment of alkali feldspar dissolution in $0.2 \mathrm{~m} \mathrm{KCl}$ and $0.05 \mathrm{~m} \mathrm{CO}_{2}$ solution at $200{ }^{\circ} \mathrm{C}$ and 300 bars (Section 3.2),
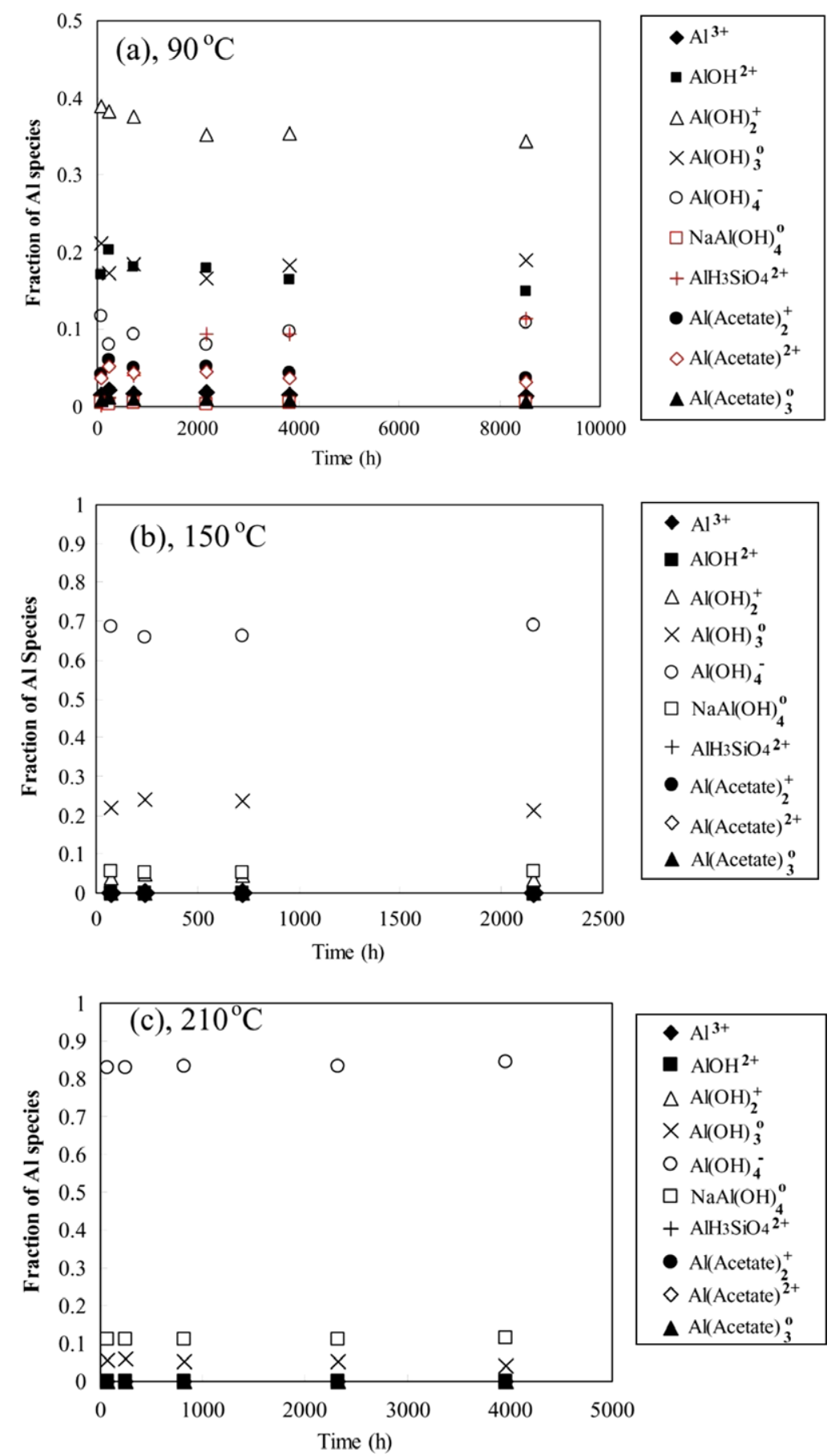

Fig. A3. Fraction of Al species in the experiment of anorthite dissolution in $0.03 \mathrm{~m} \mathrm{NaAC}$ solutions performed by Murakami et al. (1998) and described in Section 3.3. At $90^{\circ} \mathrm{C}(\mathrm{a}), 150^{\circ} \mathrm{C}$ (b), and $210^{\circ} \mathrm{C}$ (c). Al speciation was calculated with the thermodynamic properties from Table 1a. Solution $\mathrm{pH}$ was buffered around 4.7 for (a), 5.0 for (b), and 5.4 for (c). 
the $\mathrm{pH}$ varied from 4.9 at the start of the experiment to 5.7 at the end of the experiment. The dominant species is $\mathrm{Al}(\mathrm{OH})_{4}{ }^{-}$, with less than $10 \%$ as $\mathrm{Al}(\mathrm{OH})_{3}{ }^{\circ}$ (aq) at the early stage of the experiment (Fig. A2b). Arnórsson and Stefánsson (1999) argue that the thermodynamic properties for $\mathrm{Al}(\mathrm{OH})_{4}{ }^{-}$is well known.

For the anorthite dissolution experiments published by Murakami et al. (1998) (Section 3.3), the dominant species are $\mathrm{Al}(\mathrm{OH})_{2}{ }^{+}, \mathrm{Al}(\mathrm{OH})^{2+}, \mathrm{Al}(\mathrm{OH})_{3}{ }_{(\mathrm{aq})}, \mathrm{Al}(\mathrm{OH})_{4}{ }^{-}$, but $\mathrm{AlH}_{3} \mathrm{SiO}_{4}{ }^{2+}$ comprises of about $10 \%$ of the $\mathrm{Al}$ species at $90{ }^{\circ} \mathrm{C}$. The Al-acetate complexes, although included in the speciation model, only make up $<5 \%$ of the total. The calculated in situ $\mathrm{pH}$ was about 4.7 at $90{ }^{\circ} \mathrm{C}$. The experiments at $150{ }^{\circ} \mathrm{C}$ had $\mathrm{pH}$ around 5.0, and the dominant $\mathrm{Al}$ species are $\mathrm{Al}(\mathrm{OH})_{3}{ }^{\circ}$ (aq) and $\mathrm{Al}(\mathrm{OH})_{4}{ }^{-}$. The $\mathrm{Na}-\mathrm{Al}$ complex proposed by Tagirov and Schott (2001) comprises about $5 \%$ of total $\mathrm{Al}$ species, which does not significantly affect the calculated SI values. The experiments at $210^{\circ} \mathrm{C}$ had $\mathrm{pH}$ around 5.4 and the dominant species is $\mathrm{Al}(\mathrm{OH})_{4}{ }^{-}$. Neither Al-Na complex or Al-acetate complexes are significant. As mentioned earlier, calculated SI values for anorthite are $>0$ for the baseline thermodynamic dataset
(Fig. 7) while Murakami et al. (1998) demonstrated continued anorthite dissolution. Using the thermodynamic properties from Helgeson et al. (1978) would result in anorthite undersaturation (Fig. 7). There is a difference of $>16 \mathrm{~kJ} /$ mol for the standard enthalpy of formation at $25^{\circ} \mathrm{C}$ and 1 bar between those values chosen by Helgeson et al. (1978) and by Holland and Powell (1998). Arnórsson and Stefánsson (1999) also showed that the temperature variation of the anorthite solubility can also differ significantly when different sets of thermodynamic properties are used. These problems, however, seem to rest with the anorthite properties and should not affect our conclusions of secondary mineral supersaturation.

For the sanidine dissolution in $0.1 \mathrm{~m} \mathrm{NaHCO}_{3}$ solution at $300{ }^{\circ} \mathrm{C}$ and 88 bars, experiments conducted by Alekseyev et al. (1997) (Section 3.4), $\mathrm{Al}(\mathrm{OH})_{4}{ }^{-}(65 \%)$ and $\mathrm{NaA}-$ $1(\mathrm{OH})_{4}^{\circ}{ }_{\text {(aq) }}(35 \%)$ are the dominants species. The solution $\mathrm{pH}$ was around 9 . Whether or not to include the species $\mathrm{NaAl}(\mathrm{OH})_{4}{ }^{\circ}$ (aq) could contribute significantly to the calculated SI values (Fig. 7). However, even with this uncertainty of Al speciation, the calculated SI values do not reverse the signs. For the albite dissolution in $0.1 \mathrm{~m}$
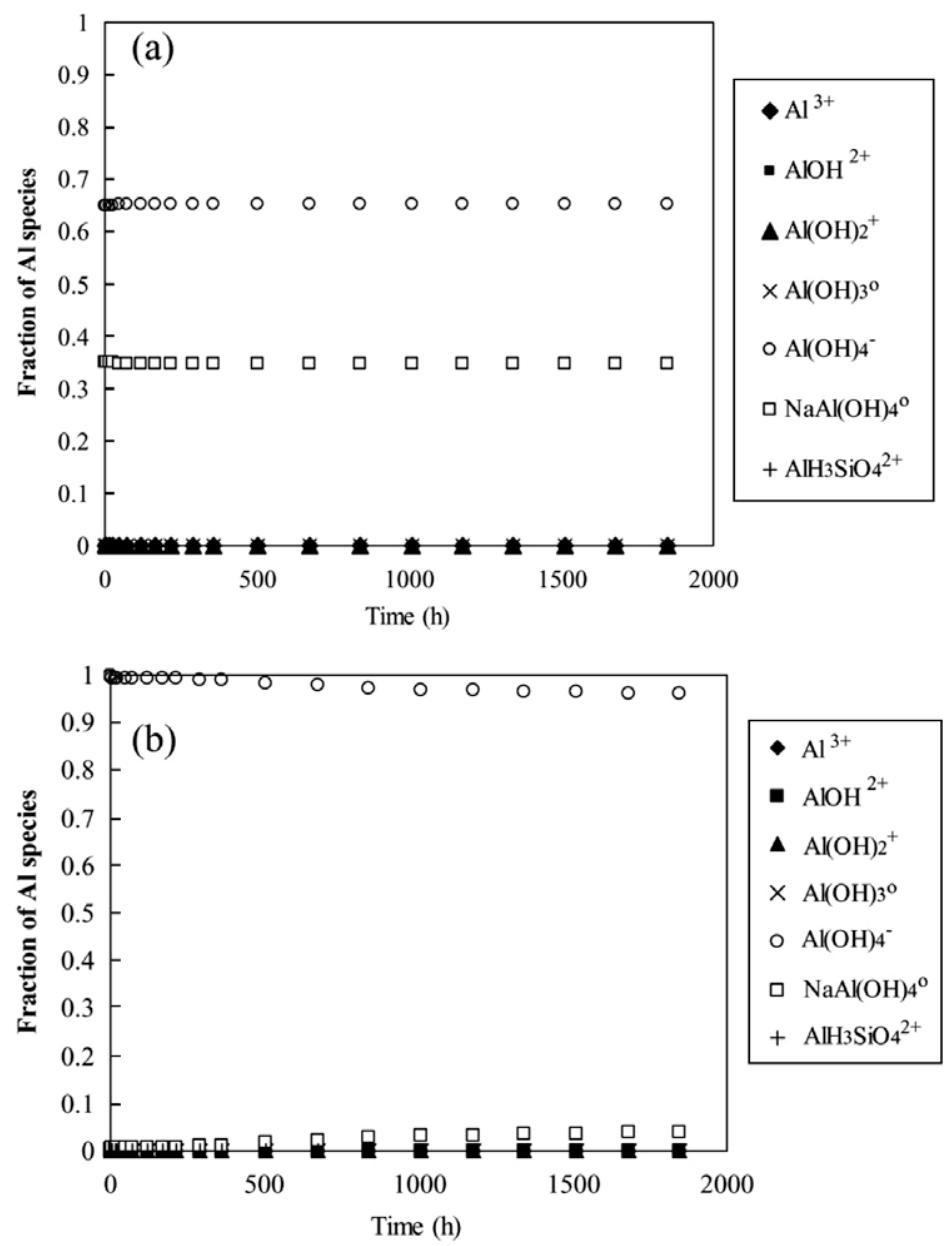

Fig. A4. Fraction of $\mathrm{Al}$ species in the experiments conducted by Alekseyev et al. (1997) at $300{ }^{\circ} \mathrm{C}$ and 88 bars (described in Section 3.4). (a) Sanidine dissolution in $0.1 \mathrm{~m} \mathrm{NaHCO}_{3}$ solution; (b) albite dissolution in $0.1 \mathrm{~m} \mathrm{KHCO}_{3}$ solution $\mathrm{Al}$ speciation was calculated with the thermodynamic properties from Table 1a. Solution $\mathrm{pH}$ was buffered around 9 for both (a) and (b). 
$\mathrm{KHCO}_{3}$ solution at $300{ }^{\circ} \mathrm{C}$ and 88 bars conducted by Alekseyev et al. (1997), the calculated in situ $\mathrm{pH}$ are also around 9, and the dominant $\mathrm{Al}$ species is $\mathrm{Al}(\mathrm{OH})_{4}{ }^{-}$ $(>95 \%)$ (Fig. A4b).

\section{A.3. Chemical impurities and crystallinity}

Another source of error is that the standard thermodynamic properties used for calculations are derived from pure end-members (typically measured from gem quality crystals) while the primary minerals (feldspars) and secondary mineral products in the experiments may not be chemically pure or may have different crystallinity from those used to derive thermodynamic properties. While Murakami et al. (1998) used an $\mathrm{An}_{95} \mathrm{Ab}_{0.5}$ anorthite, Fu et al. (2009) used a perthitic feldspar with a K-feldspar laminae with 15\% Na component. According to Arnórsson and Stefánsson (1999), the $\Delta G_{\text {mix }}$ of alkali feldspar is positive, indicating that alkali-feldspar solid solutions are more soluble than the respective pure endmembers. However, they showed that the $\Delta G_{\text {mix }}$ is less than $1 \mathrm{~kJ} / \mathrm{mol}$ for composition of $10 \% \mathrm{Na}$ low albite in the low albite-microcline series, which translates to about $0.1-0.2$ in $\log K$ at $200{ }^{\circ} \mathrm{C}$. Therefore, taking into account of the solid solution effects, the calculated albite SI values reported in Sections 3.1 and 3.2 would be $\sim 0.2$ unit lower. The Na component in the anorthite will reduce the solubility of anorthite. At $90-210{ }^{\circ} \mathrm{C}$, the $5 \% \mathrm{Na}$ will most likely introduce about 0.25 in $\log K$.

Murakami et al. (1998) noted that the boehmite in their experiments contained high concentrations of $\mathrm{Si}$. The effect of this on thermodynamic properties is unknown. Kaolin mineral occur with varying degrees of structural order and hence free energy (Drever, 2004). The errors on the SI are not assessed.

\section{APPENDIX B. EXPERIMENTAL DATA}

As briefly described in Section 3.2, two batch experiments for alkali feldspar dissolution in $\sim 0.2 \mathrm{~mol} / \mathrm{kg} \mathrm{KCl}, 50 \mathrm{mmol} /$ $\mathrm{kg} \mathrm{CO}$ solution were conducted at $200{ }^{\circ} \mathrm{C}$ and 300 bars in Professor W.E. Seyfried's lab at the University of Minnesota. A time series of fluid samples were taken in situ and the solution chemistry was analyzed (Table B1). Detailed experimental and analytical procedures are described in Fu et al. (2009).

Table B1. Major dissolved constituents in aqueous fluid ( $\mathrm{mmol} / \mathrm{kg}$, except for $\mathrm{pH}$ ) coexisting with alkali feldspar and reaction products at $200{ }^{\circ} \mathrm{C}$ and 300 bars.

\begin{tabular}{llllllllll}
\hline $\begin{array}{l}\text { Time } \\
\text { (h) }\end{array}$ & $\mathrm{SiO}_{2} \mathrm{Na}^{+} \mathrm{Al}^{3+}$ & $\mathrm{K}^{+}$ & $\mathrm{Cl}^{-}$ & $\begin{array}{l}\mathrm{CO}_{2} \\
(\mathrm{aq})\end{array}$ & $\begin{array}{l}\text { Measured } \\
\mathrm{pH}\left(25^{\circ} \mathrm{C}\right)\end{array}$ & $\begin{array}{l}\text { Calculated } \\
\text { in situ } \mathrm{pH} \\
\left(200^{\circ} \mathrm{C}\right)\end{array}$ \\
\hline 0 & - & - & - & 200.0 & 200.0 & 50.0 & 4.0 & 4.5 \\
24 & 0.40 & 0.26 & 0.01 & 196.31 & 199.22 & 47.90 & 4.3 & 4.9 \\
$120^{*}$ & 1.96 & 1.89 & 0.006 & $200.0^{\#}$ & $200.0^{\#}$ & $50.0^{\#}$ & 4.4 & 5.0 \\
144 & 1.88 & 0.45 & 0.01 & 194.30 & 196.51 & 44.47 & 4.5 & 5.1 \\
312 & 2.30 & 0.93 & 0.02 & 195.35 & 197.48 & 45.83 & 5.0 & 5.6 \\
480 & 2.42 & 1.41 & 0.06 & 196.19 & 199.40 & 45.35 & 5.1 & 5.7 \\
648 & 2.49 & 0.97 & 0.09 & 195.40 & 198.77 & 45.17 & 5.1 & 5.7 \\
\hline
\end{tabular}

\footnotetext{
* Terminated after 5 days.

\# Assumed, not measured concentrations.
}

\section{APPENDIX C. POSSIBLE AMORPHOUS PHASES AND PHASE TRANSITION}

Incongruent hydrolysis of feldspars is known to produce reaction products that are disordered, amorphous, or cryptocrystalline metastable phases (Helgeson, 1971, 1972; Petrovic, 1976). Here, we examined a working hypothesis that the solution chemistry in the experiments discussed in Section 3 was controlled by partial equilibrium with metastable amorphous phases that were not detected by XRD, SEM, or TEM. These amorphous phases have higher solubility and the partial equilibrium between these phases and aqueous solution resulted in persistent supersaturation with crystalline boehmite and kaolinite as discussed in Sections 3 and 4.1 .

Let's assume that there was an amorphous boehmite in the experiments of $\mathrm{Fu}$ et al. (2009) discussed in Section 3.1. The amorphous boehmite has the same chemical stoichiometry as crystalline boehmite but a $\Delta G_{\mathrm{f}}^{\circ}$ value $9 \mathrm{~kJ} /$ mol higher than that of the crystalline boehmite used in previous calculations. The calculated SI for this amorphous phase is one unit higher than that of the crystalline boehmite. The first three experimental samples (after 24, 120, and $216 \mathrm{~h}$ ) would be consistent with partial equilibrium between this phase and aqueous solutions. However, the SI of the stoichiometric boehmite (whatever it is, amorphous or crystalline) increased with time from 0.90 to 2.4 at $456 \mathrm{~h}$ (Fig. 3). If partial equilibrium between the amorphous boehmite and aqueous solution dominated solution chemistry during the entire experimental run, the SI values of the amorphous phase should decrease with time (see Section 2, the phase at partial equilibrium with the solution chemistry can only have $\mathrm{SI} \leqslant 0$ ).

Now, let's further assume that there was a phase transition during the $1872 \mathrm{~h}$ experiment. The first precipitated phase was an amorphous boehmite and it completely disappeared after $216 \mathrm{~h}$. A crystalline or more crystalline boehmite took control of the solution chemistry from $456 \mathrm{~h}$. The $\mathrm{SI}>0$ values for this crystalline or more crystalline phases for the rest of the experiments still indicate that partial equilibrium was not held between this crystalline phase and aqueous solutions or between any phase and aqueous solution throughout the experiments. Furthermore, XRD and SEM analyses of reaction products demonstrated crystalline boehmite after $120 \mathrm{~h}$ and $1872 \mathrm{~h}$ (Fu et al., 2009).

We can further test the working hypothesis that a halloysite with the same chemical stoichiometry as kaolinite but a $\Delta G_{\mathrm{f}}^{\circ} 16.8 \mathrm{~kJ} / \mathrm{mol}$ high than that of kaolinite (Robie and Hemingway, 1995) were present in the experiments discussed in Section 3.1. The calculated SI values for this halloysite is 1.85 SI units higher than that of kaolinite at $200{ }^{\circ} \mathrm{C}$ and is represented by a solid line in Fig. 3 at SI of 1.85. Robie and Hemingway (1995) gave a two standard deviation of $10 \mathrm{~kJ} / \mathrm{mol}$, which ware represented as two dashed lines bracketing the solid line in Fig. 3. We can see that it would be consistent with the two experimental data points at 120 and $216 \mathrm{~h}$. However, the SI values for the stoichiometric kaolin jumped to 5.13 at $456 \mathrm{~h}$. The calculated SI values are outside of the halloysite SI range. This could be explained by the complete disappearance of the 
amorphous halloysite, and the high SI values represent the control of a more crystalline phase. For the same reasons discussed in the previous paragraph, the experimental data could not be consistent with partial equilibrium with the amorphous phase throughout the experiments or at partial equilibrium with the crystalline or more crystalline kaolinite. Note that XRD and SEM analyses of reaction products demonstrated crystalline boehmite after $120 \mathrm{~h}$ and $1872 \mathrm{~h}$ (Fu et al., 2009).

In the case of experiments in Section 3.2, one could argue that partial equilibrium with an amorphous boehmite persisted throughout the experiment run within thermodynamic and analytical data uncertainties (Fig. 5). However, kaolinite and muscovite SI increase with time. Regardless of crystallinity, they cannot be at partial equilibrium with the aqueous solutions. Crystalline boehmite were detected with XRD and SEM. Only traces of muscovite were detected.

The experiments conducted by Murakami et al. (1998) discussed in Section 3.3 could be alternatively explained by partial equilibrium between an amorphous boehmite and aqueous solutions at 90,150 , and $210^{\circ} \mathrm{C}$ except for the first points in the experiments. At $90{ }^{\circ} \mathrm{C}$, it could be that the second and third points were at partial equilibrium with this amorphous boehmite with a $\Delta G_{\mathrm{f}}^{\circ}$ value $24 \mathrm{~kJ} / \mathrm{mol}$ higher than that of crystalline boehmite. Later, the Al concentrations in the aqueous solutions were controlled by an even more soluble "modified boehmite". At $150^{\circ} \mathrm{C}$, a similar case cannot be made. SI of boehmite increased and changed with time. Apparently, this is not a case of partial equilibrium. The SI for kaolinite or halloysite changed with time except 90 and $150^{\circ} \mathrm{C}$. The calculated SI values for kaolinite at $210^{\circ} \mathrm{C}$ could be argued to stay almost constant, but modified boehmite did not disappear, but persisted the whole time.

Therefore, while the presence of amorphous phases could not be ruled out, despite the deliberate efforts by Murakami et al. (1998) and Fu et al. (2009), and amorphous phases would introduce more complexity into the interpretations of the feldspar hydrolysis experiments, their presences, however, would not change our conclusions that partial equilibrium was generally not held in these laboratory experimental systems.

\section{APPENDIX D. SUPPLEMENTARY DATA}

Supplementary data associated with this article can be found, in the online version, at doi:10.1016/j.gca.2009. 03.015 .

\section{REFERENCES}

Aagaard P. and Helgeson H. C. (1982) Thermodynamic and kinetic constraints on reaction rates among minerals and aqueous solutions. I. Theoretical considerations. Am. J. Sci. 282, 237285.

Alekseyev V. A., Medvedeva L. S., Prisyagina N. I., Meshalkin S. S. and Balabin A. I. (1997) Change in the dissolution rates of alkali feldspars as a result of secondary mineral precipitation and approach to equilibrium. Geochim. Cosmochim. Acta 61, $1125-1142$.
Anderson G. M. and Crerar D. A. (1993) Thermodynamics in Geochemistry: The Equilibrium Model. Oxford University Press, New York.

Apps J. A. and Neil J. M. (1990) Solubilities of aluminum hydroxides and oxyhydroxides in alkaline solutions. In Chemical Modeling of Aqueous Solutions II (eds. D. A. Melchior and R. L. Bassett). ACS Symposium Series 416, Washington, DC.

Arnórsson S. and Stefánsson A. (1999) Assessment of feldspar solubility constants in water in the range of 0 to $350^{\circ} \mathrm{C}$ at vapor saturation pressures. Am. J. Sci. 299, 173-209.

Banfield J. F. and Barker W. W. (1994) Direct observation of reactant-product interfaces formed in natural weathering of exsolved, defective amphibole to smectite - evidence for episodic, isovolumetric reactions involving structural inheritance. Geochim. Cosmochim. Acta 58, 1419-1429.

Banfield J. F. and Eggleton R. A. (1990) Analytical transmission electron-microscope studies of plagioclase, muscovite, and Kfeldspar weathering. Clays Clay Miner. 38, 77-89.

Banfield J. F., Jones B. F. and Veblen D. R. (1991) An AEM-TEM study of weathering and diagenesis, Albert Lake, Oregon. I. Weathering reactions in the volcanics. Geochim. Cosmochim. Acta 55, 2781-2793.

Beig M. S. and Luttge A. (2006) Albite dissolution kinetics as a function of distance from equilibrium: implications for natural feldspar weathering. Geochim. Cosmochim. Acta 70, 1402-1420.

Bénézeth P., Palmer D. A. and Wesolowski D. J. (1997) The aqueous chemistry of aluminum. A new approach to hightemperature solubility measurements. Geothermics 26, 465481.

Bénézeth P., Palmer D. A. and Wesolowski D. J. (2001) Aqueous high-temperature solubility studies. II. The solubility of boehmite at $0.03 \mathrm{~m}$ ionic strength as a function of temperature and $\mathrm{pH}$ as determined by in situ measurements. Geochim. Cosmochim. Acta 65, 2097-2111.

Berman R. G. (1988) Internally-consistent thermodynamic data for minerals in the system $\mathrm{Na}_{2} \mathrm{O}-\mathrm{K}_{2} \mathrm{O}-\mathrm{CaO}-\mathrm{MgO}-\mathrm{FeO}-\mathrm{Fe}_{2} \mathrm{O}_{3}-$ $\mathrm{Al}_{2} \mathrm{O}_{3}-\mathrm{SiO}_{2}-\mathrm{TiO}_{2}-\mathrm{H}_{2} \mathrm{O}-\mathrm{CO}_{2}$. J. Petrol. 29, 445-522.

Berman R. G. (1990) Mixing properties of $\mathrm{Ca}-\mathrm{Mg}-\mathrm{Fe}-\mathrm{Mn}$ garnets. Am. Mineral. 75, 328-344.

Berner R. A. and Berner E. K. (1997) Silicate weathering and climate. In Tectonic Uplift and Climate Change (ed. W. F. Ruddiman). Plenum Press, pp. 353-364.

Blum A. and Stillings L. (1995) Feldspar dissolution kinetics. In Chemical Weathering Rates of Silicate Minerals (eds. S. L. Brantley and A. R. White). Mineralogical Society of America, Washington DC (vol. 31, pp. 291-346).

Bourcier W. L., Knauss K. G. and Jackson K. J. (1993) Aluminum hydrolysis constants to $250^{\circ} \mathrm{C}$ from boehmite solubility measurements. Geochim. Cosmochim. Acta 57, 747-762.

Brantley S. L. (1992) Kinetics of dissolution and precipitationexperimental and field results. In Proceedings of the Seventh International Conference on Water-Rock Interactions (eds. Y. Kharaka and A. Maest). Rotterdam, Balkema, Park City, Utah.

Brantley S. L. and Stillings L. (1996) Feldspar dissolution at $25^{\circ} \mathrm{C}$ and low pH. Am. J. Sci. 296, 101-127.

Bricker O. P., Jones B. and Bowser C. J. (2004) Mass-balance approach to interpreting weathering reactions in watershed systems. In Surface and Ground Water (ed. J. I. Drever). Elsevier, Oxford (vol. 5, pp. 119-132).

Burch T. E., Nagy K. L. and Lasaga A. C. (1993) Free energy dependence of albite dissolution kinetics at $80^{\circ} \mathrm{C}$ and $\mathrm{pH} 8.8$. Chem. Geol. 105, 137-162. 
Busenberg E. and Clemency C. V. (1976) The dissolution kinetics of feldspars at $25^{\circ} \mathrm{C}$ and $1 \mathrm{~atm} \mathrm{CO}_{2}$ partial pressure. Geochim. Cosmochim. Acta 40, 41-49.

Chou L. and Wollast R. (1984) Study of the weathering of albite at room temperature and pressure with a fluidized bed reactor. Geochim. Cosmochim. Acta 48, 2205-2217.

Chou L. and Wollast R. (1985) Steady-state kinetics and dissolution mechanisms of albite. Am. J. Sci. 285, 963-993.

Correns C. W. (1940) Die Chemische Verwitterung der Silikate. Nature 28, 369-376.

Correns C. W. and von Engelhardt W. (1938) Neue Untersuchungen uber die Verwiterung des Kalifeldspates. Chemie der Erde $12,1-22$.

Drever J. (2004) Volume editor's introduction. In Treatise on Geochemistry, vol. 5 (eds. H. D. Holland and K. K. Turekian). Elsevier, pp. $\mathrm{xv}-\mathrm{xvii}$.

Drever J. I. (1997) The Geochemistry of Natural Waters: Surface and Groundwater Environment, second ed. Prentice-Hall, Englewood Cliffs, NJ.

Drever J. I. and Clow D. W. (1995) Weathering rates in catchments. In Chemical Weathering Rates of Silicate Minerals, vol. 31 (eds. A. F. White and S. L. Brantley). Mineralogical Society of America, pp. 463-481.

Faure G. (1998) Principles and Applications of Inorganic Geochemistry. Prentice Hall, New York.

Federer C. A., Hornbeck J. W., Tritton L. M., Martin R. S., Pierce R. S. and Smith C. T. (1989) Long-term depletion of calcium and other nutrients in eastern US forests. Environ. Manag. 13, 593-601.

Fu Q., Lu P., Konishi H., Dilmore R., Xu H., Seyfried, Jr., W. E. and Zhu C. (2009) Coupled alkali-feldspar dissolution and secondary mineral precipitation in batch systems: 1 . New experiment data at $200^{\circ} \mathrm{C}$ and 300 bars. Chem. Geol. 91, 955964.

Ganor J., Lu P., Zheng Z. and Zhu C. (2007) Bridging the gap between laboratory measurements and field estimations of weathering using simple calculations. Environ. Geol. 53, 599610 .

Garrels R. M. and Mackenzie F. T. (1967) Origin of the chemical composition of some springs and lakes. In Equilibrium Concepts in Natural Water Systems, vol. 67 (ed. R. F. Gould). American Chemical Society, Washington, DC, pp. 222-242.

Gautier J.-M., Oelkers E. H. and Schott J. (1994) Experimental study of $\mathrm{K}$-feldspar dissolution rates as a function of chemical affinity at $150{ }^{\circ} \mathrm{C}$ and $\mathrm{pH}$ 9. Geochim. Cosmochim. Acta 58, 4549-4560.

Haar L., Gallagher J. S. and Kell G. S. (1984) NBS/NRC steam tables: thermodynamic and transport properties and computer programs for vapor and liquid states of water in SI units. Hemisphere Publishing Corporation, New York, p. 320.

Helgeson H. C. (1968) Evaluation of irreversible reactions in geochemical processes involving minerals and aqueous solutions-1. Thermodynamic relations. Geochim. Cosmochim. Acta 32, 853-877.

Helgeson H. C. (1970) A chemical and thermodynamic model of ore deposition in hydrothermal systems. In Fiftieth Anniversary Symposia, vol. 3 (ed. B. A. Morgan). Min. Soc. Amer., pp. 155186 (Special Paper).

Helgeson H. C. (1971) Kinetics of mass transfer among silicates and aqueous solutions. Geochim. Cosmochim. Acta 35, 421-469.

Helgeson H. C. (1972) Kinetics of mass transfer among silicates and aqueous solutions: correction and clarification. Geochim. Cosmochim. Acta 36, 1067-1070.

Helgeson H. C. (1974) Chemical interaction of feldspar and aqueous solutions. In The Feldspars (eds. W. S. MacKenzie and
J. Zussman). Crane, Russak and Co., Inc., New York, pp. 184 217.

Helgeson H. C. (1979) Mass transfer among minerals and hydrothermal solutions. In Geochemistry of Hydrothermal Ore Deposits (ed. H. L. Barnes). John Wiley \& Sons, New York, pp. 568-610.

Helgeson H. C., Brown T. H., Nigrini A. and Jones T. A. (1970) Calculation of mass transfer in geochemical processes involving aqueous solutions. Geochim. Cosmochim. Acta 34, 569-592.

Helgeson H. C., Delany J. M., Nesbitt H. W. and Bird D. K. (1978) Summary and critique of the thermodynamic properties of rock forming minerals. Am. J. Sci. 278A, 569-592.

Helgeson H. C., Garrels R. M. and Mackenzie F. T. (1969) Evaluation of irreversible reactions in geochemical processing involving minerals and aqueous solutions-II. Applications. Geochim. Cosmochim. Acta 33, 455-481.

Helgeson H. C., Kirkham D. H. and Flowers G. C. (1981) Theoretical prediction of the thermodynamic behavior of aqueous electrolytes at high pressures and temperatures. IV. Calculation of activity coefficients, osmotic coefficients, and apparent molal and standard and relative partial molal properties to $600{ }^{\circ} \mathrm{C}$ and $5 \mathrm{~kb}$. Am. J. Sci. 281, 1249-1516.

Helgeson H. C. and Murphy W. M. (1983) Calculation of mass transfer among minerals and aqueous solutions as a function of times and surface area in geochemical processes, I. Computational approach. Math. Geol. 15, 109-130.

Helgeson H. C., Murphy W. M. and Aagaard P. (1984) Thermodynamic and kinetic constraints on reaction rates among minerals and aqueous solutions II. Rate constants, effective surface area, and the hydrolysis of feldspar. Geochim. Cosmochim. Acta 48, 2405-2432.

Hellmann R. (1997) The albite-water system; part IV, diffusion modeling of leached and hydrogen-enriched layers. Geochim. Cosmochim. Acta 61, 1595-1611.

Hellmann R., Eggleston C. R., Hochella M. F. and Crerar D. A. (1990) The formation of leached layers on albite surfaces during dissolution under hydrothermal conditions. Geochim. Cosmochim. Acta 54, 1267-1281.

Hellmann R. and Tisserand D. (2006) Dissolution kinetics as a function of the Gibbs free energy of reaction: an experimental study based on albite feldspar. Geochim. Cosmochim. Acta 70, 364-383.

Hemingway B. S., Robie R. A. and Apps J. A. (1991) Revised values for the thermodynamic properties of boehmite, $\mathrm{AIO}(\mathrm{OH})$, and related species and phases in the system $\mathrm{Al}-$ H-O. Am. Mineral. 445, 457.

Hemley J. J., Montoya J. W., Marinenko J. W. and Luce R. W. (1980) Equilibria in the System $\mathrm{Al}_{2} \mathrm{O}_{3}-\mathrm{SiO}_{2}-\mathrm{H}_{2} \mathrm{O}$ and some general implications for alteration-mineralization processes. Econ. Geol. 75, 210-228.

Hereford A. G., Keating E., Guthrie G. and Zhu C. (2007) Reactions and reaction rates in the aquifer beneath Pajarito Plateau, north-central New Mexico. Environ. Geol. 52, 965-977.

Ho P. C., Bianchi H., Palmer D. A. and Wood R. H. (2000) Conductivity of dilute aqueous electrolyte solutions at high temperatures and pressures using a flow cell. J. Solut. Chem. 29, $217-235$.

Holdren G. R. and Berner R. A. (1979) Mechanism of feldspar weathering. I. Experimental studies. Geochim. Cosmochim. Acta 43, 1161-1171.

Holland T. J. B. and Powell R. (1998) An internally consistent thermodynamic data set for phases of petrological interest. $J$. Metamorph. Geol. 16, 309-343.

Johnson J. W., Oelkers E. H. and Helgeson H. C. (1992) SUPCRT92 - a software package for calculating the standard molal thermodynamic properties of minerals, gases, aqueous 
species, and reactions from 1-bar to 5000-bar and $0{ }^{\circ} \mathrm{C}$ to $1000{ }^{\circ}$ C. Comput. Geosci. 18, 899-947.

Krauskopf K. B. and Bird D. K. (1995) Introduction to Geochemistry. WCB McGraw-Hill, Boston.

Kwicklis E. (2004) Geochemical and isotopic constraints on groundwater flow directions, mixing, and recharge at Yucca Mountain, Nevada. Office of Civilian Radi, Waste Management.

Lasaga A. C. (1998) Kinetic Theory in the Earth Sciences. Princeton University Press, New York.

Lasaga A. C., Soler J. M., Ganor J., Burch T. E. and Nagy K. L. (1994) Chemical weathering rate laws and global geochemical cycles. Geochim. Cosmochim. Acta 58, 2361-2386.

Likens G. E., Driscoll C. T., Buso D. C., Siccama T. G., Johnson C. E., Lovett G. M., Fahey T. J., Reiners W. A., Ryan D. F., Maring C. W. and Bailey S. W. (1998) The biogeochemistry of calcium at Hubbard Brook. Biogeochemistry 41, 89-173.

Luce R. W., Bartlett R. W. and Parks G. A. (1972) Dissolution kinetics of magnesium silicates. Geochim. Cosmochim. Acta 36, 35-50.

McCollom T. M. and Shock E. L. (1997) Geochemical constraints on chemolithoautotrophic metabolism by microorganisms in seafloor hydrothermal systems. Geochim. Cosmochim. Acta 61, 4375-4391.

McHale J. M., Yurekli K., Dabbs D. M., Navrotsky A., Sundaresan S. and Aksay I. A. (1997) Metastability of spinel-type solid solutions in the $\mathrm{SiO}_{2}-\mathrm{Al}_{2} \mathrm{O}_{3}$ system. Chem. Mater. 9, 30963100 .

Murakami T., Kogure T., Kadohara H. and Ohnuki T. (1998) Formation of secondary minerals and its effects on anorthite dissolution. Am. Mineral. 83, 1209-1219.

Nagy K. L. and Lasaga A. C. (1993) Kinetics of simultaneous kaolinite and gibbsite precipitation. Geochim. Cosmochim. Acta 57, 4329-4337.

Nesbitt H. W. and Skinner W. M. (2001) Early development of $\mathrm{Al}, \mathrm{Ca}$, and $\mathrm{Na}$ compositional gradients in labradorite leached in $\mathrm{pH} 2 \mathrm{HCl}$ solutions. Geochim. Cosmochim. Acta 65, 715-727.

Nugent M. A., Brantley S. L., Pantano C. G. and Maurice P. A. (1998) The influence of natural mineral coatings on feldspar weathering. Nature 395, 588-591.

Oelkers E. H. (2001) General kinetic description of multioxide silicate mineral and glass dissolution. Geochim. Cosmochim. Acta 65, 3703-3719.

Oelkers E. H. and Helgeson H. C. (1990) Triple-ion anions and polynuclear complexing in supercritical electrolyte-solutions. Geochim. Cosmochim. Acta 54, 727-738.

Oelkers E. H., Schott J. and Devidal J. L. (1994) The effect of aluminum, $\mathrm{pH}$, and chemical affinity on the rates of aluminosilicate dissolution reactions. Geochim. Cosmochim. Acta 58, 2011-2024.

Paces T. (1973) Steady-state kinetics and equilibrium between ground water and granitic rocks. Geochim. Cosmochim. Acta 37, 2641-2663.

Paces T. (1983) Rate constants of dissolution derived from the measurements of mass balance in hydrological catchments. Geochim. Cosmochim. Acta 37, 1855-1863.

Palmer D. A., Bénézeth P. and Wesolowski D. J. (2001) Aqueous high-temperature solubility studies. I. The solubility of boehmite as functions of ionic strength (to 5 molal, $\mathrm{NaCl}$ ), temperature $\left(100-290{ }^{\circ} \mathrm{C}\right)$, and $\mathrm{pH}$ as determined by in situ measurements. Geochim. Cosmochim. Acta 65, 2081-2095.

Parkhurst D. L. and Appello A. A. J. (1999) User's guide to PHREEQC (version 2)-a computer program for speciation, batch-reaction, one dimensional transport, and inverse geochemical modeling. Water-Resource Investigation Report. U.S. Geological Survey.
Petrovic R. (1976) Rate control in feldspar dissolution II. The protective effects of precipitates. Geochim. Cosmochim. Acta 40, 1509-1521.

Pokrovskii V. A. and Helgeson H. C. (1995) Thermodynamic properties of aqueous species and the solubilities of minerals at high pressures and temperatures: the system $\mathrm{Al}_{2} \mathrm{O}_{3}-\mathrm{H}_{2} \mathrm{O}-\mathrm{NaCl}$. Am. J. Sci. 295, 1255-1342.

Price J. R., Velbel M. A. and Patino L. C. (2005) Rates and time scales of clay-mineral formation by weathering in saprolitic regoliths of the southern Appalachians from geochemical mass balance. Geol. Soc. Am. Bull. 117, 783-794.

Reed M. H. and Spycher N. F. (1984) Calculation of $\mathrm{pH}$ and mineral equilibria in hydrothermal waters with application to geothermometry and studies of boiling and dilution. Geochim. Cosmochim. Acta. 48, 1479-1492.

Robie R. A. and Hemingway B. S. (1995) Thermodynamic properties of minerals and related substances at $298.15 \mathrm{~K}$ and 1 bar $\left(10^{5}\right.$ pascals) pressure and at higher temperatures. U.S. Geological Survey Bulletin 2131, 456.

Seyfried, Jr., W. E., Janecky D. R. and Berndt M. E. (1987) Rocking autoclaves for hydrothermal experiments: II. The flexible reaction-cell system. In Hydrothermal Experimental Techniques (ed. H. L. Barnes). Wiley-Interscience, pp. 216-239.

Shock E. L. (1995) Organic acids in hydrothermal solutions: standard molal thermodynamic properties of carboxylic acids and estimates of dissociation constants at high temperatures and pressures. Am. J. Sci. 295, 496-580.

Shock E. L. and Helgeson H. C. (1988) Calculation of the thermodynamic and transport properties of aqueous species at high pressures and temperatures: correlation algorithms for ionic species and equation of state predictions to $5 \mathrm{~kb}$ and $1000^{\circ}$ C. Geochim. Cosmochim. Acta 52, 2009-2036.

Shock E. L., Helgeson H. C. and Sverjensky D. A. (1989) Calculations of the thermodynamic and transport properties of aqueous species at high pressures and temperatures: standard partial molal properties of inorganic neutral species. Geochim. Cosmochim. Acta 53, 2157-2183.

Shock E. L. and Koretsky C. M. (1993) Metal-organic complexes in geochemical processes: calculation of standard partial molal thermodynamic properties of aqueous acetate complexes at high pressures and temperatures. Geochim. Cosmochim. Acta 57, 4899-4922.

Shock E. L., Oelkers E. H., Sverjensky D. A., Johnson J. W. and Helgeson H. C. (1992) Calculation of thermodynamic and transport properties of aqueous species at high pressures, temperatures. Effective electrostatic radii, dissociation constants, standard partial molal properties to $1000^{\circ} \mathrm{C}$ and $5 \mathrm{~kb}$. $J$. Chem. Soc. Lond. Faraday Trans. 88, 803-826.

Shock E. L., Sassani D. C., Willis M. and Sverjensky D. A. (1997) Inorganic species in geologic fluids: correlations among standard molal thermodynamic properties of aqueous ions and hydroxide complexes. Geochim. Cosmochim. Acta 61, 907-950.

Small J. S. (1993) Experimental determination of the rates of precipitation of authigenic illite and kaolinite in the presence of aqueous oxalate and comparison to the $\mathrm{K} / \mathrm{Ar}$ ages of authigenic illite in reservoir sandstones. Clays Clay Miner. 41, 191-208.

Spycher N. F., Sonnenthal E. L. and Apps J. A. (2003) Fluid flow and reactive transport around potential nuclear waste emplacement tunnels at Yucca Mountain, Nevada. J. Contam. Hydrol. 62-63, 653-673.

Steefel C. I. and van Cappellen P. (1990) A new approach to modeling water-rock interaction: the role of precursors, nucleation, and Ostwald ripening. Geochim. Cosmochim. Acta 54, $2657-2677$. 
Steinmann P., Lichtner P. C. and Shotyk W. (1994) Reaction-path approach to mineral weathering reactions. Clays Clay Miner. 42, 197-206.

Sverjensky D. A., Hemley J. J. and D'Angelo W. M. (1991) Thermodynamic assessment of hydrothermal alkali feldsparmica-aluminosilicate equilibria. Geochim. Cosmochim. Acta 55, 989-1004.

Sverjensky D. A., Shock E. L. and Helgeson H. C. (1997) Prediction of the thermodynamic properties of aqueous metal complexes to $5 \mathrm{~kb}$ and $1000{ }^{\circ} \mathrm{C}$. Geochim. Cosmochim. Acta 61, 1359-1412.

Tagirov B. and Schott J. (2001) Aluminum speciation in crustal fluids revisited. Geochim. Cosmochim. Acta 65, 3965-3992.

Tanger J. C. and Helgeson H. C. (1988) Calculations of the thermodynamic and transport properties of aqueous species at high pressures and temperatures: revised equation of state for the standard partial molal properties of ions and electrolytes. Am. J. Sci. 288, 19-98.

Velbel M. A. (1990) Influence of temperature and mineral surface characteristics on feldspar weathering rates in natural and artificial systems: a first approximation. Water Resour. Res. 26, 3049-3053.

White A. F. and Brantley S. L. (2003) The effect of time on the weathering of silicate minerals: why do weathering rates in the laboratory and field? Chem. Geol. 202, 479-506.

White C., Strasizar B. R., Granite E. J., Hoffman J. S. and Pennline H. W. (2003) Separation and capture of $\mathrm{CO}_{2}$ from large stationary sources and sequestration in geological formations - co albeds and deep saline aquifers. J. Air Waste Manag. Assoc. 53, 645-715.

Wolery T. J. (1992) EQ3/6, a software package for geochemical modeling of aqueous systems: package overview and installation guide (version 7.0). URCL-MA-110662-PT-I, Livermore. California University, Lawrence Livermore Laboratory, California.

Zhu C. (2005) In situ feldspar dissolution rates in an aquifer. Geochim. Cosmochim. Acta 69, 1435-1453.

Zhu C. (2006) In situ silicate reaction rates in sandy aquifers. Geochim. Cosmochim. Acta 70, A753.

Zhu C. and Anderson G. M. (2002) Environmental Applications of Geochemical Modeling. Cambridge University Press, London.

Zhu C., Blum A. E. and Veblen D. R. (2004a) Feldspar dissolution rates and clay precipitation in the Navajo aquifer at Black Mesa, Arizona, USA. In Water-Rock Interaction (eds. R. B. Wanty and R. R. I. Seal). A.A. Balkema, Saratoga Springs, New York, pp. 895-899.

Zhu C., Blum A. E. and Veblen D. R. D. (2004b) A new hypothesis for the slow feldspar dissolution in groundwater aquifers. Geochim. Cosmochim. Acta 68, A148.

Zhu C., Veblen D. R., Blum A. E. and Chipera S. J. (2006) Naturally weathered feldspar surfaces in the Navajo Sandstone aquifer, Black Mesa, Arizona: electron microscopic characterization. Geochim. Cosmochim. Acta 70, 4600-4616.

Associate editor: Roy A. Wogelius 